\title{
A Three -Essay Empirical Analysis of Health Care Expenditures In the Economic Development of the United States, 2000 - 2009
}

\author{
Srimoyee Bose
}

Follow this and additional works at: https://researchrepository.wvu.edu/etd

\section{Recommended Citation}

Bose, Srimoyee, "A Three -Essay Empirical Analysis of Health Care Expenditures In the Economic Development of the United States, 2000 - 2009" (2015). Graduate Theses, Dissertations, and Problem Reports. 5236.

https://researchrepository.wvu.edu/etd/5236

This Dissertation is protected by copyright and/or related rights. It has been brought to you by the The Research Repository @ WVU with permission from the rights-holder(s). You are free to use this Dissertation in any way that is permitted by the copyright and related rights legislation that applies to your use. For other uses you must obtain permission from the rights-holder(s) directly, unless additional rights are indicated by a Creative Commons license in the record and/ or on the work itself. This Dissertation has been accepted for inclusion in WVU Graduate Theses, Dissertations, and Problem Reports collection by an authorized administrator of The Research Repository @ WVU.

For more information, please contact researchrepository@mail.wvu.edu. 


\title{
A Three -Essay Empirical Analysis of Health Care Expenditures In the Economic Development of the United States, 2000 - 2009
}

\author{
Srimoyee Bose
}

Dissertation submitted

to the Davis College of Agriculture, Natural Resources and Design, at the West Virginia University

in partial fulfillment of the requirements for the degree of

Doctor of Philosophy

in Natural Resource Economics

Dissertation Committee

Tesfa G. Gebremedhin, Ph.D. Chair

Alan R. Collins, Ph.D.

Peter V. Schaeffer, Ph.D.

Gerard E. D.' Souza, Ph.D.

Tami G. Calvez, Ph.D.

Usha Sambamoorthi, Ph.D.

Department of Resource Management

Morgantown, West Virginia, 2015

Keywords: Healthcare Financing, Hospital Expenditures, Healthcare Outcomes, State level,

Panel regression, Spatial Analysis

Copyright 2015 Srimoyee Bose 


\title{
ABSTRACT \\ A Three-Essay Empirical Analysis of Health Care Expenditures In the Economic Development of the United States, 2000 - 2009
}

\author{
Srimoyee Bose, M.A.
}

Healthcare spending (both per capita and total) in the United States (US) is the highest in the world. The ever-increasing healthcare spending without a corresponding improvement in health outcomes of individuals in the US requires a closer examination of state-level polices and characteristics. As state governments are a vital driver of healthcare implementation and as healthcare policy responses in containing healthcare expenses and outcomes vary among states based on the underlying state-level factors, it is critical to examine state-level variations in healthcare financing, expenditures and outcomes.

Therefore the purpose of this study was to empirically demonstrate state-level variations in financing of healthcare, hospital expenditures and health outcomes. Furthermore, empirical analyses demonstrated in this research that the association between state-level variations in healthcare needs, demographic composition, socio-economic, and political factors affect not only the individual state but also its neighbors.

Precisely, aims of the three studies were to: (1) evaluate the state-level variations in healthcare financing and the factors that affect financing of healthcare, (2) examine the state-level variations in hospital expenditures with an application of spatial regression, and (3) assess the determinants of state-level mortality rates using a spatial Durbin fixed effect model. This research used panel data from 2000 through 2009, extracted from publicly available data files.

Findings from the first study were that state-level variations in public financing of health care (Medicare and Medicaid) are associated with demographic composition (proportion of the female population, percentage of individuals over age 65, percentage of Hispanic population), economic factors (unemployment rate, per capita gross domestic product (GDP) of the state, per capita state tax revenue, FMAP rate), political climate (percentage of individuals enrolled in Medicare or Medicaid, rate of enrollment in HMO), healthcare supply factors (active physicians per 100,000 population, number of hospitals and beds) and healthcare needs (obesity rate). Additionally, variations in state-level private insurance financing was proportional to the economic factors (rate of federal funding, per capita state GDP), a supply side factor (active physicians per 100,000 population), political climate (percentage of individuals enrolled in Medicare or Medicaid) and healthcare needs (obesity rate). Lastly, state-level variations in out of pocket expenditures were associated with economic factors (per capita state tax revenue, per capita state GDP), demographic factors (percentage of African-Americans, percentage of female population, percentage of elderly population (aged 65 and above), percentage of Hispanic individuals, proportion of the population below age 17), a supply side factor (active physicians per 100,000 population), political characteristics (percentage of individuals enrolled in Medicare or Medicaid) and healthcare needs (obesity rate).

The second study reported the presence of a positive spatial dependence of hospital spending within one state on its adjacent states. This study also highlighted that rate of binge drinking, total number of hospital beds and hospitals per 1,000 residents, the unemployment rate, the percentage of African-Americans, proportion of active physicians and state gross domestic product (GDP) had 
positive impacts on its neighboring states' rates of hospital expenses. Moreover, the increasing rate of male population, Hispanic population and the rate of un-insurance of a state had negative impacts on its own rate of hospital costs but positive impacts on its bordering states' rate of hospital spending.

The third study also revealed a significant positive spatial dependence of the mortality rate among neighboring states. Population composition (percentage of African-Americans and percentage of individuals over 65 years of age) significantly increased the mortality rate of a state, while the percentage of Hispanic population, number of active physicians, percentage of married population and percentage with a college degree (bachelors or higher) reduced mortality rates. Higher rates of Hispanic population and better hospital infrastructure of an individual state increased the mortality rates of the neighboring states and higher the education level of the state decreased the mortality rate of the neighboring states.

Therefore' findings of all the three studies specified the importance of the role of socialdeterminants as well as up-stream factors such as income, social interaction and education in improving health outcomes. There is need for convergence of the two sectors: communities and health. Promoting health with synergistic efforts from the economic, social and health sectors of the economy at the state-level can lead to improved health outcomes and lower healthcare expenditures. 


\section{ACKNOWLEDGMENTS}

I would like to thank Professor Tesfa G. Gebremedhin immensely, for his guidance and mentorship throughout the entire preparation of my dissertation. I am indebted to his encouragement and advise that has helped me to proceed and complete my dissertation. I would like to express my sincere gratitude to Professor Alan R. Collins, Professor Gerard E. D Souza and Professor Peter V. Schaeffer for their valuable guidance, support, suggestions and encouragement throughout this phase.

I am very much grateful to Professor Tami Gurley Calvez for lending her immense support and providing me with ideas and propositions to proceed in the dissertation. I am highly indebted to Professor Usha Sambamoorthi for her patience, advise, insight and constant guidance in writing my dissertation and also offering me the research assistant position where I had an invaluable experience in learning new essential software and working on Medicare and Medicaid beneficiaries data.

I sincerely thank the staff and members of the Natural Resource Economics Program for providing me with the invaluable assistance and travel supports for various conferences that helped in improving my ideas to a significant level. I extend my gratefulness to the Bureau of Business and Economic Research, Regional Research Institute, Claude Worthington Benedum Foundation and the Department of Pharmaceutical Systems and Policy for providing me with the much needed financial support and assistance throughout my four years course of study.

Lastly, I would also like to thank my fellow friends at my subject field, my parents, brother, sister, brother in law and well-wishers whose enthusiasm and moral support inspired me to implement the study and collect data and achieve complete success with my dissertation. 


\section{TABLE OF CONTENTS}

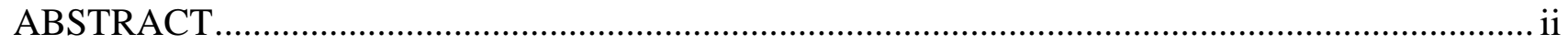

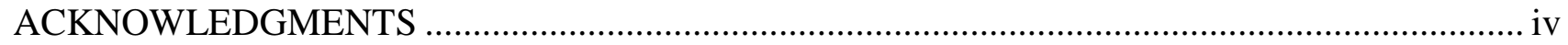

CHAPTER 1: BACKGROUND AND SIGNIFICANCE .................................................... 2

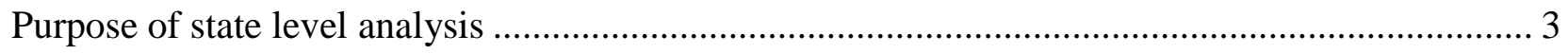

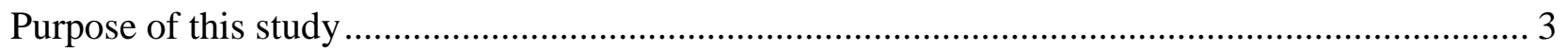

Aim of Essay 1: Examine state level variations in healthcare financing in the United States ........ 4

Aim of Essay 2: Examine state-level variations in inpatient expenditures (hospital expenditures) with an application of spatial regression

Ami of Essay 3: Examine state-level healthcare spending and health outcomes: An application of spatial Durbin panel approach to mortality ........................................................................... 5

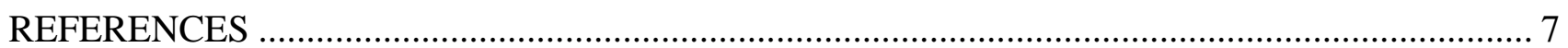

Table 1: Ranking of the US for some of the major healthcare outcomes, diseases and substance uses 9

CHAPTER 2: STATE VARIATIONS IN HEALTHCARE FINANCING IN THE UNITED

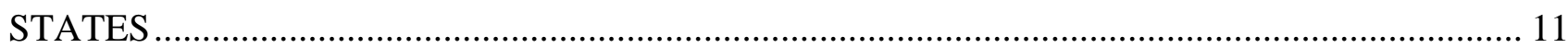

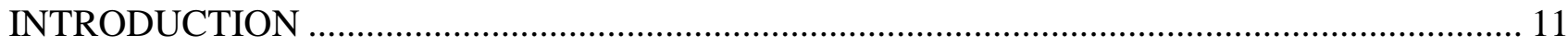

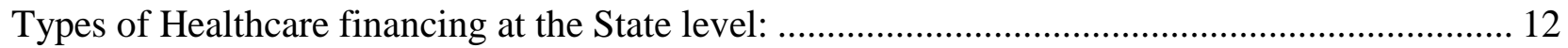

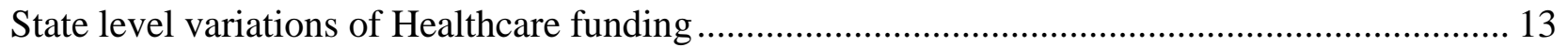

Determinants of private, public and personal healthcare funding: ........................................... 14

Table 2 provides the definition of the variables and the expected sign for the coefficients that explains the variation in public, private and out of pocket healthcare expenditures. These

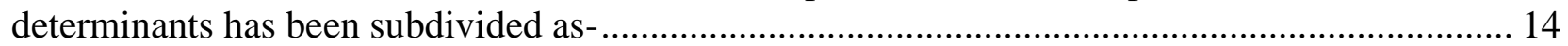

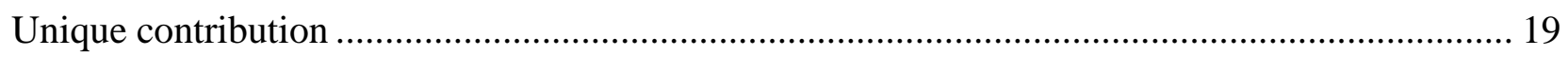

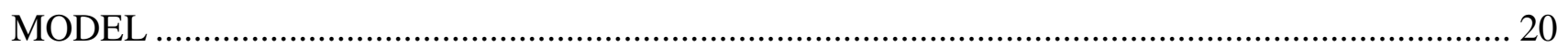

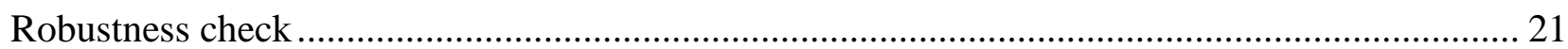

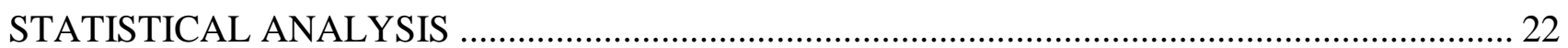

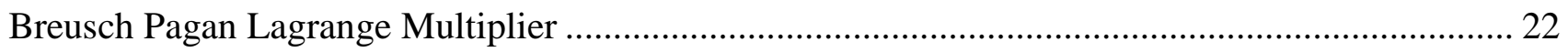

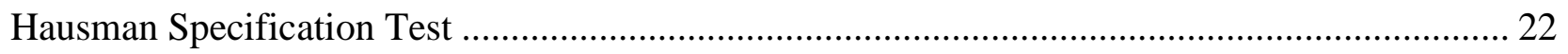

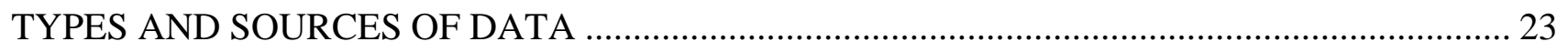

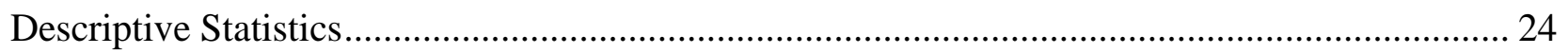

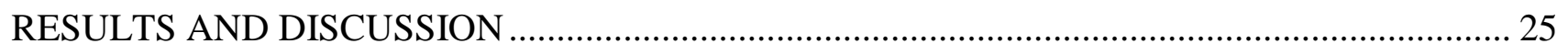

Model I: Public Sources of funding (Medicare and Medicaid) ............................................... 25

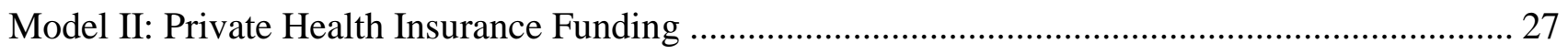




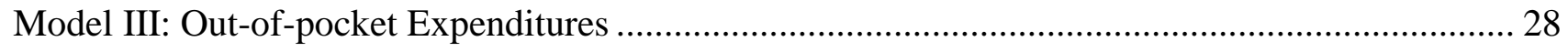

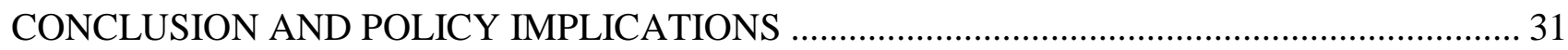

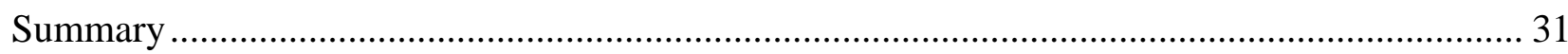

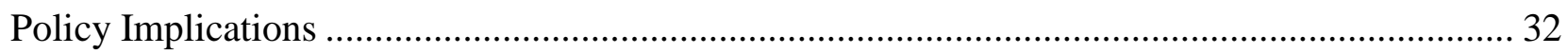

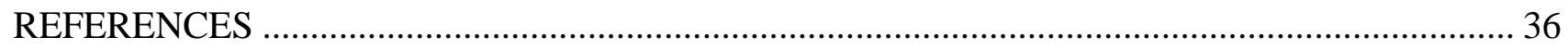

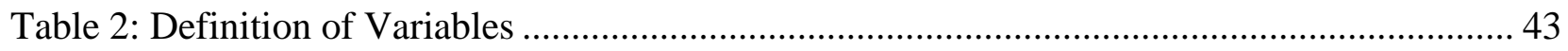

Table 3: Summary Statistics (Public, Private Health Insurance and Out Of Pocket Expenses) 2001-

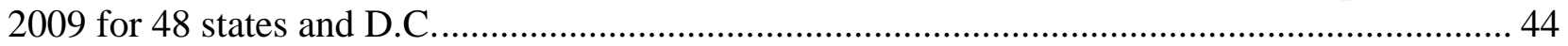

Table 4: Breusch and Pagan Lagrangian Multiplier Test Results.................................................... 45

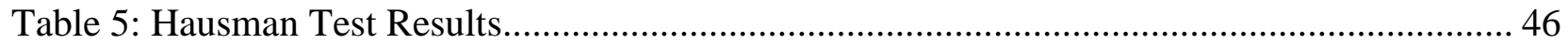

Table 6: State Fixed Effect Model, Pooled OLS Model and First Difference Model Results (Public

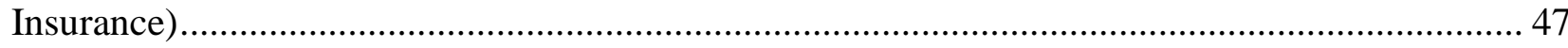

Table 7: State Fixed Effect Model, Pooled OLS Model and First Difference Model Results

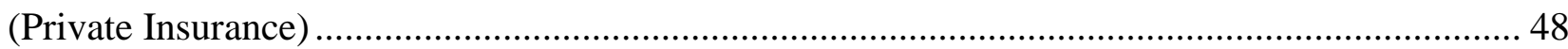

Table 8: State Fixed Effect Model, Pooled OLS Model and First Difference Model Results (Out of

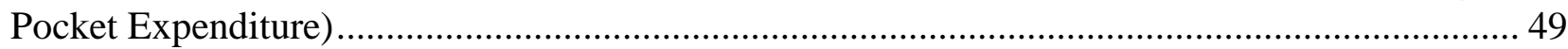

CHAPTER 3: STATE-LEVEL VARIATIONS IN INPATIENT EXPENDITURES: AN

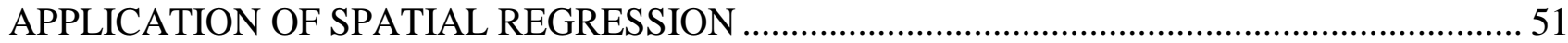

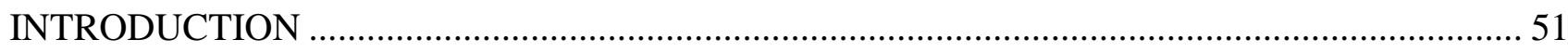

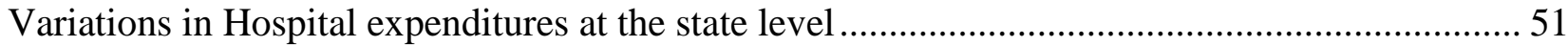

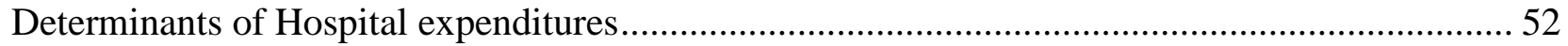

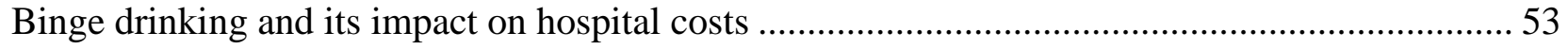

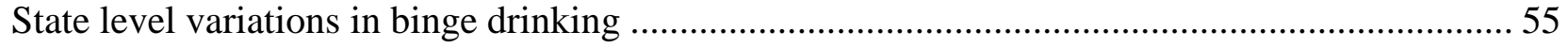

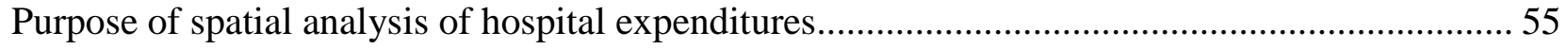

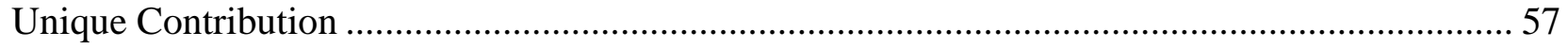

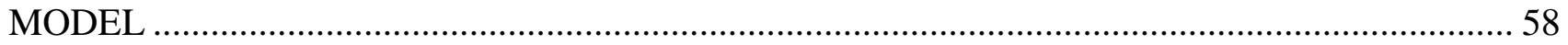

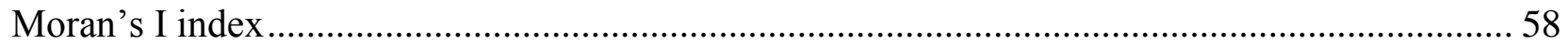

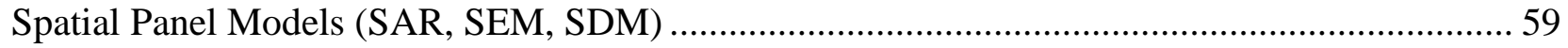

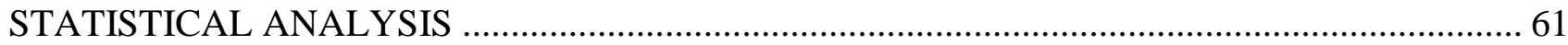

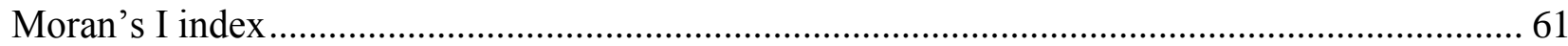

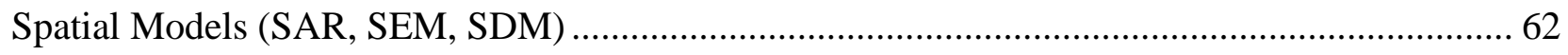

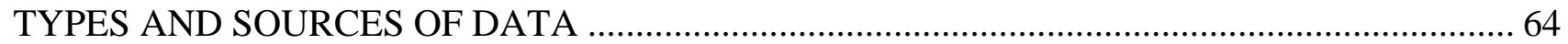

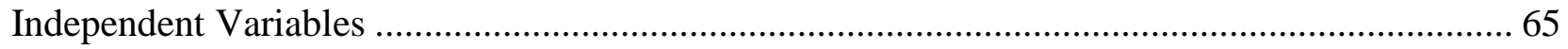

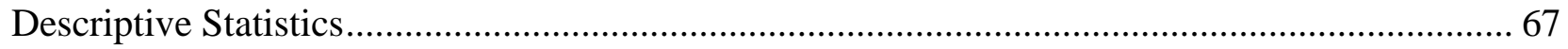

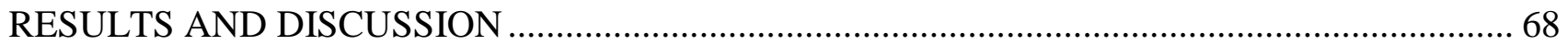




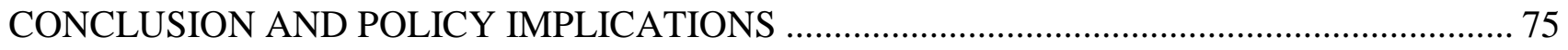

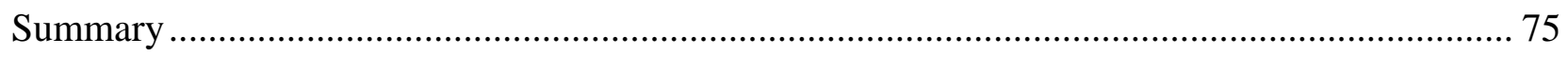

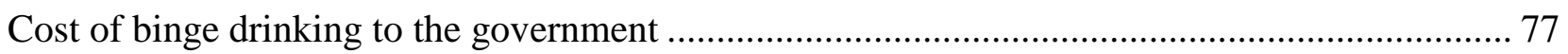

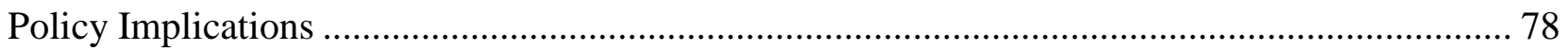

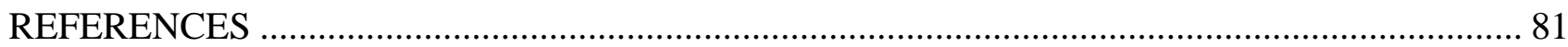

Figure 1: HRR Source: The Dartmouth Institute for Health Policy and Clinical Practice .............. 88

Figure 2: Map depicting variations in hospital expenditure in the U.S. as a percent of total health

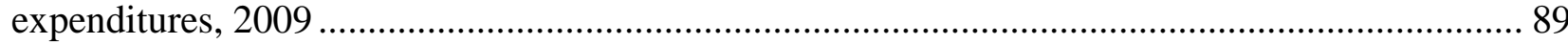

Figure 3: Moran's I scatter plot reporting presence of positive spatial autocorrelation of rate of

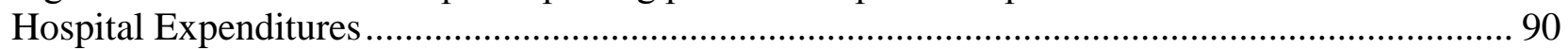

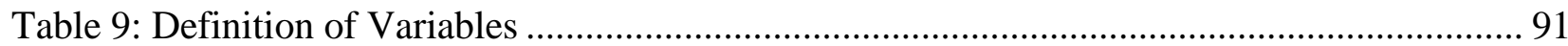

Table 10: Summary Statistics for State Level Hospital Expenses 2000-2009 for 48 States and

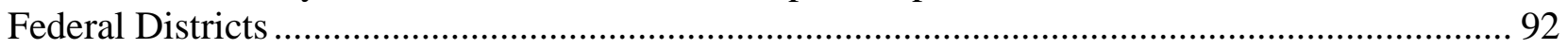

Table 11: Lagrange Multiplier Test Results for Non-Spatial Models ……………....................... 93

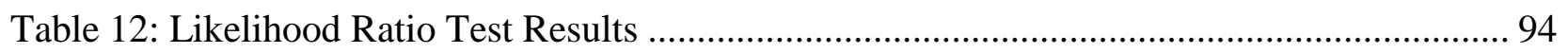

Table 13: Estimation Results of Spatial Panel Data Models (SAR and SEM) .............................. 95

Table 14: Wald Tests and Likelihood Ratio Tests Results ............................................................. 96

Table 15: Spatial Durbin Fixed Effect Model Results.............................................................. 97

Table 16: Direct, Indirect and Total Effect Results of the Spatial Durbin Fixed Effect Model ..... 98 CHAPTER 4: STATE-LEVEL HEALTHCARE SPENDING AND HEALTH OUTCOMES: AN APPLICATION OF SPATIAL DURBIN PANEL APPROACH TO MORTALITY ……………... 100

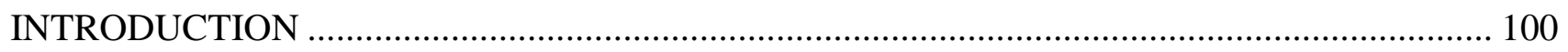

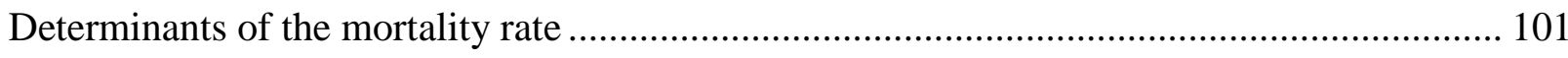

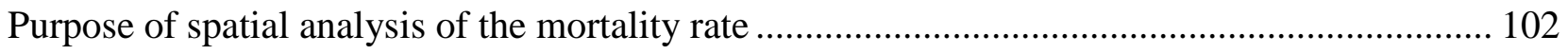

Previous spatial dependence study on the mortality rate ............................................................ 102

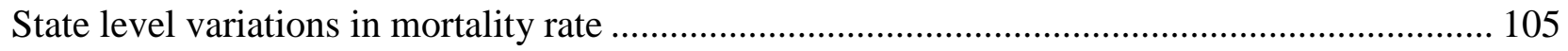

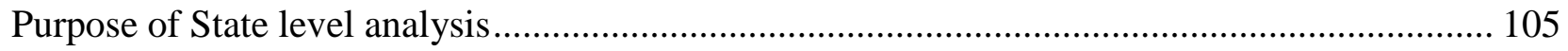

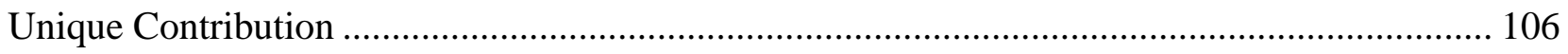

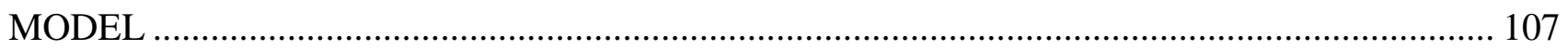

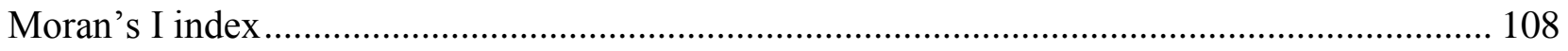

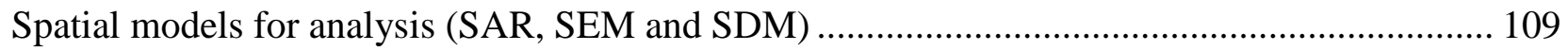

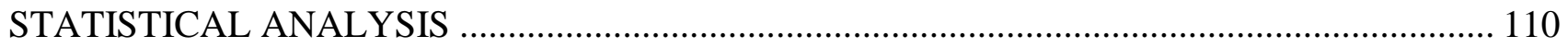

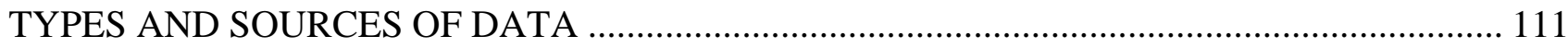

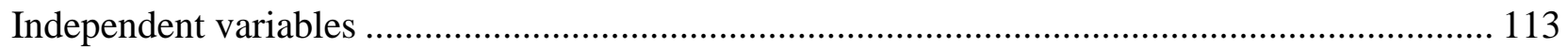




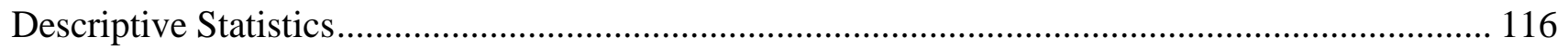

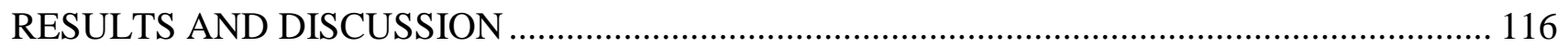

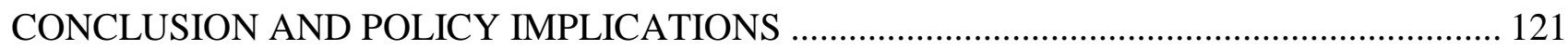

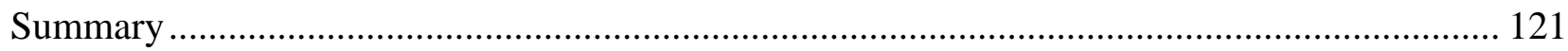

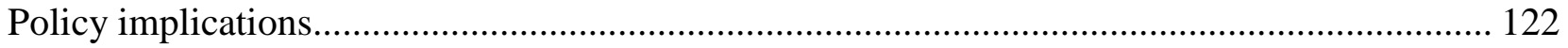

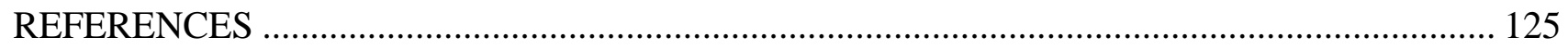

Figure 4: Variation of mortality rate across the states of the U.S. in the year 2009 ..................... 131

Figure 5: Moran's I index scatter plot reporting positive autocorrelation of mortality rate ......... 132

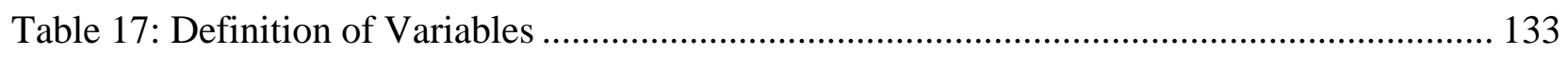

Table 18: Summary Statistics of the Dependent and Independent Variables: 2000-2009 ......... 134

Table 19: Lagrange Multiplier Test Results for Non-Spatial Models (without \% of Hospital

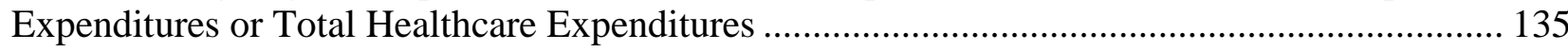

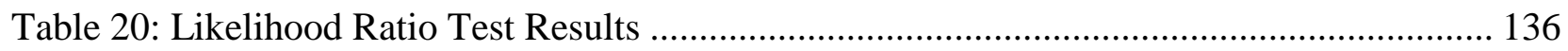

Table 21: Wald Tests, Likelihood Ratio Tests and Hausman Specification Test Results ............ 137

Table 22: Estimation Results of Spatial Panel Data Models (SAR and SEM) ............................ 138

Table 23: Spatial Durbin Fixed Effect Model Results........................................................... 139

Table 24: Direct, Indirect and Total Effect Results of the Spatial Durbin Fixed Effect Model ... 141

Table 25: Regression analysis of residuals of SDM Panel Model analysis (without Percentage of Hospital Expenditures or Total Healthcare expenditures) on percentage of Hospital expenditures

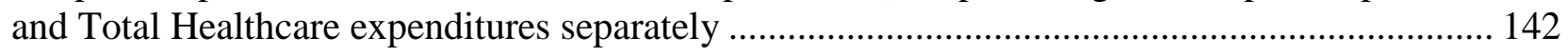

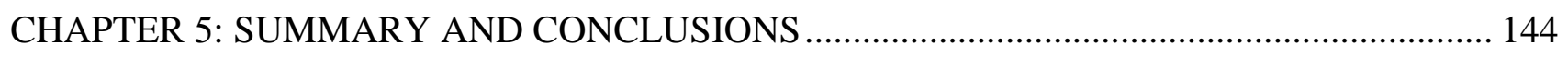

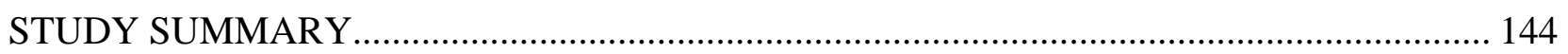

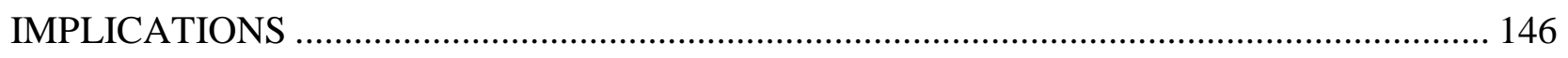

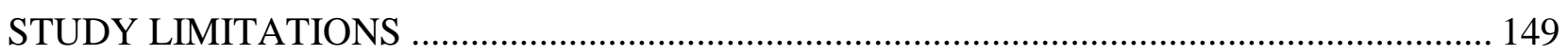

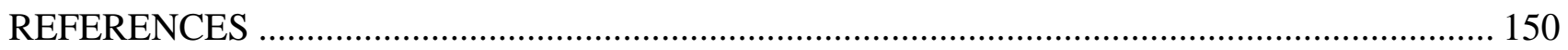


CHAPTER 1 


\section{CHAPTER 1: BACKGROUND AND SIGNIFICANCE}

According to the World Health Organization (WHO), healthcare spending in the United States (US) is the highest in the world (WHO, 2013). A total of 17.6\% of the Gross Domestic Product (GDP) is devoted to providing healthcare (OECD, 2012). Among OECD (Organization for Economic Co-operation and Development) countries, the per capita healthcare expenditures in the US is the highest and estimated at \$8,233 compared to the UK's \$3,309 in 2010 (OECD, 2012).

Additionally, the percentage of GDP on healthcare spending in the US has been increasing from $10 \%$ in 1982 (OECD, 2010) to $17.4 \% \%$ in 2013 (Centers for Medicare and Medicaid Services (CMS), 2013). It has been estimated that the percentage of GDP spent on healthcare will continue to increase and may reach $20 \%$ by 2021 (Keehan, 2012) and 30\% by 2050 (Jones, 2007). Similarly, per capita healthcare expenditures have also steadily increased from $\$ 4,878$ per person in 2000 to $\$ 8,149$ per person in 2009 (CMS, 2012), a 167\% increase.

Although the US is spending a vast amount of resources on health-care, the healthcare spending has not resulted in the highest quality of healthcare (WHO, 2009). When compared to

other developed countries, the US ranks $37^{\text {th }}$ in overall health status (WHO, 2011). For example, in 2008 , the US ranked $27^{\text {th }}$ in infant mortality among OECD countries (Centers for Disease Control and Prevention (CDC), 2011). Table 1 reports ranking of the US for some of the major healthcare outcomes, diseases and substance uses.

The ever-increasing healthcare spending without a corresponding improvement in healthcare of individuals in the US, has led to the conclusion that a closer examination of structural aspects of health care system at the state level is needed (Bipartisan Policy Center, 2012). Ability to pay (measured by GDP per capita), market power and prices, lower capacity of 
healthcare system (ratio of nurse, active physician and hospital beds to total population) and administrative complexity are some of the factors that contribute to this high healthcare spending (Reinhardt et al., 2004). Indeed, healthcare begins at the individual level and mostly influenced by state healthcare policies and resources.

\section{Purpose of state level analysis}

State-level analyses of various aspects of healthcare are critical to improve the healthcare of all Americans because as explained by Quinn (2011), "States are a vital driver of health implementation and will continue to be critically important to the success of reform (Page 244)." Quinn further added that experimentation within states on insurance coverage led to the formation of the Affordable Care Act (ACA) policy. According to Quinn, states provide an opportunity to evaluate different reforms and insurance programs which impact quality of healthcare. The state level variation in outcomes based on implementation of different health policies can provide proper answers to what level these policies are effective at different settings.

According to the report of Healthy Americans (2013), inadequate federal funding and cuts in state and local funding for state and local public health departments in recent years (29 states decreased their public health budgets from 2010-2011 to 2011-2012) has hampered their ability to provide health care services. Further, they reported that there is wide variation in state level health outcome statistics. For example— “ $6.7 \%$ of adults in Colorado and Utah have diabetes compared to $12.3 \%$ in Mississippi. Also, less than $12 \%$ of adults in Utah are current smokers while almost 30\% report smoking in Kentucky (Page 3).”

\section{Purpose of this study}

The overall aim of this study is to empirically demonstrate, at the state level, how financing of healthcare, expenditures, and health outcomes are related to healthcare needs and 
the composition of demographic, socio-economic, political and substance abuse factors at the state-level, but also on neighboring states. This study is composed of three essays.

\section{Aim of Essay 1: Examine state level variations in healthcare financing in the United States}

The first essay describes state-level healthcare resources and evaluates factors that affect these resources. Typically, state-level healthcare resources consist of state, federal, and private funding. Examples of federal funding are Medicare and federal share of Medicaid spending. Examples of private funding include the private health insurance market and personal healthcare spending by individuals and their families (i.e. out-of-pocket healthcare spending).

While there are challenges at both the national and state-levels in terms of healthcare resources, special attention should be paid to the importance of state-level resources because there are substantial state-level variations in healthcare needs, economic resources, demographic profiles, and political factors. These factors have profound influences on state health financing structure. Results of this aim reported that the percentage of elderly population, race/ethnicity (Hispanic), gender (female), the uninsured, the unemployed, the state gross domestic product, per capita tax, Medicaid and Medicare enrollees, obesity rate and HMO's can affect the composition of funding sources such as federal, state, and private.

\section{Aim of Essay 2: Examine state-level variations in inpatient expenditures (hospital expenditures) with an application of spatial regression}

The second essay focuses on one of the costliest components of healthcare expenditures, namely inpatient expenditures. In recent years, hospitalizations have reemerged as a priority for the United States healthcare system, policy makers, and research communities, due to their large share of total expenditures and morbidity and mortality burden on patient populations. Estimates of the proportion of total healthcare expenditures due to hospitalizations vary from $30-38 \%$ 
(CMS, 2010; Kaiser Family Foundation (KFF), 2004). Between 1993 and 2009, the number of hospital discharges increased from 34.3 million to 39.4 million in the U.S. (Healthcare Costs and Utilization Project (HCUP) net National Statistics on All Stays, publicly available data). In 2009, the average hospital charges were $\$ 30,655$; indeed, in 2009 the largest component of Medicare expenditures was on inpatient care and totaled \$132.6 billion (Medicare Payment Advisory Commission (MedPac), 2010).

While there are many reasons for hospitalization, an estimated $25 \%$ to $40 \%$ of all hospitalizations are for treating alcohol-related complications. In addition, 3.6\% of emergency visits and $38.9 \%$ of all hospitalizations in 2010 were due to any alcohol dependence syndrome (National Institutes of Health (NIH), 2013). Furthermore, it is plausible that the hospital spending in one state can affect the hospital expenditures of the neighboring states because 1) hospital expenditures of one state may be influenced by hospital prices, practices and policies of the neighboring states, and 2) presence of hospital facilities in a Hospital Referral Region (HRR) which serve patients across state lines. Therefore, using a Spatial Durbin Fixed Effect Model, this paper evaluated the spatial dependence of hospital expenditures.

\section{Ami of Essay 3: Examine state-level healthcare spending and health outcomes: An application of spatial Durbin panel approach to mortality}

The third essay examines the complex relationship between state-level healthcare spending and health outcomes. As seen at the national level, healthcare expenditures are not associated with a corresponding improvement in health outcomes. This may or may not be the case at the state-level. "The amount a state spends on health services is not necessarily correlated with better or worse health status (Tracking Key Health Indicators, 2014)." Furthermore, the health outcomes of residents in a state are influenced by the residents' 
demographic profiles, socio-economic factors, environmental factors, and healthcare needs. Manski (1993) notes that it is plausible that the health status of residents in a state may be influenced by the state healthcare policies of the neighboring states because of the presence of endogenous effect (behavior of one individual state is affected by its neighboring states' behaviors), exogenous effect (a state's behavior is affected by the characteristics of the exogenous group (states)) and contextual effect (policies of one state will affect the budgets of its neighboring state governments in a similar manner (Lundberg, 2011)). Further, there is the presence of "uncompensated spillovers" of knowledge, human capital, or economic growth among regions or states (Holod and Reed, 2004). Therefore, using a Spatial Durbin Fixed Effect model, the third essay highlights the determinants of state-level mortality rates. 


\section{REFERENCES}

Bipartisan Policy Center. 2012. What is Driving U.S. Health Care Spending America's Unsustainable Health Care Cost Growth? Washington D.C.

Centers for Disease Control and Prevention. 2011. http://www.cdc.gov/.

Centers for Medicare and Medicaid Services, 2012. http://www.cms.gov/Research-StatisticsData-and-Systems/Statistics-Trends-and-Reports/NationalHealthExpendData/NHE-FactSheet.html.

Centers for Medicare and Medicaid Services, 2013. http://www.cms.gov/Research-StatisticsData-and-Systems/Statistics-Trends-and-Reports/NationalHealthExpendData/NHE-FactSheet.html.

Dmytro, H., R. R. Reed. 2004. Regional spillovers, economic growth, and the effects of economic integration; 85(1); 35-42.

Healthcare Costs and Utilization Projectnet - Interactive Tool for Statistics on Hospitals Agency for Healthcare Research and Quality http //hcupnet ahrq gov/ . Accessed on April 26th, 2015.

Investing in America's Health: A State-by-State Look at Public Health Funding and Key Health Facts. April 2013. Trust for America's Health. http://healthyamericans.org/report/105/\%20

Jones, C.I. 2007. Why have health expenditures as a share of GDP risen so much? National Bureau of Economic Research, University of California Berkeley, 9325:1-33.

Keehan, S .P., G.A Cuckler, A. M. Sisko, A. J. Madison, S. D. Smith, J.M. Lizonitz, J. A. Poisal and C. J. Wolfe. 2012. National Health Expenditure Projections: Modest Annual Growth Until Coverage Expands And Economic Growth Accelerates. Health Affairs. doi: 10.1377/hlthaff.2012.0404.

Lundberg, J. 2011. On the definition of W in empirical models of yardstick competition, Department of Economics, Umea University, Sweden.

Manski, C.F. 1993. Identification of Endogenous Social Effects: The Reflection Problem. Review of Economic Studies, 60(1):531-542.

National health care and medicare spending. Medicare Payment Advisory Commission. 20110. http://www.medpac.gov/documents/publications/june-2010-data-book-section-1-nationalhealth-care-and-medicare-spending.pdf?sfvrsn=2.

Organization for Economic Co-operation and Development. 2012. Health Care Cost. 
Quinn, B.C. 2011.State-Level Health Policy Research: Looking Back, Looking Ahead. Health Research and Educational Trust. doi: 10.1111/j.1475-6773.2010.01229.x. Health Service Research. 46:1, Part II.

Rettenmaier A.J. and T. R. Saving. 2009. Perspectives on the Geographic Variation in Health Care Spending. National Center for Policy Analysis.

State Health Facts. Kaiser Family Foundation. 2004. http://kaiserhealthnews.org.

Tracking Key Health Indicators. 2014. http://www.pewtrusts.org/en/multimedia/datavisualizations/2014/health-indicators.

The Commonwealth Fund. Health Care in the Two Americas. Findings from the Scorecard on State Health System Performance for Low- Income Populations. 2013. http://www.commonwealthfund.org/publications/fund-reports/2013/sep/low-incomescorecard.

World Health Organization, National Health Account database. Accessed on http://apps.who.int/nha/database/DataExplorerRegime.aspx. 
Table 1: Ranking of the US for some of the major healthcare outcomes, diseases and substance uses

\begin{tabular}{|l|r|r|l|l|}
\hline & $\begin{array}{l}\text { Year of } \\
\text { ranking }\end{array}$ & Rank & $\begin{array}{l}\text { Number of } \\
\text { countries considered } \\
\text { for ranking }\end{array}$ & Source \\
\hline Life Expectancy & 2011 & 30 & OECD countries & $\begin{array}{l}\text { Organization for Economic Cooperation } \\
\text { and Development Stat Extracts } \\
\text { http://stats.oecd.org }\end{array}$ \\
\hline Obesity & 2014 & 1 & World & $\begin{array}{l}\text { http://health.usnews.com/health- } \\
\text { news/health- } \\
\text { wellness/articles/2014/05/28/america- } \\
\text { tops-list-of-10-most-obese-countries. }\end{array}$ \\
\hline $\begin{array}{l}\text { Alcohol } \\
\text { consumption }\end{array}$ & 2011 & 22 & OECD countries & $\begin{array}{l}\text { Organization for Economic Cooperation } \\
\text { and Development Stat Extracts } \\
\text { http://stats.oecd.org. }\end{array}$ \\
\hline & & & & $\begin{array}{l}\text { National Institute of Drug Abuse. } \\
\text { http://www.drugabuse.gov/news- } \\
\text { events/nida-notes/2009/11/united-states- } \\
\text { ranks-first-in-lifetime-use-three-drugs }\end{array}$ \\
\hline Drug Use & 2009 & 1 & 17 countries & $\begin{array}{l}\text { World Lung Foundation and American } \\
\text { Cancer Society. }\end{array}$ \\
\hline Smoking & 2012 & 34 & 71 countries & \\
\hline
\end{tabular}


CHAPTER 2 


\section{CHAPTER 2: STATE VARIATIONS IN HEALTHCARE FINANCING IN THE UNITED STATES}

\section{INTRODUCTION}

In the United States (US), the rising cost of healthcare has been a long-standing issue. Healthcare expenditures have reached $\$ 2.9$ trillion in 2013 (CMS, 2013) from $\$ 666.2$ billion in 1990 (CMS, 1990). According to Chernew (2015), during most of the post-World War II period, inflation-adjusted health care costs have been rising at a much faster rate than the GDP growth rate. It is projected that healthcare spending may account for as high as 38\% of GDP by 2075 (Chernew, 2015). There is growing pressure on both the federal and state governments in the US to contain healthcare spending. Many reasons have been cited for rising healthcare spending. These include: rising prevalence of disease in the population, changing clinical thresholds for diagnosing and treating disease, and innovations (new technology) in treatment (Chernew, 2015).

Whatever be the reasons behind the escalating healthcare costs, the rising costs of healthcare are not unique to the federal government of the US. States are also facing escalating health expenditures in the same way. For example, in 2012,31.5\% of state and local government budgets were spent on healthcare which is an $8 \%$ increase over the previous year and twice the national rate of increase (CMS, 2014). State and local government healthcare expenditures has increased by $262 \%$ from 1987-2013 with Medicaid increasing by 386\% (Pew Charitable Trust, 2015). Rapidly rising health care costs are driving up the fiscal sector's longterm difficulties (Government Accountability Office (GAO), 2008). Healthcare spending is the single greatest threat to state and local government long-term fiscal health. In 2013, state and local government health costs was 3.8\% of GDP of the country and it will increase to $7.2 \%$ in 2060 (GAO, 2013). 
For example, in 2009, California spent the maximum amount on health spending $(\$ 2,30,089.80)$ and Wyoming spent the least $(\$ 3,832.65)(\mathrm{CMS}, 2013)$. Per capita healthcare expenditures similarly varied widely among the states. Utah spent the least $(\$ 5,030.94)$ with median spending being that for Louisiana $(\$ 6,795.26)$ and the District of Columbia $(\$ 10,348.85)$ spent the maximum. The magnitude of healthcare expenditures at the state-level is influenced by a variety of factors. These may include the demographic profiles (OECD, 2006; Wang, 2009) of the residents, economic environment (Firat and Kein, 2013; Wang, 2009), political climate, supply of healthcare (Martin et al., 2002; Murthy, 1994; Wang, 2009) and other factors.

Containing costs has become a priority for all state governments. To understand, the policy response of state governments in containing healthcare expenditures, it is critical to examine the sources of funding for healthcare at the state level. Therefore, the primary objective of this paper is to describe the various sources of funding for healthcare at the statelevel and examine the association between demographic profiles of the residents, economic environment, political climate, healthcare infrastructure and other factors and the healthcare funding by sources.

\section{Types of Healthcare financing at the State level:}

State's finances healthcare to their residents through Medicaid, Medicare, subsidized premium to public employees, Children's Health Insurance Programs (CHIP), private health market and out-of-pocket spending by families.

Medicare is the public insurance program created under the Social Security Act in July 1965 to provide coverage and funding for healthcare needs of the people at and above age 65, younger people with disabilities, end stage renal disease and amyotrophic lateral sclerosis 
(CMS website). Medicaid is the "government insurance program for persons of all ages whose income and resources are insufficient to pay for health care (America's Health Insurance Plans (HIAA), pg. 232)." It reallocates funds toward poor, low-income and sick populations. Out-ofpocket expenditure as defined by WHO (2014) is the:

...direct outlay by households, including gratuities and in-kind payments, to health practitioners and suppliers of pharmaceuticals, therapeutic appliances, and other goods and services whose primary intent is to contribute to the restoration or enhancement of the health status of individuals or population groups.

Private health insurance comprises of the insurance coverage's provided by the nongovernmental organizations, such as private companies.

\section{State level variations of Healthcare funding}

Medicaid funding varies widely among the states. "Eight states account for over $50 \%$ of the Medicaid program's spending (California, New York, Texas, Florida, Illinois, Pennsylvania, Ohio, and Massachusetts). California and New York together spend 24.8\% of the nation's Medicaid dollars. The 30 smallest Medicaid programs combined spend only 21\% of Medicaid program dollars (Meara, 2012). Similar variations are also evident for Medicare funding (Rettenmaier and Saving, 2009). California (10.7\%), Florida (8.3\%), New York (7.2\%), Texas (7.1\%), Pennsylvania (5\%), Ohio (4.1\%), Illinois (4.1\%) and Michigan (3.7\%) are the states with largest amount of Medicare spending of the total US spending on Medicare in 2009 (CMS, 2009).”

In 2009, the lowest state level private health insurance coverage rate was for New Mexico (24\%), while the highest for the District of Columbia (49.1\%). Michigan (10.2\%) had the out- 
of-pocket expenses with Louisiana, having the largest (17.2\%) (Medical Expenditure Panel Survey (MEPS), 2009; CMS, 2009).

\section{Determinants of private, public and personal healthcare funding:}

Table 2 provides the definition of the variables and the expected sign for the coefficients that explains the variation in public, private and out of pocket healthcare expenditures. These determinants has been subdivided as-

\section{Economic profile}

The economic climate of the state influences the sources of funding. The factors contributing to economic variations are-

1) Gross Domestic Product (GDP) - One of the important factors that influence healthcare funding at the state-level is the state's GDP. A change in the GDP of a state can change the private, public, and personal healthcare funding. For example, when the state economy flourishes, the state government has more money to spend on all sectors of the economy, including healthcare. Thus, an increase in GDP will be associated with an increase in public health funding (Rettenmaier and Saving, 2009). An increase in GDP may reflect improve economic characteristics of the individual. Therefore, an increase in GDP will also be associated with an increase in private insurance market. An increase in GDP may reflect increase income of the residents of the state and therefore, an increase in GDP may be associated with increased affordability of medical services resulting in higher out-of-pocket healthcare spending as well.

2) Unemployment rate and poverty rate-The unemployment rate, a proxy for economic climate of the state can change the level of public health spending. As unemployment rate increases, the healthcare spending by the state will also increase. Individuals without jobs may not have insurance coverage and may need to rely on Medicaid or public assistance for 
healthcare coverage (Rettenmaier and Saving, 2009). Similarly with increase in poverty rate, public health insurance increases as these people have to rely on public health funding to access healthcare services as they don't have any alternative method of payment. Thus, as unemployment and poverty rate increases, the proportion of public funding may also increase (Mays and Smith, 2011). Increasing unemployment rates may cause an upward pressure on outof-pocket spending (Nair, 2006), if the unemployed do not qualify for Medicaid coverage.

3) Uninsurance rate- The rise in the number of uninsured people drives up the out-ofpocket expenses because now to access health services, these people have to pay on their own. They don't have any additional support of private of public sources. Therefore, a rising rate of uninsured increases the expenses (Nair, 2006).

4) State tax revenue- The government funds increasing healthcare costs though taxes or by borrowing (Emanuel and Fuchs, 2008). CMS (2008) report states that "the financial burden of health care costs resides with businesses, households, and governments that pay insurance premiums, out-of-pocket costs, or finance health care through dedicated taxes or general revenues."

5) Federal funding- Percentage of federal funding to the state general fund (Benjamin, 1986) is an important driving factor for public health insurance financing to the states over the years. The more the central government provides funds to the states, the lesser is the burden on the state's economy. This compensation amount also determines how much interference the states want from the federal government and how much independence they want in their health reform decisions (Bachrach and Boozang, 2011).

6) Federal Medicaid Assistance Percentage (FMAP) - A higher rate of Federal Medicaid Assistance Percentage (FMAP) may be associated with lower levels of healthcare funding by 
the state. For example, in 2012, FMAP rates were as high $74.17 \%$ in Mississippi and as low as 50\% in Wyoming (Federal Register, 2014). As reported by Meara (2012), "Federal government finances the majority of Medicaid spending with states covering the remainder at rates that vary from $24 \%$ in the poorest states to $50 \%$ in states with higher incomes."

\section{Demographic profile}

Demographic profiles of the state may also influence the nature of healthcare spending.

7) Aged population- As the proportion of elderly increases, healthcare funding by the state may also increase. This may be because elderly individuals need expensive and long-term healthcare (Benjamin, 1986; Calmus, 2013). Elderly individuals are more likely to use long-term medical care and home health care facilities (Calmus, 2013; McCall, 2001). Elderly over age 65 are typically covered through Medicare (Fischer, 1980). However, elderly are also more likely to be poor (Wu and Baer, 2010) and therefore, dually eligible for Medicaid. Indeed, many residents spend-down so that they become eligible for Medicaid and can gain access to nursing home care (Kassner, 2000). All these factors may interact with each other and lead to higher healthcare funding by the state (Benjamin, 1986; Lukens, 2014; Hanratty et al. 2012).

8) Race -The African-American population has different lifestyle, cultural differences and socio-economic disadvantages (Bose, 2015; Nair, 2006). They also constitute the low or middle income group of population and suffer from various chronic diseases and poor health conditions (14.6\%, CDC website). They also constitute the group with a very high un-insurance rate $(21 \%$, Kaiser State Health Facts, 2011). Hence, a greater part of this population might be depending on personal spending on healthcare needs.

9) Ethnicity- Concentrating on the ethnic disparity, it has been observed that $25 \%$ of Medicaid enrollees are Hispanics (Kaiser Medicaid Facts, May 2011). Medicare also covers a 
small percentage $(5 \%)$ of the Hispanic population in the U.S. $32 \%$ of the Hispanic individuals are uninsured. Therefore, a major proportion of Hispanic population who has insurance is covered by Medicaid or Medicare. As a result, with increasing population of Hispanics in the U.S. (U.S. Census Bureau, 2012), the public healthcare funding might increase.

10) Gender-The female population needs more medical care in form of prescription drugs, checkups, doctor visits, and they have a higher percentage of insurance coverage in the form of Medicaid (58\% in 2011, Kaiser State Health Facts) and Medicare, (56\% in 2013, Kaiser State Health Facts) as in comparison to the male population. Hence, an increase in the rate of the female population will drive the public health insurance market upwards (Nair, 2006).

\section{Political Climate}

The political climate of the state also influences the spending by the state.

11) Party in control of state legislatures-Budget and other policy decisions are made by the major governing party. States with democrats as the governing majority may be more likely to be in favor of investing state funds on healthcare and expand access to health insurance compared to states with republicans as the governing majority (Lukens, 2014; Rosenthal, 2004; Fischer,1980).

12) Enrollment rate -As highlighted by Meara (2012), 50\% of the 59 million Medicaid enrollees lives in eight states (California, New York, Texas, Florida, Illinois, Pennsylvania, Ohio, and Massachusetts). Out of this, $25 \%$ of the enrollment is from California and New York. The enrollment rates vary widely because of the diverging criteria's of the states to be eligible for Medicaid coverage. Rate of Medicare enrollment also witnessed similar variation. In 2009, West Virginia has the largest enrollment of $20.71 \%$ and Utah had the smallest of 
9.84\%. Wade et al. (1995), Lukens (2014) also reported that total enrollment positively influenced public healthcare funding.

13) Health Maintenance Organizations (HMO)-Yet another factor that may influence healthcare spending by states are the penetration of health maintenance organizations (HMO). There is evidence of association between HMO penetration rate and healthcare financing (Baker, 2000). HMO enrollees are more likely to use preventive care (Greene et al., 2001) and less likely to use expensive services such as inpatient care (Tu et al., 2000). As stated by Wickizer and Feldstein (1995), competitive strategies of managed care and their entry in the market reduce the health insurance premium growth rate and also prevent the private insurance market to expand. All this may result in reduction of the overall health care funding (Greene et al., 2001).

\section{Healthcare needs}

Another important factor associated with healthcare spending is healthcare needs of states' residents.

14) Obesity rate- This is of specific importance with respect to the US as obesity rates and thereby obesity-attributable healthcare expenditures vary across states (Trogdon et al., 2012). As reported by them, 50\% of the obesity-attributable expenditures in 2003 ( $\$ 75$ billion) was funded by Medicare and Medicaid. While Wyoming had the lowest spending of $\$ 87$ million (\$38 million from public healthcare funding), California had the highest spending of \$7.7 billion ( $\$ 1.7$ billion from public healthcare funding). This demonstrates that there may be a positive association of healthcare needs with healthcare funding. 


\section{Healthcare supply variables}

The supply-side variables, such as the proportion of active physicians and the total number of hospitals and hospital beds, vary widely across the states (Zuckerman et al., 2014) and influence health insurance markets (Benjamin, 1986).

15) Active physicians-The greater the number of physicians treating Medicare and Medicaid patients, the higher the amount of money the state and federal governments have to reimburse for their service fees. Further it also increases the private health insurance funding and personal funding. Hence, with increase in physicians, healthcare funding increases in general (Benjamin, 1986; Lukens, 2014).

16) Hospitals and hospital beds-Higher number of hospital beds and number of hospitals in a state may have ambiguous effect on healthcare funding. Increase in number of beds might lead to an increase in total healthcare funding (Benjamin, 1986). Kiselev (2010) reported that hospitals are suffering financial debt due to low reimbursements from Medicare and Medicaid coverage and also due to greater amount of uninsured population. The number of privately owned hospitals has been increasing and the number of publicly owned hospitals is decreasing thereby causing a downward impact on public healthcare funding (Horwitz, 2005).

\section{Unique contribution}

No study so far has examined factors associated with all three types of healthcare financing at the state-level. As mentioned earlier, it is critical to understand the sources of healthcare funding and its determinants at the state-level. Therefore, this study describes the sources of funding (public (Medicare and Medicaid) and private (private insurance and out-ofpocket expenses)) and the demographic profiles, economic environment, political climate, and 
supply-side factors associated with healthcare funding sources between the period of 2001 and 2009.

Employing a state fixed-effect model helps in controlling the fixed differences among the states that are unobservable state-level factors which potentially leads to inefficient estimates (Lukens, 2014). In addition to the fixed-effects method, this paper presents the pooled ordinary least squares (OLS) analysis because a pooled model incorporates both between-state and within-state variation (Lukens, 2014) and a first-difference model as a robustness check to the afore-mentioned methods of analysis.

\section{MODEL}

A panel data regression model has been considered for the state-level data analysis for this study for all of the three models. This is because the panel regression analysis "is a method of studying a particular subject within multiple sites, periodically observed over a defined time frame (page 1) (Yaffee, 2003)." It is a combination of time series with crosssections that enhances the quality and quantity of data in ways that will not be possible to achieve using only one of these two dimensions (Yaffee, 2003). Therefore, as stated by Yaffee (2003), "Panel data analysis endows regression analysis with both spatial and temporal dimension (page 1).” Hence, in order to control for the unobserved heterogeneity, panel regression analysis approach is considered to be the most appropriate method for this multiple year's dataset. It also removes bias from the estimation techniques that might have been the problem faced by the previous studies.

The basic framework of the panel data regression model used for this study is of the

form:

$$
Y_{i t}=X_{i t}^{\prime} \beta+Z_{i}^{\prime} \alpha+u_{i t}
$$


Where $\mathrm{u}=$ =rror term, $\mathrm{t}=$ time period and $\mathrm{i}=$ state. $\mathrm{X}_{\mathrm{it}}$ has $\mathrm{K}$ regressors without the inclusion of the constant term. The heterogeneity or individual effect is $Z_{i}{ }^{\prime} \alpha$, where $Z_{i}$ contains a constant term and group specific variables, which may or may not be observed. If $\mathrm{Z}_{\mathrm{i}}$ is observed for all individuals, then the model is reduced to an Ordinary Least Square Model. The two types of panel data models considered for the analysis are-fixed effects model and random effects model. STATA 12 is used to perform the data analysis.

\section{Fixed effect model}

$$
Y_{i t}=\beta_{1} X_{i t}+\alpha_{i}+u_{i t}
$$

$\alpha_{i}$ is the coefficient for each entity, $Y_{i t}$ is the dependent variable, $t=$ time, $X_{i t}$ represents one independent variable, $\beta_{1}$ is the coefficient for $X_{i t}$ and $u_{i t}$ is the error term

\section{Random effect model}

$$
\mathrm{Y}_{\mathrm{it}}=\beta_{1} \mathrm{X}_{\mathrm{it}}+\alpha+\mathrm{u}_{\mathrm{it}}+\varepsilon_{\mathrm{it}}
$$

Where $u_{i t}$ is the between entity error term and $\varepsilon_{i t}$ is within entity error term.

\section{Robustness check}

The first difference method has been employed to check the robustness of the panel regression model and the pooled OLS model used for the study. The first-difference method eliminates measurement error and inconsistency created by unobserved effects (omitted variables) from the model (McManus, 2011) by regressing changes of healthcare fundings on the changes in explanatory variables (Lukens, 2014). This model is also referred to as the firstdifference fixed effects model. For instance, considering the general form of the model as-

$$
Y_{i t}=X_{i t}^{\prime} \beta+c_{i}+u_{i t}
$$

Therefore the first-difference transformation can be written as-

$$
\begin{aligned}
& Y_{i t}-Y_{i t-1}=\left(X_{i t}^{\prime}-X_{i t-1}{ }^{\prime}\right) \beta+c_{i}-c_{i}+u_{i t}-u_{i t-1} \\
& \text { Or, } \Delta Y_{i t}=\Delta X_{i t}{ }^{\prime} \beta+\Delta u_{i t} \text { with no intercept term (McManus, 2011). }
\end{aligned}
$$




\section{STATISTICAL ANALYSIS}

\section{Breusch Pagan Lagrange Multiplier}

To determine which model is appropriate for the state-level data analysis, the Breusch and Pagan Lagrange multiplier [1980] (LM) test is performed.

$$
\mathrm{LM}=\frac{\left(\sum_{\mathrm{i}=1}^{\mathrm{N}} \mathrm{T}_{\mathrm{i}}\right)^{2}}{2\left(\sum_{\mathrm{i}=1}^{\mathrm{N}} \mathrm{T}_{\mathrm{i}}\left(\mathrm{T}_{\mathrm{i}}-1\right)\right)}\left[\frac{\sum_{\mathrm{i}=1}^{\mathrm{N}}\left(\sum_{\mathrm{t}=1}^{\mathrm{T}_{\mathrm{i}}} \mathrm{e}_{\mathrm{it}}\right)^{2}}{\sum_{\mathrm{i}=1}^{\mathrm{N}}\left(\sum_{\mathrm{t}=1}^{\mathrm{T}_{i}} \mathrm{e}_{\mathrm{it}}\right)^{2}}-1\right]^{2} \mathrm{e}_{\mathrm{it}} \text { is the residual term of the OLS model. This }
$$

follows $\chi^{2}$ distribution.

It considers the null hypothesis, $\mathrm{H}_{0}=$ the best fit model is Ordinary Least Square Model

(OLS) against the alternative $\mathrm{H}_{1}=$ the fixed effect or random effect model is the more

appropriate model. If the LM test value is significant and it rejects the null hypothesis, then it is confirmed that the OLS model is not applicable for this analysis. This is followed by the Hausman specification test (1978) to see which of the random effect or the fixed effect model is the preferred one.

\section{Hausman Specification Test}

$$
H=\left(\beta_{1}-\beta_{0}\right)^{\prime}\left(\operatorname{Var}\left(\beta_{0}\right)-\operatorname{Var}\left(\beta_{1}\right)\right)^{\prime \prime}\left(\beta_{1}-\beta_{0}\right),
$$

The Hausman test examines the null hypothesis $\mathrm{H}_{0}=$ coefficients estimated by the random effects estimator which is consistent and efficient $\left(\beta_{1}\right)$ are same as the ones estimated by the consistent fixed effects estimator $\left(\beta_{0}\right)$ (Princeton University Library, Data and Statistical Services). The alternative hypothesis $\mathrm{H}_{1}=$ coefficients estimated by the efficient random effects estimator $\left(\beta_{1}\right)$ are different from the ones estimated by the consistent and efficient fixed effects estimator $\left(\beta_{0}\right)$. If the test value is insignificant, then random effect model needs to be used for the study. However, if the value falls in the critical region and it is significant, then the state fixed effect model is the appropriate one. 


\section{TYPES AND SOURCES OF DATA}

The data that has been used for the study is collected from various sources. The first data source is the U.S. Bureau of Economic Analysis. This source provides data on consumer expenditure variables that represent state-level statistics. Data on personal consumption expenditure for health from this source has been used to calculate the state-level out-of-pocket expenditures on health services. This out-of-pocket spending value is the average amount of money spent by the consumers of a state on health care services from their own income (apart from spending on health insurances). The second data source that has been used is the Centers for Medicare and Medicaid Services(CMS). Data on total personal health care spending, public funding (Medicare and Medicaid), and private health insurance funding has been obtained across the states for the years 2001 to 2009 (Health Expenditures by State of Residence) from this resource.

The third data source used is the U.S. Census Bureau. This contains data of the independent variables for state-level analysis namely - the gross domestic product of each state, the percentage of population above age 65 , percentage of population below age 17 , number of active physicians per 100,000 civilian population, poverty rate, unemployment rate, percentage of uninsured people, region, HMO, party in control of the U.S. state legislatures, state tax revenue, percentage of Medicare enrollment, percentage of Medicaid enrollment and percentage distribution of population by gender, ethnicity and race (Population Estimates, U.S. Census Bureau).

The fourth source is the State Health Facts which is the data source provided by the Henry Kaiser Family Foundation. Data on the hospital bed per 1,000 population, FMAP and the total number of community hospitals are obtained from this data source. The final data source is 
the U.S. State Expenditure Report. It provides data on the percentage of federal funding to each state over time period considered for the study. The fifth data source is Center for Disease Control and Prevention $(C D C)$. Data for obesity rate has been obtained from this source. The last data source used is the Department Of Health And Human Services to acquire the Federal Medicaid Assistance Program rate.

The classification of variables used for this state-level analysis is provided in Table 2. Eighteen independent variables are in the per capita or percentage form for this analysis. An interaction term of hospital beds and the total number of hospitals has been considered for the analysis as they are highly correlated (0.77). The dependent variables for the three models arePer capita value of public healthcare funding, private health insurance financing and out-ofpocket expenses.

\section{Descriptive Statistics}

The descriptive statistics for the dependent and independent variables used for the analysis has been summarized in Table 3 . The statistical values indicate that the independent variables vary widely across the states and over the years. The unemployment rate reaches a maximum of $13.3 \%$ for Michigan. The percentage of African-American population varies from Maine $(0.37 \%)$ being the lowest to the District of Columbia $(60.26 \%)$ being the highest. The uninsured rate also covers a large range, from $4.4 \%$ to $26.1 \%$, with Florida, Georgia, Nevada, and Texas falling in the higher bracket. In terms of percentages, while out-of-pocket expenses varied from $11.1 \%$ (Utah) to $20.57 \%$ (West Virginia), public funding varied from $24.3 \%$ (Utah) to $50.1 \%$ (New York) and private health insurance varied from 22.6\% (New Mexico) to 50.8\% (District of Columbia). Federal funds reach a maximum of $49.1 \%$ (Louisiana) with Massachusetts being the lowest of all. 


\section{RESULTS AND DISCUSSION}

\section{Model I: Public Sources of funding (Medicare and Medicaid)}

With the LM test in Table 4 ( $\chi$ bar $^{2}$ value $=657.48,1 \%$ level of significance) suggesting that the suitable model for this study is a panel regression model, the Hausman specification test $\left(\chi^{2}=99.58,1 \%\right.$ significance level $)$ in Table 5 states that the fixed-effect panel model is preferred to the Random effect model. The $\mathrm{R}^{2}$ value for the state fixed-effect model is 0.93 , which reports that $93 \%$ of variations in state-level public health insurance funding are explained by this model in Table 6. Therefore, it is a very good fit model to elucidate the changes in public funding across the states over time. Factors such as the unemployment rate, the proportion of the female population, active physicians per 100,000 population, percentage of people over age 65 , per capita GDP of the state, the percentage of Hispanic population, total enrollment rate (Medicare and Medicaid), per capita tax revenue and obesity rate demonstrates positive effects on public health care financing. Alternatively, FMAP rate, interaction term of hospitals and beds and percentage of $\mathrm{HMO}$ rate negatively impact public healthcare financing.

The aged population mostly uses public sources of funding to pay for their medical care. Thus with an increase in percentage of elderly people, the state and central government has to invest more money to cover a much larger population under Medicare, to pay for their treatments and medical bills, causing the public source of health care funding to increase. It can also be seen that with the rise in the unemployment rate, public healthcare funding experiences a positive increase. The rise in the number of people with no jobs leads the state government to invest more money on unemployment insurances and these people are also entitled to Medicare and Medicaid if their income level falls below the stipulated federal poverty level (criteria to be fulfilled to be enrolled as Medicaid beneficiary). Concentrating on the racial disparity, it has been observed that 
27\% of Hispanic individuals are covered by Medicaid (Kaiser Medicaid Facts, May 2011) and $5 \%$ is covered by Medicare. Therefore, with increase in the percentage of Hispanic population with insurance, public financing of healthcare increase. Evidently, female population needs more medical care in forms of prescription drugs, checkups, doctor visits, and they have a higher percentage of insurance coverage in the form of Medicaid (58\% in 2011, Kaiser State Health Facts) and Medicare, (56\% in 2013, Kaiser State Health Facts) as in comparison to the male population. Hence, an increase in the rate of the female population will drive the public health insurance market upwards.

It can be seen that an increase in supply side variable such as the number of physicians boost public health care financing. With rise in the number of active physicians, the state and local government has to pay more for their fee for services thereby increasing the total funding. Per capita state GDP also has a positive impact on the public healthcare funding. Rise in total GDP demonstrates that the state economy is doing well hence the state can invest more funding on health insurance coverage for the children, poor, needy and elderly population. Hence, the total public healthcare funding rises. Rise in enrollment rate for Medicare and Medicaid beneficiaries means that state government is investing more funds in public health insurance financing. Increase in per capita state tax revenue implies that state government can finance more state health costs. Thus, with rise in state tax revenue, public healthcare financing increases.

With increasing obesity rate, the obesity rate, the obesity-attributable medical expenditures increases. As a result it increases the Medicaid and Medicare funding along with it as seen before that $50 \%$ of this expenditures are funded by public healthcare financing. With rise in the enrollment rate in $\mathrm{HMO}$, the population has fewer requirements of inpatient and outpatient services and suffers less from chronic diseases. This lowers down the total public health care 
financing. Increase in FMAP rate is negatively associated with public healthcare funding. The higher the amount of assistance that federal government provides to a state, the lower is the amount of funding that the state has to invest. With rising number of hospitals and beds, total public healthcare funding decreases. With time, number of privately owned hospitals is increasing and state owned hospitals are decreasing. The reimbursement rate for Medicare and Medicaid patients are lower for hospitals. This might be causing a decreasing trend in total public healthcare funding. Thus all of the above mentioned significant factors add up to impact the public health funding of a state positively.

\section{Model II: Private Health Insurance Funding}

It is apparent from Table 4 that the Breusch Pagan LM test value $\left(\chi\right.$ bar $\left.^{2}=207.43\right)$ is significant at the $1 \%$ level. This rejects the null hypothesis $\left(\mathrm{H}_{0}=\mathrm{OLS}\right.$ is the preferred model, against $\mathrm{H}_{1}=$ Random or fixed effect model is the preferred model) stating that a panel regression analysis (a fixed effect model or a random effect model) is the suitable one. Thus, in implementing the Hausman specification test results (Table 5), which rejects the null hypothesis, too $\left(\chi^{2}=60.09\right.$, significant at $1 \%$ level $)$, it is inferred that fixed effect model is the most appropriate fit to estimate the factors influencing state-level private health insurance funding. The $\mathrm{R}^{2}$ value for the state fixed effect model in Table 7 highlights that the model and its independent variables have been able to capture $84 \%$ of the fluctuations in private health insurance funding.

The set of factors that positively influences private health insurance fund are per capita state GDP, active physicians per 100,000 populations, enrollment rate and obesity rate. Apart from these factors, rate of federal funding to the state general funding has negative impacts on private health insurance. The largest positive significant effect on the deviations of private health 
insurance financing is revealed by the GDP of the state. The rise in the GDP means economy of the state is doing well. It means the average income of the people will increase and they will be able to afford more private health insurance coverage for their health services from the profit and non-profit organization selling those insurances. The results highlight that an increase in the proportion of active physicians in a state increases the total private health insurance funding of the state. Increase in the obesity rate not only increases public healthcare funding but it also increases private health insurance funding. Rise in the rate of federal funding to the state general fund compensates a larger share of the medical spending. Hence this has a negative impact on the private health insurance market.

\section{Model III: Out-of-pocket Expenditures}

The $\chi \operatorname{bar}^{2}$ value of the LM (Breusch Pagan) test (581.29) in Table 4 is significant at $1 \%$ level. Thus this test rejecting the ordinary least square estimation process signifies that either fixed effect or random effect model is the best fit model. Performing Hausman specification test, the $\chi^{2}$ value $=64.06$ of the test result in Table 5 being significant at $1 \%$ level rejects the null hypothesis $\mathrm{H}_{0}=$ Random effect model (the individual specific effects are not correlated with the regressors) and indicates that the alternative hypothesis $\mathrm{H}_{0}=$ fixed-effect model (the individual specific effects are correlated with the regressors) is the appropriate one. Table 8 provides the coefficients of explanatory variables, their standard errors, and t statistics for out-of-pocket spending resulting from the state fixed-effect panel analysis, pooled OLS model analysis, and first-difference model analysis. The $\mathrm{R}^{2}$ value from the state fixed effect model affirms that approximately $92 \%$ of variation in the state-level out-of-pocket expenses has been explained by the explanatory variables thus confirming the model to be a very good fit. Per capita state tax revenue, proportion of the population that is African-American and female population, active 
physicians, proportion of the population above age 65, per capita state GDP, enrollment rate and obesity rate has positive and significant influences (at $1 \%$ level) on out-of-pocket spending. Additionally, the percentage of population below age 17 and percentage of Hispanic population has negative impact on personal health care funding.

The elderly suffer from more health problems than does the rest of the population. Medicare provides the aged with finance needed to pay for their medical bills, but this doesn't cover all costs incurred for their treatments, such as the long-term health care facilities (only certain services are covered by Medicare for a limited time period), prescription drugs, etc. Additionally, the federal government doesn't compensate the entire fees of physicians who are treating Medicare patients. The federal government is also reducing the reimbursement rates for the services provided by physicians to Medicare patients, thereby placing this group of the population at a greater risk of getting turned down from being treated or getting efficient health care services. Therefore, they need additional resources to pay for their extra medical needs. The premiums needed to be paid to buy private health insurance, as additional funding is much higher for the elderly since they are more susceptible to becoming sick and have greater medical care needs. Furthermore, the medical benefits that the employers of firms offer after the retirement of their employees are declining (Golberstein et al. 2013; Lukens 2014). As a result, the elderly population has to depend on their own incomes to pay for the charges that are not financed by public sources. Therefore, with the rise in the elderly population of a state, the out-of-pocket expenditures of the state increase.

The African-American population has cultural differences and socio-economic disadvantages (Bose, 2015). They also constitute the low or middle income group of population and suffer from various chronic diseases and poor health conditions (14.6\%, CDC). They also 
constitute the group with a very high un-insurance rate (21\%, Kaiser State Health Facts, 2011). Hence, a greater part of this population uses their own income to pay for the health care services that they access, driving the total state out-of-pocket spending upwards. The rise in per capita state GDP and the per capita state tax revenue indicates that the average income of people is higher, helping them to spend more on medical facilities as needed. Hence, there is a rise in all the three types of financing of the health care services. Out-of-pocket expenses being one of them experience the same increase.

The increase in supply side variables such as the number of active physicians has witnessed a higher number of hospitalizations and office visits, thereby creating additional health expenses for the people of the state.

It can be seen that the proportion of the population below age 17 has a negative impact on the out-of-pocket expenditures. This group of population on average being very healthy does not need health services as others do. This leads to a decrease in the total out-of-pocket expenses of the state. Hispanics comprises of the highest percentage of uninsured people (30.7\% in 2010, Walt et al., 2011). This group of population usually doesn't access health care facilities to a large extent. This will decrease the total out of pocket expenses.

First-difference analysis as a check of robustness for the state fixed effects model results is presented along with each of the models in Table 6,7 and 8. These "additional specification controls for the unobserved differences between states (Page 27)" and the robustness check "provides considerable confidence to the estimates (Page 27)" (Lukens, 2014). Coefficients of all the variables that are significant in state fixed effect analysis for public insurance funding are also significant in first difference analysis except for per capita state tax (insignificant) and FMAP rate (opposite sign). Results varied among state fixed effect and first difference analysis 
for private insurance funding. While, percentage of federal funding and enrollment rate (Medicare and Medicaid) are insignificant, percentage of Hispanic population is significant for first difference analysis. Finally, findings of out of pocket expenses varied widely. In addition to the significant variables of state fixed effect analysis of out of pocket expenses; uninsured rate, percentage of federal funding, FMAP rate, HMO rate and proportion of active physicians are significant and percentage of aged, female, state tax revenue, enrollment and obesity rate are insignificant for first difference analysis. Hence, this paper has successfully established the determinants that have been causing variations in the all the three sources of healthcare funding among the states.

\section{CONCLUSION AND POLICY IMPLICATIONS}

\section{Summary}

The present analysis determines that economic profile, demographic factors, social and political variables, healthcare needs, supply side and other factors explain variation in all three sources of financing — public (Medicare and Medicaid), private health insurance and out-ofpocket expenses at state-level health care from 2001 to 2009. Employing models of state fixed effect, pooled ordinary least square and first-difference analysis (for a robustness check), it can be seen that these variables impact the types of funding extensively. It can be seen that public funding (Medicare and Medicaid) within a state is positively influenced by the unemployment rate, the proportion of the female population, active physicians per 100,000 population, percentage of people over age 65, per capita GDP of the state, the percentage of Hispanic population, percentage of individuals enrolled in Medicare or Medicaid, per capita tax revenue, and obesity rate. Alternatively, FMAP rate, interaction term of hospitals and beds and percentage of $\mathrm{HMO}$ enrollment negatively impact public healthcare financing. 
While private insurance financing is inversely proportional to the federal fund rate, it is directly (positively) proportional to active physician, per capita state GDP, percentage of individuals enrolled in Medicare or Medicaid and obesity rate. Lastly, out of pocket expenditures are positively impacted by the African-Americans, females, per capita tax revenue, active physician, proportion of elderly population (aged 65 and above), per capita state GDP, percentage of individuals enrolled in Medicare or Medicaid and obesity rate. It is also negatively influenced by percentage of Hispanic population and proportion of the population below age 17 .

\section{Policy Implications}

Cost of healthcare is a perennial policy concern. Policy responses to contain healthcare have been fragmented and have focused on some aspects. The majority of public healthcare funding by state governments comes from Medicare and Medicaid. Currently, healthcare funding by public sources (i.e. Medicare and Medicaid) make up 44\% of healthcare spending (CMS, 2012) and is expected to increase to $50 \%$ by 2021(WHO, National Health Account database, World Bank). Therefore, Medicare/Medicaid reforms to contain costs will help in reducing the reliance on healthcare funding by public sources for all the states.

This study's findings highlighted the role of factors beyond healthcare sector. Unfortunately, all healthcare policy reforms have exclusively focused on healthcare sector. Policy efforts are needed to strengthen non-health sector as well. For example, findings from this study suggest that the economic profile of the states such as unemployment rates, GDP, state tax revenues play a significant role in healthcare funding by public sources. As the economic stability is one of the key components to reduce the reliance on healthcare funding 
from public sources. Indeed, the US economic climate shapes the health coverage and costs, and financial access to care and health outcomes (Impact of the Economy on Health Care, 2009)

Social determinants of health also need to become one of the most essential parts of our healthcare conversation. Changes in social norms by denormalization/stigmatization (eliminate or change health behaviors which were considered acceptable or desirable to reduce or eradicate resistance towards health policies), change of attitude and isolation of morality instead of discrimination or social isolation, increasing networks should be the goal to enact health policy successfully.

Effectiveness of any health policy depends on the population's rate of utilization and access which depends on the demographic profile of the population. "Increasing health insurance coverage as a reform is not sufficient to systemic barriers to access like health care workforce shortages in low-income communities, or the higher prevalence of chronic diseases in some populations (WHO)." To promote a social determinant approach towards healthcare policy, policy efforts need to be coordinated among different sectors of the economy, different population groups and organizations (WHO, 2015).

Patient Protection and Affordable Care Act (ACA) included some reforms to reduce overall healthcare spending and financing while maintaining reasonable healthcare quality. These reforms include cost-savings through Accountable Care Organizations (ACOs), restrictions on the amount of money spent on administrative costs and marketing bundle payments, moving from FFS to payment based on outcomes etc. "Under bundled payments, doctors, hospitals and other health providers share a fixed payment that covers the average cost of a "bundle" of services (Hernandez, 2014). The "health care organizations will have more autonomy on funds and deliver care (Hernandez, 2014). Further under this payment system, 
healthcare providers will be forced to treat a minimum number of patients (because of threshold administrative costs) thereby increasing more treatments and access of healthcare for the people.

"ACO is a network of doctors and hospitals that shares financial and medical responsibility for providing coordinated care to patients thereby limiting unnecessary spending. It takes care of the healthcare requirements of the elderly (as it needs to manage of a minimum of 5,000 Medicare beneficiaries)" (Gold, 2014). Therefore this organizations will focus on reducing hospital costs by decreasing hospital stays, emergency visits, expensive tests etc. and it has been projected that ACO will save Medicare spending by $\$ 940$ million in 4 years (Gold, 2014).

In this study, states with higher obesity rates had higher share of healthcare spending across all sources. Annual medical care costs of obesity in the U.S. were about $\$ 190.2$ billion in 2012 or $21 \%$ of the total medical costs (Cawley, 2012). Obesity "put individuals at risk for the leading causes of death in the US including: heart disease, certain cancers, and stroke, as well high cholesterol, type 2 diabetes, sleep apnea, and other negative physical and mental health outcomes (CDC)." Obesity prevention requires approaches that "ensure a sustainable, adequate, and nutritious food supply; a habitat that lends itself to easy uptake of healthier food; participation in physical activity; and a family, educational, and work environment that positively reinforces healthy living. Very little of this action sits within the capabilities or responsibilities of the health sector (WHO)".

As acknowledged earlier, most states have reduced their public healthcare budget in 2011-2012. However, the federal government has initiated programs in 28 state health departments via CDC (bureaucratic federal agency) to prevent and control obesity and other 
chronic diseases (American Obesity). Preventing obesity and its related chronic diseases should be a major focus of healthcare cost-containment efforts. Obesity Prevention efforts can save billions of dollars over 75 years. Therefore increasing funding for obesity-prevention programs will be important to achieve results in improving health and reducing healthcare costs and financing for the future. Another way of addressing this issue is changing the choice structure of people (people are forced to make healthy choices) to make the prevention programs and health policies more effective to control costs.

This study's findings suggest that investment in prevention of diseases and obesity may reduce healthcare spending by all sources (i.e. government, private, and individuals). Currently, most of the healthcare spending is devoted to treating chronically ill patients and very little is spent on health promotion and prevention. According to Thorpe (2005), an overwhelming percentage (90\%) of spending is for sicker patients, spending $\$ 1,000$ per year or more. The ACA "breaks new ground" by investing in prevention of diseases (Advisory Committee on Immunization Practices (vaccinations, preventive care and screening), U.S. Preventive Services Task Force (screening for cancer, HIV and depression, alcohol-misuse counseling, effective treatment, follow-up and immunizations)) and promoting health and wellness in the population (Howard et al. 2010). Such prevention investments need to be amplified to reduce healthcare spending on sickness. 


\section{REFERENCES}

A Primer, Key Information on Health Care Costs and Their Impact. 2012. The Henry and Kaiser Family Foundation.

Annual Report of the Boards of Trustees of the Federal Hospital Insurance and Federal Supplementary Medical Insurance Trust Funds, 2013.

ASPE Issue Brief, Long-Term Growth of Medical Expenditures -Public and Private. 2005. Accessed on August 15th, 2014. http://www.aspe.hhs.gov/health/MedicalExpenditures/index.shtml.

Austin, A. and V.Wetle. 2012. The United States Health Care System. Combining Business, Health and Delivery. Pearson, 2nd edition, New Jersey.

Bachrach, D. and P. Boozang. 2011. Federally-Facilitated Exchanges and the Continuum of State Options. National Academy of Social Insurance.

Bose, S. 2015. Determinants of Per Capita State-Level Health Expenditures in the United States: A Spatial Panel Approach. The Journal of Regional Analysis and Policy.45.Forthcoming

Baker, L.C.. 2000. HMO Market Penetration and Costs of Employer-Sponsored Health Plans. Health Affairs. Sep/Oct 2000: 121-128.

Benjamin A. E. 1986. Determinants of State Variations in Home Health Utilization and Expenditures under Medicare. Medical Care, 24(6): 535-54.

Bipartisan Policy Center. 2012. What is Driving U.S. Health Care Spending America's Unsustainable Health Care Cost Growth? Washington D.C.

Brien, E.O., K. B. Wu and D. Baer . 2010. Older Americans in Poverty: A Snapshot AARP Public Policy Institute. AARP, 601 E Street, NW, Washington, DC 20049.

Cawley, J. and C.Meyerhoefer.2012.The medical care costs of obesity: an instrumental variables approach. Journal of Health Economics. 31(1):219-230.

Cebula, R.J. and M. Toma. 2008. An Empirical Analysis of Determinants of Interstate LivingCost Differentials, 2005. Journal of Regional Analysis and Policy, 38(3): 222- 228.

Center for Policy Innovation Discussion Paper \#7 on Health Care. 2013.The Long-Term Care Financing Crisis. Diane Calmus.

Centers for Medicare and Medicaid Services, National Health Expenditure Accounts, Sponsor Highlights. 2014. http://www.cms.gov/Research-Statistics-Data-and-Systems/StatisticsTrends-and-Reports/NationalHealthExpendData/NationalHealthAccountsHistorical.html.

Centers for Medicare and Medicaid Services. 2011. Health Expenditures by State of Residence. http://www.cms.gov/NationalHealthExpendData/downloads/resident-state-estimates.zip. Accessed on August 15th, 2014. 
Centers for Medicare and Medicaid Services. Health expenditures by sponsors: business, household and government.

http://www.cms.hhs.gov/NationalHealthExpendData/downloads/bhg08.pdf. Accessed on February 6, 2015.

Centers for Medicare and Medicaid Services: http://www.cms.gov/Research-Statistics-Data-andSystems/Statistics-Trends-and-Reports/NationalHealthExpendData/Downloads/restables.pdf. Accessed on July 2nd 2014.

Centers for Medicare and Medicaid Services: http://www.cms.gov/Research-StatisticsData-andSystems/Statistics-TrendsandReports/NationalHealthExpendData/Downloads/restables.pdf.

Chaikind, H. and C. Copeland. 2012. ACA: A Brief Overview of the Law, Implementation, and Legal Challenges. Congressional Research Service.

Centers for Medicare and Medicaid Services, 1990. http://cms.hhs.gov/Research-Statistics-Dataand-Systems/Research/HealthCareFinancingReview/Downloads/CMS1191185dl.pdf.

Centers for Medicare and Medicaid Services, 2013. http://www.cms.gov/Research-StatisticsData-and-Systems/Statistics-Trends-and-Reports/NationalHealthExpendData/NHE-FactSheet.html.

Chernew, E., R. A. Hirth and D. M. Cutler. 2003. Increased Spending On Health Care: How Much Can The United States Afford? Michael. doi: 10.1377/hlthaff.22.4.15. Health Affairs; 22(4); 15-25.

DeNavas-Walt, C., B.D. Proctor and J. C. Smith. 2010. Income, Poverty, and Health Insurance Coverage in the United States: 2009. Current Population Reports. Washington DC: U.S. Government Printing Office.

DeNavas-Walt, C., B. D. Proctor and J. C. Smith. 2011. Income, Poverty, and Health Insurance Coverage in the United States: 2010. United States Census Bureau.

Duckett, P. and A.Samantha. 2013. Health coverage for the Black Population Today and Under the Affordable Care Act. State Health Facts, Kaiser Family Foundation.

Duggan, M. 2002.Does Contracting Out Increase the Efficiency of Government Programs? Evidence from Medicaid HMOs" (NBER Working Paper No. 9091),. NBER Working Paper No. 9091.

Emanuel, E. J., and V. R. Fuchs. 2008. Who Really Pays for Health Care? The Myth of Shared Responsibility. The Journal of the American Medical Association; 299(9):1057-1059. doi:10.1001/jama.299.9.1057.

Facts, Henry J. Kaiser Family Foundation. 2000-2009. http://kff.org/statedata/. Accessed on May 25 th, 2014. 
Firat, B. and C.T. Kien. 2013. The determinants of Canadian provincial health expenditures: evidence from a dynamic panel. Journal of Applied Economics 45(2):201-212.

Fischer, C.R. 1980. Differences by Age Group in Health Care Spending. Health Care Financing Review, spring: 65-90.

FY 2016: Federal Register. 2014; 79(231): 71426-71428.

Government Accountability Office. 2014. State and Local Governments’ Fiscal Outlook: 2014 Update. http://www.gao.gov/fiscal_outlook/state_local_fiscal_model/overview\#t=0.

Graves, J. A. and K. Swartz. 2013. Understanding State Variation in Health Insurance Dynamics Can Help Tailor Enrollment Strategies for ACA Expansion. 10.1377/hlthaff.2013.0327. Health Affairs. 32(10); 1832-1840.

Greene, J., J. Blustein, , and K. A. Laflamme. 2001. Use of Preventive Care Services, Beneficiary Characteristics, and Medicare HMO Performance. Health Care Finance Review.22(4); 141-153.

Gold, J. 2014. FAQ On ACOs: Accountable Care Organizations, Explained. http://kaiserhealthnews.org/news/aco-accountable-care-organization-faq/.

Hanratty, B., E. Lowson, L. Holmes, G. Grande, J. Addington-Hall, S. Payne and J. Seymour. 2012. Funding health and social services for older people - a qualitative study of care recipients in the last year of life. Journal of the Royal Society of Medicine. 105(5): 201207.

Harman, J.S., K. J. Kelleher, C. F. Reynolds and H. A. Pincus. 2004. Out-of-Pocket Healthcare Expenditures of Older Americans with Depression. Journal of American Geriatrics Society, 52:809-813.

Hausman, J. A. 1978. Specification Tests in Econometrics. Econometrica 46 (6): 1251-1271. ISSN 0012-9682.

Horwitz, J.R. 2005. Making Profits and Providing Care: Comparing Nonprofit, For-Profit, And Government Hospitals. Health Affairs. 24(3); 790-801.

Hernandez, D. 2014. Some California Hospitals, Insurers Disappointed in 'Bundled Payments. http://kaiserhealthnews.org/news/some-california-hospitals-insurers-disappointed-inbundled-payments/

Howard K. K., and K. G. Sebelius. 2010. Promoting Prevention through the Affordable Care Act. New England Journal of Medicine; 363:1296-1299.

Investing in America's Health: A State-by-State Look at Public Health Funding and Key Health Facts. 2013. Trust for America's Health.

http://healthyamericans.org/report/105/\%20http://www.commonwealthfund.org/publicati ons/fund-reports/2013/sep/low-income-scorecard. 
IMS institute for health care informatics. Health care information among privately insured individuals under the age 65. 2012. New Jersey, USA.

http://www.imshealth.com/deployedfiles/ims/Global/Content/Insights/IMS\%20Institute\% 20for\%20Healthcare\%20Informatics/Healthcare\%20Spending/IHII_Spending_Report.pd

Jones, C.I. 2007. Why have health expenditures as a share of GDP risen so much? National Bureau of Economic Research, University of California Berkeley, 9325:1-33.

Kaiser State Health Facts. http://kaiserhealthnews.org/news/report-health-spending-will-climbto-nearly-one-fifth-of-gdp/.

Kaiser Commission on Medicaid Facts. 2011. Medicaid's Role for Hispanic Americans. https://kaiserfamilyfoundation.files.wordpress.com/2013/01/8189.pdf.

Kassner, E. 2000. Medicaid Financial Eligibility for Older People: State - AARP. assets.aarp.org/rgcenter/health/2000_06_medicaid.pdf.

Kaiser State Health Facts. 2013. http://kff.org/medicaid/state-indicator/spending-on-acute-care/. Urban Institute estimates based on data from CMS (Form 64) (as of 9/19/14).

Kiselev, M. 2010. Hospitals in Distress: How the Economy has Affected Financing of Health Care. Illinois Business Law Journal, 21:34.

Keehan, S.P., G. A. Cuckler, A. M. Sisko, A. J. Madison, S. D. Smith, J. M. Lizonitz, J. A. Poisal and C. J. Wolfe. 2004. National Health Expenditure Projections: Modest Annual Growth Until Coverage Expands And Economic Growth Accelerates. Health Affairs. doi:10.1377/hlthaff.2012.0404.

Kronebusch, K. 1993. Causes of Medicaid Expenditure Growth, Unpublished Dissertation. Harvard University. Medicaid Politics.

Lukens, G. 2014. State Variation in Health Care Spending and the Politics of State Medicaid Policy US Office of Management and Budget, Journal of Health Politics, Policy and Law; 39(6): 1213-1251.

Lundberg, J. 2011. On the definition of W in empirical models of yardstick competition, Department of Economics, Umea University, Sweden.

Meara, E. 2012. Geographic Variation in Health Care Spending and Utilization in Subgroups: Medicaid, Uninsured, and Undocumented Populations.

Mays, G.P. and S. A. Smith. 2011. Evidence Links Increases in Public Health Spending To Declines in Preventable Deaths. doi: 10.1377/hlthaff.2011.0196. Health Affairs; 30(8); 1585-1593.

Manski, C.F. 1993. Identification of endogenous social effects: the reflection problem. Review of Economic Studies, 60(1);531-542.

Martin, A., L.Whittle, K. Levit, G. Won and L. Hinman. 2002. Health Care Spending During 1991-1998: A Fifty-State Review. Health Affairs 21(4); 112-126. 
Martin, A., G. Cuckler, L. Whittle, S. Heffler, A. Sisko, D. Lassman and J. Benson. 2011. Health spending by state of residence, 1991-2009, Health Affairs, 1(4); 1-31.

McCall, N. 2001. Long Term Care: Definition, Demand, Cost, and Financing. In: McCall N, ed. Who Will Pay for Long Term Care? Insights from the Partnership Programs. Chicago: Health Administration Press,:3-31. http://www.ache.org/PUBS/1mccall.pdf. Accessed June 10, 2014.

McManus, P.A. 2011. Introduction to Regression Models for Panel Data Analysis Indiana University Workshop in Methods.

Messer, J. and M.C.Berger. 2002. Public financing of Health expenditures, insurance, and health outcomes. Applied Economics, 34 (17): 2105-2113.

Minott, J. 1995. Does Medicaid managed care market penetration impact provider participation, costs, utilization, and access? Health Care Financial Rev. 16(3); 11-25.

Minott, J. 2010. Changes in Health Care Financing and Organization (HCFO), XIII(5).

Murthy, N.R.V. and V. Ukpolo. 1994. Aggregate health care expenditure in the Unites States: evidence from co integration tests. Applied Economics. 26; 797-802.

National Institute of Health (NIH), NHLBI Obesity Education Initiative. Clinical Guidelines on the Identification, Evaluation, and Treatment of Overweight and Obesity in Adults. Available online: http://www.nhlbi.nih.gov/guidelines/obesity/ob_gdlns.pdf.

Nair, R.R. 2006. Factors Influencing Expenditures, Health Care Resource Utilization and Quality of Life of Diabetes Patients - A Fixed Effects Model With Meps, PhD. Thesis.

National health care and medicare spending. Medpac. 2014. http://www.medpac.gov/documents/publications/june-2014-data-book-section-1-nationalhealth-care-and-medicare-spending.pdf?sfvrsn=2.

Nolte, E. and C.M. McKee. 2012. in Amenable Mortality Deaths Avoidable Through Health Care Progress. Health Affairs, 31(9): 2114-2122.

Novignon, J., S. A. Olakojo and J. Nonvignon. 2012. The effects of Public and Private Health care expenditure on health status in sub-Saharan Africa: Evidence from panel data analysis. Health Economics Review, 2:22.

Organization for Economic Co-operation and Development. 2013. Health at a Glance 2013: OECD Indicators, OECD Publishing. doi: 10.1787/health_glance-2013-en.

Organization for Economic Co-operation and Development. 2012. Health Care Cost.

Organization for Economic Cooperation and Development. 2011. OECD Health Data, 2011. Paris. 
Organization for Economic Co-operation and Development (OECD) http://www.cdc.gov/nchs/data/hus/2011/020.pdf ranking infant mortality. Health Data. 2011, Available from: http://www.oecd.org/home/.

Paradise, J. and R. Garfield. 2013. What is Medicaid's Impact on Access to Care, Health Outcomes, and Quality of Care? Setting the Record Straight on the Evidence.

Personal Consumption Expenditures by State Statistics. U.S. Department of Commerce / Bureau of Economic Analysis / Regional Product Division.

Princeton University Library, Data and Statistical Services. http://dss.princeton.edu/online_help/stats_packages/stata/panel.htm.

Quinn, B.C. 2011. State-Level Health Policy Research: Looking Back, Looking Ahead. Health Research and Educational Trust doi: 10.1111/j.1475-6773.2010.01229.x. Health Service Research. 46:1, Part II.

Reinhardt, U.E., P. S. Hussey, and G. F. Anderson. 2004. U.S. Health Care spending In an International Context. Why is U.S. spending so high, and can we afford it? Cost and Competition. Health Affairs; 23(3).

Rettenmaier, A.J. and T. R. Saving. 2009. Perspectives on the Geographic Variation in Health Care Spending. National Center for Policy Analysis.

Rosenthal, A. 2004. Heavy Lifting: The Job of the American Legislature. Washington, DC: Congressional Quarterly.

Robert Wood Johnson Foundation. 2013. The Long-Term Returns of Obesity Prevention Policies.

Robert Wood Johnson Foundation. 2009. Changes in Health Care Financing and Organization. Impact of the Economy on Health Care.

Squires, D. 2012. Explaining High Health Care Spending in the United States: An International Comparison of Supply, Utilization, Prices, and Quality. New York: The Commonwealth Fund.

State and Local Fiscal Challenges: Rising Health Care Costs Drive Long-Term And Immediate Pressures. Gao-09-210t: Published: Nov 19, 2008.

State and Local Governments' Fiscal Outlook: April 2013 Update. Gao-13-546sp: Published: Apr 29, 2013. Publicly Released: Apr 29, 2013.

Social Security. Medicare. http://www.ssa.gov/medicare/.

Trogdon, J.G., E. A. Finkelstein, C. W. Feagan and J. W. Cohen. 2012. State- and Payer-Specific Estimates of Annual Medical Expenditures Attributable to Obesity. Obesity. 20(1); 214 220. 
Thorpe, K.E. 2005. The Rise in Health Care Spending and What to Do About It. Health Affairs; 24(6):1436-1445.

Tracking Key Health Indicators. 2014. http://www.pewtrusts.org/en/multimedia/datavisualizations/2014/health-indicators.

Tu, H.T, P.Kemper and H. J. Wong. 2000. Do HMOs Make a Difference? Use of Health Services. Inquiry. 36(4):400-410.

U.S. Alcohol Epidemiologic. Data Reference Manual. 2013. Alcohol-Related Emergency Department Visits and Hospitalizations and Their Co-Occurring Drug-Related, Mental Health, and Injury Conditions in the United States. National Institute of Alcohol Abuse and Alcoholism, MD.9.

U.S. Census Bureau. 2009. Population Estimates. Accessed on June 20th 2014, http://www.census.gov/popest/data/historical/2000s/vintage_2009/index.html.

United Census Bureau, U.S. Department of Commerce. 2000-2009. Accessed on May 22nd, 2014.http://www.census.gov/.

Wang, Z. 2009. The determinants of health expenditures: evidence from US state-level data. Applied Economics 41:429-435.

Wickizer T.M. and P.J. Feldstein. 1995. The Impact of HMO competition on private health insurance premiums, 1985-1992. Inquiry; 32(3); 241-251.

World Development Indicators, World Health Statistics. 2013. Accessed on July 10th, 2014.

World Development Indicators, World Health Statistics. 2013. http://www.who.int/gho/publications/world_health_statistics/EN_WHS2013_Part3.pdf?u $\mathrm{a}=1$.

World Health Organization, National Health Account database. http://apps.who.int/nha/database/DataExplorerRegime.aspx. Accessed on July 20th, 2014.

World Health Organization, National Health Account database. http://apps.who.int/nha/database/DataExplorerRegime.aspx. Accessed on July 20th, 2014.

World Health Organization. 2000. Report on Health System: Improving Performance. World Health Report. Bulletin WHO.

Yaffee, R. 2003. A Primer for Panel Data Analysis, Fall. New York. nyu.edu.

Zuckerman, S., L. Skopec and K. McCormack. 2014. Reversing the Medicaid Fee Bump: How Much Could Medicaid Physician Fees for Primary Care Fall in 2015? Evidence from a 2014 Survey of Medicaid Physician Fees. 
Table 2: Definition of Variables

\begin{tabular}{|c|c|c|c|c|}
\hline Dependent Variables & Definition & & & \\
\hline $\begin{array}{l}\text { Per capita Public Health insurance } \\
\text { funding (a) }\end{array}$ & Per capita value of Public Funding (Medicare and Medicaid) & & & \\
\hline $\begin{array}{l}\text { Per capita Private health insurance } \\
\text { funding (b) }\end{array}$ & Per capita value of Private Health Insurance Funding & & & \\
\hline Per capita Out of Pocket Expenses (c) & Per capita value of Out of Pocket Expenditure & & & \\
\hline Independent Variables & & \multicolumn{3}{|c|}{ Expected sign of coefficients } \\
\hline Economic Profile & & (a) & (b) & (c) \\
\hline Uninsured rate & Percentage of people without any insurance & + & - & + \\
\hline Per capita GDP & Per capita value of state Gross Domestic Product & + & + & + \\
\hline Unemployment rate & Proportion of unemployed population & + & - & + \\
\hline Federal funding rate & Percentage of federal fund to states & - & - & - \\
\hline FMAP rate & Percentage of Federal Medicaid Assistance Program & - & - & - \\
\hline Per capita State tax revenue & Per capita value of State tax revenue & + & - & + \\
\hline Poverty rate & Percentage of population below the poverty line & + & - & + \\
\hline \multicolumn{5}{|l|}{ Demographic Profile } \\
\hline Proppopbelow17 & Proportion of the population below age 17 & - & - & - \\
\hline Proppopabove65 & Proportion of the population above age 65 & + & + & + \\
\hline African-American & Percentage of African-American population & + & + & + \\
\hline Female & Percentage of female population & + & + & + \\
\hline Hispanic & Percentage of Hispanic Population & + & + & - \\
\hline \multicolumn{5}{|l|}{ Political Profile } \\
\hline Party in Control of State Legislature & Republican $=0$ and Democrat $=1$ & + & - & - \\
\hline $\begin{array}{l}\text { Percentage enrolled in Medicare and } \\
\text { Medicaid }\end{array}$ & Total percentage of enrolled in Medicare and Medicaid & + & + & + \\
\hline HMO & Percentage enrolled in Health Maintenance Organizations & - & - & - \\
\hline \multicolumn{5}{|l|}{ Healthcare needs } \\
\hline Obesity rate & Percentage of population suffering from obesity & + & + & + \\
\hline \multicolumn{5}{|l|}{ Supply factors } \\
\hline Hospital & The total number of community hospitals & - & + & - \\
\hline Hospbed & Total number of hospital beds per 1000 population & + & - & + \\
\hline Actphys & $\begin{array}{l}\text { The total number of active physicians per } 100,000 \\
\text { population }\end{array}$ & + & + & + \\
\hline Region dummy & $\begin{array}{l}\text { Regions (as named in CMS coded in numeric dummy } \\
\text { format for analysis purpose Northeast }=0 \text {, Midwest }=1 \text {, } \\
\text { West }=2 \text {, South }=3 \text { ) }\end{array}$ & - & - & - \\
\hline
\end{tabular}


Table 3: Summary Statistics (Public, Private Health Insurance and Out Of Pocket Expenses) 2001-2009 for 48 states and D.C.

\begin{tabular}{|c|c|c|c|c|c|c|}
\hline Variable & Unit & Observations & Mean & Standard Deviation & Minimum & Maximum \\
\hline Region dummy & Unit & 441 & 2.612 & 1.028 & 1.000 & 4.000 \\
\hline Per capita Out of Pocket expenses & $\$$ & 441 & 9110.194 & 2512.844 & 3662.561 & 17845.520 \\
\hline Per capita Private health insurance & $\$$ & 441 & 20592.140 & 5132.524 & 10570.620 & 50843.020 \\
\hline Per capita Public healthcare funding & $\$$ & 441 & 20589.770 & 5773.549 & 7994.667 & 41817.430 \\
\hline \multicolumn{7}{|l|}{ Demographic profile } \\
\hline Proportion of population above age 65 & $\%$ & 441 & 12.790 & 1.527 & 8.500 & 17.600 \\
\hline Proportion of population below17 & $\%$ & 441 & 24.490 & 2.108 & 18.930 & 43.757 \\
\hline Percentage of African-American population & $\%$ & 441 & 11.658 & 11.561 & 0.373 & 60.268 \\
\hline Percentage of Female population & $\%$ & 441 & 49.222 & 0.721 & 47.044 & 51.014 \\
\hline Percentage of Hispanic population & $\%$ & 441 & 9.224 & 9.523 & 0.732 & 45.567 \\
\hline \multicolumn{7}{|l|}{ Economic profile } \\
\hline Uninsured rate & $\%$ & 441 & 13.738 & 3.875 & 4.400 & 26.100 \\
\hline Per capita GDP (Gross Domestic Product) & $\$$ & 441 & 42346.540 & 16599.940 & 23668.720 & 165330.200 \\
\hline Unemployment rate & $\%$ & 441 & 5.339 & 1.664 & 2.700 & 13.300 \\
\hline Federal fund $\%$ & $\%$ & 441 & 28.054 & 7.807 & 3.943 & 49.170 \\
\hline Per capita tax revenue & $\$$ & 441 & 2619.215 & 2974.148 & 1282.240 & 26687.540 \\
\hline Poverty rate & $\%$ & 441 & 12.236 & 3.196 & 5.400 & 23.100 \\
\hline Percentage of enrollment in HMO & $\%$ & 441 & 19.465 & 11.895 & 0.100 & 64.100 \\
\hline \multicolumn{7}{|l|}{ Political profile } \\
\hline Control of State legislature & Unit & 441 & 1.508 & 0.501 & 1.000 & 2.000 \\
\hline Enroll rate & $\%$ & 441 & 32.291 & 6.155 & 18.653 & 56.381 \\
\hline FMAP rate & $\%$ & 441 & 63.156 & 8.836 & 50.000 & 84.240 \\
\hline \multicolumn{7}{|l|}{ Healthcare outcomes } \\
\hline Obesity rate & $\%$ & 441 & 24.306 & 3.581 & 14.900 & 35.400 \\
\hline \multicolumn{7}{|l|}{ Health supply factors } \\
\hline Active physician per 100,000 population & Unit & 441 & 262.011 & 94.498 & 154.000 & 817.134 \\
\hline Hospital bed per 1000 population & Unit & 441 & 0.294 & 0.215 & 0.012 & 1.087 \\
\hline Total number of Hospitals & Unit & 441 & 99.825 & 79.715 & 5.000 & 428.000 \\
\hline
\end{tabular}


Table 4: Breusch and Pagan Lagrangian Multiplier Test Results Breusch and Pagan Lagrangian multiplier test for random effects

\begin{tabular}{|l|l|l|l|}
\hline & $\begin{array}{l}\text { Public } \\
\text { Insurance }\end{array}$ & Private Insurance & Out of Pocket Expenditure \\
\hline $\bar{\chi}^{2}$ & $657.48^{* * *}$ & $207.43^{* * *}$ & $581.29 * * *$ \\
\hline P value & 0.000 & 0.000 & 0.000 \\
\hline
\end{tabular}


Table 5: Hausman Test Results

Hausman Specification Test

\begin{tabular}{|l|l|l|l|}
\hline & Public Insurance & Private Insurance & Out of Pocket Expenditure \\
\hline$\chi^{2}(17)$ & $99.58 * * *$ & $60.09 * * *$ & $64.06 * * *$ \\
\hline $\mathrm{P}$ & 0.000 & 0.000 & 0.000 \\
\hline
\end{tabular}


Table 6: State Fixed Effect Model, Pooled OLS Model and First Difference Model Results (Public Insurance)

\begin{tabular}{|c|c|c|c|c|c|c|c|c|c|}
\hline \multirow[b]{2}{*}{ Per capita Public Healthcare Funding } & \multicolumn{3}{|c|}{ State fixed effect model } & \multicolumn{3}{|c|}{ Pooled OLS model } & \multicolumn{3}{|c|}{ First difference model } \\
\hline & Coefficient & S.E & $\mathrm{T}$ value & Coefficient & S.E & T value & Coefficient & S.E & $\mathrm{T}$ value \\
\hline Proportion of population above age 65 years & $2291.227 * * *$ & 266.922 & 8.580 & $778.073 * * *$ & 99.137 & 7.850 & $1585.339 * * *$ & 296.147 & 5.350 \\
\hline Proportion of population below age 17 years & -27.566 & 55.252 & -0.500 & 12.678 & 76.629 & 0.170 & 13.905 & 10.519 & 1.320 \\
\hline Percentage of Hispanic population & $306.515^{* *}$ & 133.882 & 2.290 & -13.959 & 18.994 & -0.730 & $1425.227 * * *$ & 375.306 & 3.800 \\
\hline Percentage of African-American population & 59.037 & 226.969 & 0.260 & -18.143 & 20.477 & -0.890 & 60.338 & 364.023 & 0.170 \\
\hline Percentage of Female population & $8605.453 * * *$ & 1163.734 & 7.390 & 435.873 & 377.567 & 1.150 & $5810.266^{* * *}$ & 1037.140 & 5.600 \\
\hline Unemployment rate & $188.366^{* *}$ & 73.252 & 2.570 & $252.960 * * *$ & 68.452 & 3.700 & $119.046 * *$ & 60.346 & 1.970 \\
\hline Per capita GDP & $0.070 * *$ & 0.035 & 2.010 & $0.164 * * *$ & 0.022 & 7.560 & $0.234 * * *$ & 0.055 & 4.230 \\
\hline Poverty rate & 21.504 & 46.975 & 0.460 & $176.480 * * *$ & 61.298 & 2.880 & 14.259 & 22.129 & 0.640 \\
\hline Federal fund $\%$ & -0.418 & 16.802 & -0.020 & $-35.180 * *$ & 15.864 & -2.220 & 18.052 & 15.442 & 1.170 \\
\hline Per capita tax revenue & $0.691 * *$ & 0.278 & 2.490 & $-0.829 * * *$ & 0.128 & -6.460 & 0.143 & 0.414 & 0.340 \\
\hline Control of State legislature & -287.102 & 211.186 & -1.360 & $-907.640 * * *$ & 248.544 & -3.650 & -50.286 & 112.544 & -0.450 \\
\hline HMO rate & $-33.235 * *$ & 13.089 & -2.540 & -13.563 & 12.453 & -1.090 & $-19.778 * *$ & 7.355 & -2.690 \\
\hline Percentage enrolled in Medicare and Medicaid & $183.880 * * *$ & 29.105 & 6.320 & $273.943 * * *$ & 24.585 & 11.140 & $55.295 * * *$ & 19.026 & 2.910 \\
\hline Obesity rate & $496.669 * * *$ & 49.619 & 10.010 & $773.910 * * *$ & 41.795 & 18.520 & $110.902 * * *$ & 27.763 & 3.990 \\
\hline Active physician per 100,000 population & $27.125 * * *$ & 6.218 & 4.360 & $34.020 * * *$ & 3.036 & 11.210 & $8.053 * *$ & 4.870 & 3.650 \\
\hline (Total Hospitals*Hospital bed) per 1000 people & $-5825.754 *$ & 3271.185 & -1.780 & -513.159 & 639.577 & -0.800 & 25.318 & 371.338 & 0.070 \\
\hline \multicolumn{10}{|l|}{ Region dummy } \\
\hline Mid-west & & & & $-5279.688 * * *$ & 397.013 & -13.300 & & & \\
\hline South & & & & $-6571.919 * * *$ & 457.473 & -14.370 & & & \\
\hline West & & & & $-5202.200 * * *$ & 534.237 & -9.740 & & & \\
\hline Constant & $-463610.400 * * *$ & 57145.050 & -8.110 & $-50807.700 * *$ & 19700.080 & -2.580 & & & \\
\hline F value & $293.4 * * *$ & & & $186.39 * * *$ & & & $52.38 * * *$ & & \\
\hline $\mathrm{R}$ square & 0.9339 & & & 0.8985 & & & 0.776 & & \\
\hline $\mathrm{N}$ observation & 441 & & & 441 & & & 392 & & \\
\hline
\end{tabular}

\footnotetext{
$* * *, * *, *$ represent $1 \%, 5 \%$ and 10 level of significance
} 
Table 7: State Fixed Effect Model, Pooled OLS Model and First Difference Model Results (Private Insurance)

\begin{tabular}{|c|c|c|c|c|c|c|c|c|c|}
\hline \multirow[b]{2}{*}{ Per capita Private health insurance funding } & \multicolumn{3}{|c|}{ State fixed effect model } & \multicolumn{3}{|c|}{ Pooled OLS model } & \multicolumn{3}{|c|}{ First difference model } \\
\hline & Coefficient & S.E & $\mathrm{T}$ value & Coefficient & S.E & $\mathrm{T}$ value & Coefficient & S.E & $\mathrm{T}$ value \\
\hline Proportion of population above age 65 & 237.374 & 333.389 & 0.710 & -69.076 & 92.237 & -0.750 & -79.228 & 782.286 & -0.100 \\
\hline Proportion of population below age 17 & -100.975 & 69.011 & -1.460 & -99.273 & 71.295 & -1.390 & -37.196 & 60.720 & -0.610 \\
\hline Percentage of Hispanic population & 254.108 & 167.221 & 1.520 & $-46.633 * * *$ & 17.672 & -2.640 & $1564.747 * * *$ & 348.694 & 4.490 \\
\hline Percentage of African-American population & 186.037 & 283.488 & 0.660 & $-59.185 * * *$ & 19.051 & -3.110 & -87.221 & 304.347 & -0.290 \\
\hline Percentage of Female population & 1736.658 & 1453.524 & 1.190 & $665.338 * *$ & 351.286 & 1.890 & 939.874 & 1657.060 & 0.570 \\
\hline Poverty rate & -1.103 & 58.672 & -0.020 & $-151.555 * * *$ & 57.031 & -2.660 & 21.256 & 46.929 & 0.450 \\
\hline Uninsured rate & 63.926 & 51.687 & 1.240 & 32.603 & 49.339 & 0.660 & 26.496 & 40.618 & 0.650 \\
\hline Per capita GDP & $0.269 * * *$ & 0.044 & 6.120 & $0.219 * * *$ & 0.020 & 10.870 & $0.219 * * *$ & 0.045 & 4.930 \\
\hline Unemployment rate & 97.328 & 91.493 & 1.060 & $399.280 * * * *$ & 63.687 & 6.270 & 85.694 & 104.305 & 0.820 \\
\hline Federal fund $\%$ & $-37.368 *$ & 20.985 & -1.780 & -19.455 & 14.760 & -1.320 & -9.119 & 20.950 & -0.440 \\
\hline Per capita tax revenue & -0.200 & 0.347 & -0.570 & -0.061 & 0.119 & -0.510 & 0.297 & 0.380 & 0.780 \\
\hline Control of State legislature & 15.825 & 263.774 & 0.060 & $-891.457 * * *$ & 231.244 & -3.860 & -470.752 & 392.765 & -1.200 \\
\hline HMO rate & -17.675 & 16.349 & -1.080 & 16.870 & 11.586 & 1.460 & -6.830 & 16.429 & -0.420 \\
\hline Percentage enrolled in Medicare and Medicaid & $92.358 * *$ & 36.353 & 2.540 & -13.038 & 22.874 & -0.570 & 2.314 & 46.807 & 0.050 \\
\hline FMAP rate & -0.708 & 34.331 & -0.020 & $-41.634 *$ & 22.243 & -1.870 & -4.424 & 49.042 & -0.090 \\
\hline Obesity rate & $264.278 * * *$ & 61.976 & 4.260 & $560.366^{* * * *}$ & 38.885 & 14.410 & 66.679 & 52.252 & 1.280 \\
\hline Active physician per 100,000 population & $37.273 * * *$ & 7.767 & 4.800 & $14.233 * * *$ & 2.824 & 5.040 & $11.697 * *$ & 5.604 & 3.100 \\
\hline (Total Hospitals *Hospital bed) per 1000 people & -367.936 & 4085.766 & -0.090 & $-3685.807 * * *$ & 595.059 & -6.190 & -428.280 & 599.283 & -0.710 \\
\hline \multicolumn{10}{|l|}{ Region dummy } \\
\hline Mid-west & & & & -600.040 & 369.379 & -1.620 & & & \\
\hline South & & & & $-3045.433 * * *$ & 425.630 & -7.160 & & & \\
\hline West & & & & $-3000.033 * * *$ & 497.051 & -6.040 & & & \\
\hline Constant & -99853.020 & 71375.130 & -1.400 & -27341.120 & 18328.840 & -1.490 & & & \\
\hline F value & $112.02 * * *$ & & & $168.42 * * *$ & & & $47.63 * * *$ & & \\
\hline R square & 0.844 & & & 0.888 & & & 0.366 & & \\
\hline N observation & 441 & & & 441 & & & 392 & & \\
\hline
\end{tabular}

$* * *, * * *$ represent $1 \%, 5 \%$ and 10 level of significance 
Table 8: State Fixed Effect Model, Pooled OLS Model and First Difference Model Results (Out of Pocket Expenditure)

\begin{tabular}{|c|c|c|c|c|c|c|c|c|c|}
\hline \multirow[b]{2}{*}{ Per capita Out of Pocket Expenses } & \multicolumn{3}{|c|}{ State fixed effect model } & \multicolumn{3}{|c|}{ Pooled OLS model } & \multicolumn{3}{|c|}{ First difference model } \\
\hline & Coefficient & S.E & $\mathrm{T}$ value & Coefficient & S.E & $\mathrm{T}$ value & Coefficient & S.E & $\mathrm{T}$ value \\
\hline Proportion of population above age 65 & $555.880^{* * * *}$ & 131.405 & 4.230 & $316.443 * * *$ & 45.179 & 7.000 & 20.903 & 10.017 & 2.090 \\
\hline Proportion of population below age 17 & $-58.073 * *$ & 27.201 & -2.130 & $-85.564 * *$ & 34.921 & -2.450 & $0.134 * *$ & 0.033 & 4.000 \\
\hline Percentage of Hispanic population & $-197.390 * * *$ & 65.910 & -2.990 & $-24.488 * * *$ & 8.656 & -2.830 & $26.978 * * *$ & 7.648 & 3.530 \\
\hline Percentage of African-American population & $484.977 * * *$ & 111.736 & 4.340 & $-50.277 * * *$ & 9.332 & -5.390 & $20.179 *$ & 10.663 & 1.890 \\
\hline Percentage of Female population & $3278.414 * * *$ & 572.904 & 5.720 & $881.130 * * *$ & 172.064 & 5.120 & 5.655 & 3.556 & 1.590 \\
\hline Poverty rate & 28.168 & 23.125 & 1.220 & $73.793 * * *$ & 27.934 & 2.640 & -273.642 & 217.189 & -1.260 \\
\hline Uninsured rate & 23.165 & 20.372 & 1.140 & -13.793 & 24.167 & -0.570 & $472.206 * * *$ & 190.382 & 2.480 \\
\hline Per capita GDP & $0.097 * * *$ & 0.017 & 5.590 & $0.099 * * *$ & 0.010 & 9.990 & $-7.692 *$ & 4.161 & -1.850 \\
\hline Per capita tax revenue & -0.180 & 0.137 & -1.310 & $-0.492 * * *$ & 0.058 & -8.410 & 8.882 & 7.360 & 1.210 \\
\hline Federal fund $\%$ & -8.630 & 8.271 & -1.040 & $-34.156^{* * * *}$ & 7.230 & -4.720 & $2319.312 * * *$ & 547.296 & 4.240 \\
\hline Unemployment rate & $195.562 * * *$ & 36.062 & 5.420 & $97.189 * * *$ & 31.195 & 3.120 & 164.861 & 251.013 & 0.660 \\
\hline Control of State legislature & -82.277 & 103.966 & -0.790 & $-406.459 * * *$ & 113.266 & -3.590 & 8.882 & 7.360 & 1.210 \\
\hline HMO rate & -5.092 & 6.444 & -0.790 & $-14.764 * *$ & 5.675 & -2.600 & $16.048 *$ & 8.713 & 1.840 \\
\hline Percentage enrolled in Medicare and Medicaid & $77.183 * * *$ & 14.329 & 5.390 & $85.105 * * *$ & 11.204 & 7.600 & -0.265 & 0.202 & -1.310 \\
\hline FMAP rate & 8.964 & 13.532 & 0.660 & $42.712 * * *$ & 10.895 & 3.920 & $59.399 * * *$ & 11.488 & 5.170 \\
\hline Obesity rate & $216.664 * * *$ & 24.428 & 8.870 & $336.478 * * *$ & 19.047 & 17.670 & 164.861 & 251.013 & 0.660 \\
\hline Active physician per 100,000 population & $24.535 * * *$ & 3.061 & 8.010 & $18.566 * * *$ & 1.383 & 13.420 & $422.101 * * *$ & 138.157 & 3.060 \\
\hline (Total Hospitals *Hospital bed) per 1000 people & -1451.493 & 1610.397 & -0.900 & $-584.965 * * *$ & 291.467 & -2.010 & -14.586 & 15.387 & -0.950 \\
\hline \multicolumn{10}{|l|}{ Region dummy } \\
\hline Mid-west & & & & -618.211 & 180.926 & -3.420 & & & \\
\hline South & & & & -1493.817 & 208.479 & -7.170 & & & \\
\hline West & & & & -2212.698 & 243.461 & -9.090 & & & \\
\hline Constant & $-180970.400 * * *$ & 28132.380 & -6.430 & -54812.910 & 8977.673 & -6.110 & & & \\
\hline F value & $248.11^{* * *} *$ & & & $168.25 * * *$ & & & $121.05 * * *$ & & \\
\hline $\mathrm{R}$ square & 0.9227 & & & 0.888 & & & 0.792 & & \\
\hline $\mathrm{N}$ observation & 441 & & & 441 & & & 392 & & \\
\hline
\end{tabular}

$* * *, * * *$ represent $1 \%, 5 \%$ and $10 \%$ level of significance 
CHAPTER 3 


\section{CHAPTER 3: STATE-LEVEL VARIATIONS IN INPATIENT EXPENDITURES: AN APPLICATION OF SPATIAL REGRESSION}

\section{INTRODUCTION}

Healthcare spending in the US has increased from \$75 billion in 1970 to an estimated \$2.9 trillion or $\$ 9,255$ per person in 2013 (CMS, 2013). The increase in healthcare spending is documented across all services such as inpatient care, physician and clinical services, home healthcare services, prescription drugs, nursing care, durable medical equipment and others (CMS, 2013). Of all the services, hospital expenditures constituted the major portion of the total healthcare spending. In 2013, 32.3\% (\$936.9 billion) was spent on hospital care (CMS, 2013).

In recent years, hospitalizations have reemerged as a priority for the United States healthcare system, policy makers, and research communities, due to their large share of total expenditures and morbidity and mortality burden on patient populations. At the national-level, between 1993 and 2009, nation-wide, the number of hospital discharges increased from 34.3 million to 39.4 million (Healthcare Cost and Utilization Project (HCUP), 2009). In 2009, the average hospital charges were \$30,655 (American Health Association (AHA), 2009). The largest component of Medicare expenditures was on inpatient care and totaled \$132.6 billion (MedPac, 2010). Out of $\$ 822.3$ billion of private health insurance spending in $2010,20.4 \%$ or $\$ 167.7$ billion was spent on hospital expenditures (IMShealth, 2012). Additionally, $\$ 592$ billion out of $\$ 2,988.4$ billion of Medicaid funding has been spent on hospital costs in 2013 (Kaiser Family Foundation (KFF), 2013).

\section{Variations in Hospital expenditures at the state level}

At the state-level, hospital expenditures are the highest component of total healthcare expenditures with large variations across the states. In 2009, the lowest hospital expenditure was 
$\$ 806.89$ million (Wyoming), median was $\$ 5,623.21$ million (Arizona) and the highest was $\$ 41,567.24$ million (California). The share of hospital expenditures to total expenditures was the highest in the District of Columbia, 47\% between 2000 and 2009, followed by South Dakota, Vermont, and Missouri (45\% in 2009), California (33\% in 2009), Nevada, Oregon, and Alabama. Tennessee had the lowest share of hospital expenditures to total expenditures (29\% in 2009) (Centers for Medicare and Medicaid Services (CMS), 2011).

\section{Determinants of Hospital expenditures}

A study by Gornick (1982) highlighted that there is a wide range of variation in the rate of hospitalization and length of stay across the regions of the US, thereby causing a large variation in the hospital charges and expenses across these regions.

Knickman and Foltz (1984) concluded that socio-economic differences (age, race, income, education) among the regions of the U.S. have higher impact on hospital utilizations and costs than the length of stay. Knickman and Foltz (1985) also reported that population factors and hospital infrastructures, such as the number of hospital beds and physicians, had a major impact on these interregional hospital use variations. For example, female ( 80 days per 1000 population greater than male), older people (aged 65 years and above had 1947 days per 1000 population) and populations with lower income (individual with income $>\$ 15,000$ had 0.208 fewer days per year less hospital stay than individual with income $<=\$ 5000$ ) had lower rate of hospital stays.

A variety of factors contributed to hospital expenditures. Studies have documented the association between hospital expenditures and demographic characteristics, such as gender (Qureshi et al., 2013), age (Ziaeian et al., 2015), race/ethnicity (CDC, 2013), access to care such as presence of health insurance (Qureshi et al., 2013; CDC, 2013), and health status of individuals (Ziaeian et al., 2015; Qureshi et al., 2013), supply-side factors (Qureshi et al., 2013), and others. 
One study examined the state-level variations in hospital expenditures (Bopp and Cebula, 2009). This study attributed the variations in inpatient expenditures to state-level variations in demographic profiles, socio-economic characteristics, access to healthcare, and healthcare infrastructure. Using a panel regression analysis, these researchers concluded that health insurance coverage and age-composition of the population were associated hospital expenditures. Higher the rates of health insurance coverage and greater the proportion of elderly in the state, higher were the hospital expenditures (Bopp and Cebula, 2009). Wul et al. (2014) reported that per capita income, unemployment rate, aged population above 65 years and staffing increased hospital expenditures between 2001 and 2007. According to the American Hospital Association (2005), the increasing hospital care spending can be explained by the changing demographics (a growing population of the elderly), costs of hospital supply factors, wages of physicians and improvement in technology.

\section{Binge drinking and its impact on hospital costs}

The above mentioned studies highlighted the role of demographic, socio-economic characteristics, healthcare needs, access to care and cost of providing hospital care in influencing hospital expenditures. However, it has been reported that an excessive amount of drinking (binge drinking) can lead to substantial state-level variations in hospital expenditures. It has been estimated that $20 \%$ to $25 \%$ of all patients in U.S. general hospital beds (not in maternity or intensive care) were treated for complications of alcohol-related problems (The Cost of Substance Abuse to America's Health Care System, 1994). In 2008, 12\% of hospital stays among 18-44 years old, $21 \%$ of hospital stays among $45-64$ years old and $12 \%$ of $65-84$ years were due to alcohol related disorders (HCUP, 2008). 
The Centers for Disease Control and Prevention (CDC) estimated that excessive drinking costs were $\$ 223.5$ billion in 2006 (Bouchery et al., 2006), out of which the cost from binge drinking was about $\$ 170.7$ billion (Economic Costs of Excessive Alcohol Consumption in the United States, 2006 (2011)). The estimated per-capita expenditure of excessive drinking was \$746, which included direct medical care costs, lost productivity, and crime (CDC, 2012).

It is also the third leading lifestyle-related cause of death in the United States every year (CDC). In the recent years, excessive alcohol use led to 88,000 deaths and 2.5 million years of potential life lost (YPLL) each year in the United States from 2006 to 2010 (CDC, AlcoholRelated Disease Impact (ARDI), Stahre et al., 2014). Excessive drinking is the third leading preventable cause of death (Economic Costs of Excessive Alcohol Consumption in the United States, 2006 (2011)).

Excessive drinking is characterized as binge drinking, heavy drinking and any drinking by pregnant women or people younger than age 21 (CDC). Binge drinking, in particular, is defined as 5 or more alcoholic beverage drinks for men per occasion and 4 or more drinks for women per occasion, all within a two-hour period (The Cost of Substance Abuse to America's Health Care System, 1994). According to the definition of the National Institute on Alcohol Abuse and Alcoholism, "Binge drinking is a pattern of drinking that brings a person's blood alcohol concentration (BAC) to 0.08 grams percent or above." It has been seen that binge drinkers in the US drink an average of 8 drinks more than four times a month (CDC, Vital Signs, 2012). In the year 2009, the overall prevalence of binge drinking among adults in the 50 states and District of Columbia of the US was an average of $15.2 \%$ of the total population (Kanny, 2011). In 2013, $24.6 \%$ of the population above 18 years reported binge drinking in the past month (Substance Abuse and Mental Health Services Administration (SAMSHA), 2013). It is also associated with 
many health problems, such as unintentional and intentional injuries, alcohol poisoning, high blood pressure, stroke, other cardiovascular diseases, sexually transmitted diseases, etc. (CDC, 2012), leading to an increase in total hospital expenses. Rehm et al. (2009) has recognized alcohol misuse as an important risk factor for chronic disease and injury and also captured its high social and economic cost on the economy. Hunkeler et al. (2001) compared moderate drinker to non-drinkers and reported that those with a drinking history exhibited significantly higher use of outpatient visits and hospital care than nondrinkers with no drinking history and recent drinkers. Jeremy et al. (2004) reported an inverse relationship of alcohol use with the amount of health care utilization.

\section{State level variations in binge drinking}

There are state-level variations in binge drinking and the rate of binge drinking has been increasing at a fast rate. In 2000, Utah had the lowest binge alcohol usage at 14\%, Mississippi and North Carolina percentages were second lowest at 16.8\%, while North Dakota was the highest (29\%). In 2009, the number of states with highest binge alcohol use increased to include North Dakota (29.77\%), South Dakota (29.71\%), District of Columbia (29.63\%) and Wisconsin (29.03\%) with Pennsylvania (24.07\%) and Utah still having the lowest consumption rate at $14.07 \%$ (SAMSHA, 2009). It is a problem for every state, as even states that have low binge drinking rates "also suffer as they are binge drinking more often and in higher amounts" (CDC, Vital Signs, 2012).

\section{Purpose of spatial analysis of hospital expenditures}

In this context, the proposed study examined the state-level variations in hospital expenditures due to binge drinking, after controlling demographic, socio-economic characteristics, healthcare status, and supply-side factors. To understand how binge drinking affects hospital expenditures, it is important to account for the spatial dependence between states. 
Often, hospital expenditures of one state may be influenced by hospital prices, practices and policies of the neighboring states.

1) Mobley and colleagues demonstrated that hospital expenditures of a specific region were affected by the prices in the neighboring regions (Mobley et al., 2004). Baltagi and Yen (2014) used state-level data for the years 2005 through 2008 and found the existence of spatial dependence of hospital treatment rates among the states. For example, a " $1 \%$ increase in average treatment rate of heart attack, heart failure, pneumonia in neighboring hospitals is associated with an increase of $0.31 \%, 0.41 \%$, and $0.46 \%$, respectively, in the hospital's own treatment rate (page 16)."

2) Yet another reason to focus on spatial dependence is the presence of hospital facilities which serve patients across states. For example, the investigators of the Dartmouth Atlas defined Hospital Referral Regions (HRR) to explain geographical variations in inpatient use and expenditures (Dartmouth Institute for Health Policy and Clinical Practice) as shown in figure 1. HRRs "represent regional health care markets for tertiary medical care that generally requires the services of a major referral center. The regions were defined by determining where patients were referred for major cardiovascular surgical procedures and for neurosurgery. Each Hospital Service Area (HSA) was examined to determine where most of its residents went for these services. The result was the aggregation of the 3,436 hospital service areas into 306 HRRs (Dartmouth Atlas of Health Care)." A HRR can serve residents of neighboring states. For example, Evansville Hospital referral region comprised of Illinois, Indiana, and Kentucky.

3) Using these HRRs and quality score, Baltagi and Yen (2014), reported that there is geographical clustering and correlation of medical quality of one HRR with neighboring HRR. From their investigation, it was evident that hospital treatments, prices, costs, quality, and patient 
referrals are not specific to one state but rather they cross boundaries and are influenced by characteristics of the neighboring states. Gilmer and Kronick $(2009,2011)$ demonstrated that there is presence of positive correlation across the hospital referral regions.

4) Manski (1993) suggested three ways to clarify the reasons behind the interaction between the local governments/states supporting the idea of spatial dependence, which areendogenous effect, exogenous effect and contextual and correlated effect. Endogenous effect (Bugni, 2012) proposes that "individual behavior (state) is affected by endogenous group behavior." Exogenous effect reports that "individual behavior (state) is affected by exogenous group characteristics (Bugni, 2012)" For example_-gains from public expenditures (hospital expenditures) or socio-economic characteristics of one state enter into the welfare function of the adjacent states (Lundberg, 2011; Bose, 2015). The contextual and correlated effect advocates that policy measure (example- health policy) of a state will influence the resources and budget decisions of its adjacent state in a similar way (Lundberg, 2011).

As health policies are determined and enacted at the state level, the presence of spatial dependence of health expenditures across the neighboring states makes it evident that state health policies are dependent on their neighbors (Bose, 2015). They follow or try to compete among each other to attract federal funds, increase profits, improve health care reforms, and balance their costbenefit situations. Hospital expenditures, being the integral part of the total health expenditure of the states, follow a similar pattern.

\section{Unique Contribution}

Therefore, it is necessary to incorporate spatial dependence to understand variation in hospital expenditures. This study extends prior literature on the spatial dependence in analyzing hospital expenditures. The unique contribution of this study is analyzing spatial dependence of 
state-level hospital expenditures from 2000 to 2009. This model captures the direct and indirect effect estimates (as described below in model) of the factors on hospital expenditures which is not possible in any other regression methods. Thus, this study also analyzes the direct and indirect impact of these variables on state-level rate of hospital expenditures.

\section{MODEL}

To find the impact of the explanatory variables on the percentage of hospital expenses across the states, the basic regression model is defined as:

$$
Y_{i t}=\beta_{0}+\beta_{1} X_{i t}+\mu_{i}+\lambda_{t}+\varepsilon_{i t}
$$

Where $\mathrm{Y}=$ dependent variable, $\mathrm{X}=$ independent variables, $\mathrm{t}=$ time period, $\mathrm{i}=$ state variable, $\mu_{\mathrm{i}}$ $=$ individual state effects, $\lambda_{\mathrm{t}}=$ time period effect (2000 to 2009) and $\varepsilon_{\mathrm{it}}=$ the error effect for time period $\mathrm{t}$ and state $\mathrm{i}$. Table 9 identifies the variables used for the analysis.

Previous studies have used ordinary least squares, weighted least squares or panel regression model to deduce the prime factors causing variation in the rate of hospital expenses but, these are incorrect estimation procedures because applying these methods will not only cause in providing biased but also inefficient estimates. This is because hospital costs have geographical variation across the US. These methods lack the ability to "capture the peculiarities or the influence of space or location in state, county or region data analysis" (Anselin, 1988; LeSage and Pace, 2009). Therefore, it can be inferred that, spatial econometric model analysis is the correct estimation method for state-level analysis of changes in hospital expenditures.

\section{Moran's I index}

Accordingly, the first step of analysis is to employ Moran's I index (1950), to comprehend if there is a presence of any spatial autocorrelation among the states for the hospital spending. This index assumes normality of the error term. If the index is rejected, it indicates that there is a 
presence of spatial interaction, but it does not specify the exact spatial model that can be employed for analysis. Moran's I is expressed by the formula:

$$
\mathrm{I}=\frac{N \sum_{i} \sum_{j} w_{i j}\left(Y_{i}-Y\right)\left(Y_{j}-Y\right)}{\sum_{i} \sum_{j} w_{i j} \sum_{i}\left(Y_{i}-Y\right) 2}
$$

The value of the Moran's I index varies from -1 to +1 displaying if hospital expenses have a clustered, dispersed, or random spatial pattern across the states. In addition, Moran's I scatter plot provides a graphical representation of the cluster or dispersion characteristics among the states for a hospital expenditure variable. In equation (2), $\mathrm{Y}$ is the mean value of $\mathrm{Y}_{\mathrm{i}}$ (rate of hospital expenditure for state $\mathrm{i}$ ) and $\mathrm{Y}_{\mathrm{j}}$ (the rate of hospital expenditure for state $\mathrm{j}$ ). It is assumed that $\mathrm{w}_{\mathrm{ij}}$ is the element of the spatial weight binary contiguity matrix for the $\mathrm{i}^{\text {th }}$ and $\mathrm{j}^{\text {th }}$ states (Zhao et al., 2014).

Binary contiguity weight matrix is a matrix that considers regions or states with common borders as neighbors. Therefore, the value of the matrix $\mathrm{w}_{\mathrm{ij}}$ is one when the two states $\mathrm{i}$ and $\mathrm{j}$ has a common boundary or are adjoining regions and $\mathrm{w}_{\mathrm{ij}}$ is zero if $\mathrm{i}$ and $\mathrm{j}$ has no conjoint boundary. This spatial weight matrix has been row-standardized, which means each of the elements of the weight matrix is created after dividing them by its row sum (which is the sum of the weights of its neighbors $\sum_{\mathrm{i}} \sum_{\mathrm{j}} \mathrm{w}_{\mathrm{ij}}$ offers the summation of the components of the spatial weight matrix (Zhao et al., 2014).

\section{Spatial Panel Models (SAR, SEM, SDM)}

With Moran's I index verifying the presence of spatial autocorrelation among the states, spatial panel data models are considered for further investigation of the state-level variation in hospital spending. Three specific spatial panel data models developed by LeSage and Pace (2009), Anselin (2008), and Elhorst (2014) are considered for this study. The first model specified 
is the Spatial Auto Regressive model, which is also known as the SAR model. The functional form of the SAR model is stated as-

$$
\mathrm{Y}_{\mathrm{it}}=\lambda \sum_{\mathrm{j}=1}^{\mathrm{N}} \mathrm{W}_{\mathrm{ij}} \mathrm{Y}_{\mathrm{jt}}+\mathrm{X}_{\mathrm{it}} \beta+\phi+\mu_{\mathrm{i}}+\delta_{\mathrm{t}}+\varepsilon_{\mathrm{it}} \quad \text { (SAR) (3) }
$$

The SAR model demonstrates the presence of any spatial interaction between state i's dependent variable with that of the neighboring states $j$ 's dependent variable. $Y_{i t}$ and $Y_{j t}$ are the rate of hospital expenditures for the states, $\mathrm{i}$ and $\mathrm{j}$ at time period t. $\sum_{\mathrm{j}=1}^{\mathrm{N}} \mathrm{W}_{\mathrm{ij}} \mathrm{Y}_{\mathrm{jt}}$ is the sum of the interaction effect of $\mathrm{Y}_{\mathrm{it}}$ with $\mathrm{Y}_{\mathrm{jt}}$ for $\mathrm{N}$ observations with $\lambda$ being the response parameter of the endogenous interaction effect (Elhorst, 2014) and $\mathrm{W}_{\mathrm{ij}}$ being the element of the spatial weight matrix $\mathrm{W}$, which has $(\mathrm{NxN})$ observations with $\mathrm{N}$ being the total number of observations and $\mathrm{k}$ being the nearest number of neighbors. $\mathrm{X}_{\mathrm{it}}$ represents the matrix of the independent variables for state $\mathrm{i}$ at the time period t. $\beta$ is the vector of coefficients of the non-spatially weighted explanatory variables. $\phi$ is the constant term, $\mu_{\mathrm{i}}$ is the individual state effect or spatial specific effect, $\delta_{\mathrm{t}}$ is the time period effect, and $\varepsilon_{\mathrm{it}}$ is the error term, which is multivariate normal with zero mean and variance $\sigma^{2}$, and it is independently and identically distributed (Elhorst, 2014).

The second spatial model incorporated for analysis is the Spatial Error Model, also known as SEM. The functional form of this model (Elhorst, 2014) is expressed by-

$$
Y_{i t}=\phi+X_{i t} \beta+\mu_{i}+\delta_{t}+\eta \sum_{j=1}^{N} W_{i j} u_{i t}+\varepsilon_{i t}
$$

SEM incorporates the spatial dependence of the error term in the model. Along with the variables mentioned earlier in the equation (3) and dropping the term, $\lambda \sum_{j=1}^{N} W_{i j} Y_{j t}$, equation (4) consists of an additional term $\sum_{j=1}^{N} W_{i j} u_{i t}$, where $\sum_{j=1}^{N} W_{i j} u_{i t}$ is the sum of the spatial dependence of the error term of state $\mathrm{i}$ with its neighboring states, $\mathrm{j}$ and $\eta$ and denotes the spatial auto-correlation index. The third model is the Spatial Durbin model, also known as SDM. The mathematical form of the model can be expressed as- 


$$
\mathrm{Y}_{\mathrm{it}}=\phi+\lambda \sum_{\mathrm{j}=1}^{\mathrm{N}} W_{i j} \mathrm{Y}_{\mathrm{jt}}+\mathrm{X}_{\mathrm{it}} \beta+\sum_{\mathrm{j}=1}^{\mathrm{N}} \mathrm{W}_{\mathrm{ij}} \mathrm{X}_{\mathrm{jt}} \theta+\mu_{\mathrm{i}}+\delta_{\mathrm{t}}+\varepsilon_{\mathrm{it}} \quad(\mathrm{SDM})(5)
$$

This model contains both the spatially lagged dependent variable, and the spatially lagged independent variables. In addition to all of the aforementioned variables in equation (3) and (4), the new variables in equation (5) are- $\theta$ which is the vector of coefficients of the spatial dependence of the independent variables and $\sum_{j=1}^{\mathrm{N}} \mathrm{W}_{\mathrm{ij}} \mathrm{X}_{\mathrm{jt}}$, which provides the sum of the interaction effect of independent variables of state $i$ with that of the neighboring states, explanatory variables.

\section{STATISTICAL ANALYSIS}

\section{Moran's I index}

Moran's I index value tells us the presence of spatial cross correlation among the state's rate of hospital expenditures. If the z statistic of Moran's I index is significant, it confirms the existence of spatial autocorrelation or spatial association among the hospital spending rates of the states over the years. If the index value is positive, the hospital expenditure rate of state $\mathrm{i}$ has a positive autocorrelation with its neighbors, while if it is negative, it has a negative autocorrelation.

Moran's I scatter plot displays the relation between the hospital expenditure (horizontal axis) for the time period of 2000 to 2009 with the spatial lags of the hospital expenditure (vertical axis). The spatial lag of hospital spending is generated from the product of the spatial weight matrix Wij with the hospital expenditure rate of the neighboring states. There are four quadrants in the scatter plot. The points in the upper right (or high-high) and lower left (or low-low) quadrants indicate a positive spatial association of values. The lower right (or high-low) and upper left (or low-high) quadrants include observations that exhibit negative spatial association (SAS/STAT 9.3 User's Guide). 


\section{Spatial Models (SAR, SEM, SDM)}

After confirming the presence of spatial spillover, the study follows the specification tests as mentioned in Elhorst (2014) to determine which one of the three spatial panel models is the most appropriate one for the study The first step of analysis is to find out if the non-spatial panel data models (Pooled Ordinary Least Square Model [OLS], Spatial Fixed-effect Model, Time Period Fixed-effect Model, and Spatial and Time Period Fixed-effect model) are more suitable for the study or the spatial panel data models, (Spatial Autoregressive Model [SAR] or Spatial Error Model [SEM])are Lagrange Multiplier (LM) tests have been employed to achieve this purpose. Both classic and robust LM test is used for this purpose. Both these tests are "based on the residuals of the non-spatial models (Elhorst, 2010)." The difference between the classic and the robust is that the latter considers the potential misspecification that the former might have.

$$
\mathrm{LM}_{\delta}=\frac{\left.\mathrm{e}^{\mathrm{T}}\left(\mathrm{I}_{\mathrm{T}} \times \mathrm{W}\right) \mathrm{Y} / \sigma 2\right) 2}{\mathrm{~J}} \text { and } \mathrm{LM}_{\lambda}=\frac{\left.\mathrm{e}^{\mathrm{T}}\left(\mathrm{I}_{\mathrm{T}} \times \mathrm{W}\right) \mathrm{e} / \sigma 2\right) 2}{\mathrm{~T} \times \mathrm{T}_{\mathrm{W}}} \text { (Classic LM tests), where "e is the }
$$

residual vector of a pooled regression model without spatial or time specific effects (Elhorst,

$$
\begin{gathered}
\text { 2010)" and } \mathrm{J}=\frac{\left.\left[\left(\left(\mathrm{I}_{\mathrm{T}} \times \mathrm{W}\right) \mathrm{X} \beta\right) \mathrm{T}\left(\mathrm{I}_{\mathrm{NT}}-\mathrm{X}\left(\mathrm{X}^{\mathrm{T}} \mathrm{X}\right)^{-1} \mathrm{X}^{\mathrm{T}}\right)\left(\mathrm{I}_{\mathrm{T}} \times \mathrm{W}\right) \mathrm{X} \beta\right)+\mathrm{TT}_{\mathrm{W}} \sigma 2\right)}{\sigma 2}, \mathrm{~T}_{\mathrm{W}}=\operatorname{tr}\left(\mathrm{WW}+\mathrm{W}^{\mathrm{T}} \mathrm{W}\right) \\
\text { Robust } \mathrm{LM}_{\delta}=\frac{\left.\left.\mathrm{e}^{\mathrm{T}}\left(\mathrm{I}_{\mathrm{T}} \times \mathrm{W}\right) \mathrm{Y} / \sigma 2\right)-\mathrm{e}^{\mathrm{T}}\left(\mathrm{I}_{\mathrm{T}} \times \mathrm{W}\right) \mathrm{e} / \sigma 2\right) 2}{\mathrm{~J}-\mathrm{TT}_{\mathrm{W}}} \quad(\text { Elhorst, 2010) } \\
\text { Robust } \mathrm{LM}_{\lambda}=\frac{\left.\left.\mathrm{e}^{\mathrm{T}}\left(\mathrm{I}_{\mathrm{T}} \times \mathrm{W}\right) \mathrm{e} / \sigma 2\right)-\mathrm{e}^{\mathrm{T}}\left(\mathrm{I}_{\mathrm{T}} \times \mathrm{W}\right) \mathrm{Y} / \sigma 2\right) 2}{\mathrm{TT}_{\mathrm{W}}\left[1-\frac{\mathrm{T} \mathrm{T}_{\mathrm{W}}}{\mathrm{J}}\right]} \text { (Elhorst, 2010) }
\end{gathered}
$$

If the LM test is rejected, it represents that the spatial panel model is the applicable one. The next step is to discover the presence of the joint significance of the individual spatial fixed effects and time-period fixed effects. Likelihood ratio (LR) tests have been implemented for this purpose. If the LR test gets rejected, affirming the presence of joint significance of both the effects, the next step followed is to apply the Wald test and Likelihood ratio (LR) test to finally verify if 
the Spatial Durbin model (SAR) is the preferred model in comparison to the Spatial Autoregressive or Spatial Error model (Elhorst, 2012).

Therefore, the two hypotheses that are tested for this purpose are- (i) $\mathrm{H}_{0}: \theta=0$ (SAR is a better model in comparison to the SDM model) versus $\mathrm{H}_{1}: \theta \neq 0$ (the SDM model can be condensed to SAR model) and (ii) $\mathrm{H}_{0}: \theta+\lambda \beta=0$ (SEM is preferred in comparison to the SDM model) versus $\mathrm{H}_{1}: \theta+\lambda \beta \neq 0$ (the SDM model is favored to SEM model). If the null hypothesis, $\mathrm{H}_{0}$, in (i) is rejected, SDM model captures all aspects of this analysis better than the SAR model. Alternatively, if the null hypothesis, $\mathrm{H}_{0}$, in (ii) is rejected, then SDM is a superior model to the SEM (Elhorst, 2014). After reaching to the conclusion about which model is the idealistic one, the Hausman specification test helps to differentiate between the spatial panel random effects model and the spatial panel fixed effects model. The spatial panel random effects model is considered as the null hypothesis in this specification test. If the null hypothesis gets rejected, then the spatial panel fixed effect model is counted as the apt one for the study.

The last step is to evaluate the direct and indirect effects (LeSage and Pace, 2009) of the independent variables. The direct effect is the impact on the rate of hospital spending of state i by a unit amount of changes in state i's explanatory variables. This direct effect also incorporates feedback effect, which is the effect of state i's independent variables on its dependent variable that passes on to the neighboring states and comes back to state $i$. The indirect effect constitutes the variations in the hospital costs of the neighboring states produced by the changes in the independent variables of state $\mathrm{i}$. This is a cumulative effect value, as it includes the effect of all of the neighbors of state i. The total effect is the sum of the indirect and direct effects. 


\section{TYPES AND SOURCES OF DATA}

The data used for this study has been extracted from four different sources. The first data source is Centers for Medicare and Medicaid Services (CMS, Health Expenditures by State of Residence). From this resource, data on the following variables has been obtained, namely total hospital spending and total health care spending by states for the years 2000 to 2009 . The percentage of hospital expenses for each state for each year has been calculated by dividing hospital spending to total health care spending. This has been treated as the dependent variable for the study.

The rest of the variables mentioned below are considered independent variables in the analysis. The second data source is the Substance Abuse and Mental Health Services Administration (SAMHSA), Center for Behavioral Health Statistics and Quality (formerly known as the Office of Applied Studies). From this source, data on the percentage of people with binge alcohol use has been collected (National Survey on Drug Use and Health, State Estimates of Substance Use and Mental Disorder). This used the criteria of men having five or more drinks and women having four or more drinks in a two-hour time period.

The third source used to obtain data on variables related to the demand for health care is the United States Census Bureau. This Census report contains data on variables such as: state shape files, Federal Information Processing Standard (FIPS) code for the states, Gross Domestic Product of each state, the percentage of the population above age 65 and below age 17, number of active physicians per 100,000 civilian population, poverty rate, percentage of people enrolled in HMO, percentage of Medicaid expenditures, uninsured rate of people, unemployment rate, gender and race. All of the afore-mentioned variables have been used for the analysis. The state-level shape data file, acquired from the U.S. Census Bureau (Topologically Integrated Geographic Encoding 
and Referencing (TIGER) report, gives the latitudinal and longitudinal value of each state, providing information on the geographic area of each state. The latitudinal and longitudinal values of the states have been used to determine the contiguity weight matrix used for the spatial analysis model.

Last, but not the least; the fourth source is the State Health Facts (Henry J. Kaiser Family Foundation, 2000-2009). Statistics on the hospital beds per 1,000 population and the total number of community hospitals are obtained from here. The interaction of these two variables has been used in the analysis due to their high correlation value (0.77). All the variables are considered from the year 2000 to $2009^{1}$ and for 48 states and Washington, DC. Alaska and Hawaii are not included in the analysis because states with no neighbors will lead to inefficient estimates for the spatial dependence model. MATLAB 12 software has been used to obtain the results of the spatial panel analysis.

\section{Independent Variables}

All of the socio-economic, demographic and health supply variables as mentioned are assumed to have significant contribution in explaining the changes in the percentage of U.S. statelevel hospital expenses. Hispanics are a healthy group of population as compared to any other races. Therefore, it is predicted for the study that increases in Hispanic population of a state will have a negative impact on the state's hospital costs. The African-American population in general suffers from major chronic diseases such as heart disease, stroke, cancer, etc. $14.6 \%$ of the African-American population is estimated to have been suffering from poor health (CDC, 2012). It can be hypothesized that they are sicker than other racial groups. Alongside, as they are also the

\footnotetext{
${ }^{1}$ The years considered for analysis are 2000 to 2009 . This time period is considered because this is the most recent period for which data are available for all of the variables considered for analysis. Increasing the number of years would lead to dropping explanatory variables, which may cause a decrease in the model's efficiency.
} 
less insured population (21\%) in comparison to the whites, the African-American population is unable to pay for the hospital charges incurred, leading to the rising costs of the hospitals from the unpaid share of the service charges. It is evident from past literatures that the female population uses more hospital services and health care utilization than male (Cameron et al., 2009; CDC, 2001) leading to rise in the total hospital charges. Therefore, a rise in percentage of the male population will lead to a decline in total hospital expenditure.

With increasing Medicaid expenditure and managed care by the federal and state governments jointly, it can be assumed that the hospital charges and expenses will be under control and hence will have an inverse relation (Dartmouth Atlas of Health Care in the United States). The total health care expenditures of a state increases with increasing Medicaid expenditures but the rising Medicaid expenditures helps in managing the costs incurred by the hospitals. It is also seen that the average population below age 17 is the healthiest population. As a result, it is hypothesized in this study that state hospital expenditures have a negative relation with the increase in the younger generation of population (Martin et al., 2011).

The percentage of the population above sixty-five can act in either way. They might have a negative or positive relation with hospital costs. This is the population that has the poorest health and hence is in need of constant care. They are usually long-term care patients and are taken care of - at homes, nonprofit organizations or nursing homes after initial treatment. Therefore, their impact is considered to be ambiguous.

With rise in the percentage of uninsured people, it is expected that they will access fewer medical services, as they are unable to afford the high charges without insurance coverage (Martin et al., 2002; Martin et al., 2011). The poverty rate and the unemployment rate will also increase the total cost of the hospitals. These sections of people suffer from illness more than others do due to 
deficiency in a proper diet, poor hygiene, and a lack of sanitation, and they are more likely to be admitted to emergency rooms and intensive care units, thereby driving the costs up as they are unable to pay for the high charges. They are also mostly treated for very low charges or for free and this causes to form an additional burden on the hospital service charges and hence total hospital expenses.

The increase in per capita state GDP will initiate investment in every aspect of the state economy. Health infrastructure, being an important factor for the improved and reformed economy, will also witness a rise in total expenditure in the form of new staff, infrastructures, supplies, better equipment, etc., which will add to the total hospital costs. It is also seen that positive changes in health supply factors, such as the number of hospitals, active physicians, and hospital beds per 1,000 population, has an upward impact on hospital expenditures. This is because the regions and states that witness a greater influx of physicians and hospital beds also seem to witness a higher number of visits to physicians and higher hospitalization volumes (Bose, 2015; Fisher et al., 2004).

Another important factor that has a significant impact on the hospital expenditures is alcohol abuse. Binge drinking or excessive drinking of alcohol leads to many chronic diseases such as heart disease, stroke, liver failure, road accidents, head injuries, high blood pressure, cancer, depression, etc. Therefore, it is very obvious that hospital expenditure will have a positive impact on the rise in percentage of people involved in excessive drinking.

\section{Descriptive Statistics}

The descriptive statistics for the dependent and independent variables used for analysis have been summarized in Table 10. The dependent variable is the percentage of hospital expenditures (hospital expenses to the total amount of health care spending). The statistical values 
indicate that the independent variables vary widely across the states and over the years. The rate of binge drinking use varies from $14.07 \%$ to $29.77 \%$ across the states (2000-2009). Connecticut has the lowest percentage of hospital care expenses, while Washington, D.C., spending the highest amount. The poverty rate ranges from $6 \%$ to $21.9 \%$, whereas the unemployment rate reaches an ultimate value of $13.3 \%$ in Michigan. The total number of community hospitals fluctuates from six (Delaware) to 428 (Texas). Medicaid expenditures also cover a wide range, from a low value of $16 \%$ to a high value of $60 \%$. The African-American population varies from Maine $(0.37 \%)$ being the smallest to the District of Columbia's (60.26\%) being the largest. Hispanic population can be seen to be residing mostly in New Mexico (45.56 \%), with the lowest percentage in West Virginia $(0.67 \%)$. The uninsured rate also covers a large range, from $4.4 \%$ to $26.1 \%$, with Florida, Georgia, Nevada, and Texas falling in the higher bracket.

\section{RESULTS AND DISCUSSION}

Examining Figure 2, it can be seen that for the year 2009, while South and Pacific West have lower rate of hospital expenditures, Midwest has higher rate of hospital expenses. Moran's I index value (0.25) in Figure 3 is significant at the 5\% level reporting the presence of positive spatial autocorrelation of the hospital expenditure rate for state $i$ with its neighboring states. Hence, the next specification tests necessary to find the appropriate model can be performed. Hereafter, the classic and robust Lagrange Multiplier tests (LM) are implemented to evaluate whether the spatial panel data models are preferred to the four non-spatial panel models, namely the pooled ordinary least square model (OLS), the spatial fixed effect model, the time period fixed effect model, and the spatial and time period fixed effect model.

The classic LM test (Table 11) is rejected for the two null hypotheses: i) missing spatially lagged dependent variable and ii) missing spatial auto-correlated error term for all of the four non- 
spatial models mentioned above (Elhorst, 2014). The robust LM test for the null hypothesis of missing spatially lagged dependent variable for the spatial and time period fixed effect model $\left(4^{\text {th }}\right.$ model) is not significant. Additionally, the robust LM test for the null hypothesis of missing spatial error term for the spatial fixed effect model is also not significant. As a result, the spatial panel model can be considered as a superior model than the rest of the non-spatial panel data models.

This confirmation of the presence of spatial spillover in the data leads to the next step, which is using the likelihood ratio test (LR) to affirm the presence of joint significance of spatial fixed effects and time period fixed effects. The results in Table 12 indicate that the joint test of missing spatial fixed effects $\left(\chi^{2}=966.248, \mathrm{df}=49, \mathrm{p}<0.001\right)$ and missing time period fixed effects $\left(\chi^{2}=36.384, \mathrm{df}=10, \mathrm{p}<0.001\right)$ are both rejected at the $1 \%$ level of significance, thereby validating the use of a two-way fixed-effect model for analysis (Elhorst, 2014). Table 13 provides the estimated coefficients of the variables in question using the SAR and SEM models.

In order to ascertain that the SDM model cannot be further reduced to either the SAR model or the SEM model, Wald test and likelihood ratio tests has been conducted for both the models. Both tests, as seen in Table 14, reject the null hypothesis of SAR being preferred to SDM (Wald test $-\chi^{2}=107.411, \mathrm{df}=14, \mathrm{p}$ value is $0.000<0.001$, and $\mathrm{LR}$ test $-\chi^{2}=91.531, \mathrm{df}=14, \mathrm{p}$ value is $0.000<0.001$ ) and SEM being preferred to SDM (Wald test $-\chi^{2}=99.036, \mathrm{df}=14, \mathrm{p}$ value is $0.000<0.001$, and LR test $-\chi^{2}=84.138, \mathrm{df}=14, \mathrm{p}$ value is $0.000<0.001$ ), ensuring that the spatial Durbin panel model is the relevant model for this analysis (Elhorst, 2014).

Finally, to narrow down as to which one of the two SDM models (Spatial Durbin random effect model or fixed effect model) is the most pertinent and robust one, Hausman's (1978) specification test has been applied. Assuming the random effect SDM model as the null hypothesis model for this specification test, rejection of the null hypothesis (84.680 degrees of freedom: 29, 
significance: 0.000) indicates that the spatial Durbin fixed effect model is the best fit model. The SDM model has two unique advantages - first, it provides unbiased coefficients in comparison to the SAR or SEM model as it incorporates the lags of both the dependent and independent variables in the equation, and second, it enables us to capture the direct (also includes the feedback effect) and indirect effects in a model.

The results in Tables 15 and 16 provide detailed information of the estimated, direct, indirect, and total coefficients for the explanatory variables using the SDM fixed-effect model. The values of direct effect in Table 15 are different from Table 16 because the direct effect values in the latter table also include feedback effects. The magnitude of lambda (the interaction effect of the rate of hospital expenses of state $i$ with state $j$ ) is 0.12 and is significant at the $1 \%$ level. This means that the increase in the rate of hospital expenditures of the neighboring states by $1 \%$ leads to an increase of $0.12 \%$ of hospital costs of state i. As mentioned earlier, state healthcare expenditures and health policy decisions depend on their adjacent states; therefore, this positive interaction effect suggests that hospital expenditure follows the same path.

This spillover effect can be described in terms of fiscal competition, exogenous effect, and diffusion policy, as mentioned by Manski (1993). State governments are inclined toward following or adopting policies similar to their adjacent states. There are several reasons for this. First, hospitals in a state usually compete with its neighboring regions to increase their revenue by improving their qualities through improvised technologies, hiring specialized physicians, and increasing the number of hospital beds in order to attract more patients (Baltagi and Yen, 2014). This will increase their investment costs leading to an increase in total hospital expenditures. Secondly, there are no market forces that will force hospitals to lower their rates. This market does not work efficiently as there is no governmental regulation on hospital rates or price ceiling, 
thereby driving the hospital charges and total costs to soar up (some hospitals charge "markup of more than 1,000 percent for the same medical services" Anderson and Bai, 2015).

The rate of binge drinking in each state has positive direct, indirect and total influences on the hospital expenditure rate. The tables indicate that every $10 \%$ rise in population with excessive alcohol consumption will cause a total rise of $1.6 \%$ (approximately $2 \%$ ) in the total spending rate of the hospitals. In comparison to other variables, the rise in rate of hospital expenditures due to rise in percentage of population with binge drinking can be prevented. Therefore, accounting for the rate of healthcare expenditures due to binge drinking will provide the policy makers an initiative to create better prevention measures to decrease the rate of binge drinking and thereby controlling the rate of hospital costs.

This estimate includes the effect of both positive significant direct and indirect impact of the percentage change of alcohol abuse. Therefore, the rise in the percentage of people of state $\mathrm{i}$ with excessive alcohol consumption not only increases its own hospital spending rate but also those of its neighboring states. As hospital referral regions (HRR) are cross boundaries; fatalities, road accidents, self-harm, unintentional and intentional injuries and wounds caused during drinking, and chronic diseases caused by alcohol, misuse such as liver cirrhosis, cancer, stroke, and heart problems lead to increase in total expenditures of the hospitals of the state and also of its neighbors.

Concentrating on demographic variables, specifically, the percentage of Hispanic population and the percentage of male population, we see that their direct effects in Table 16 are negative and significant at the $1 \%$ level. As explained earlier, Hispanic population is healthier in comparison to that of the non-Hispanic population (Zhang et al., 2012). They also have a higher life expectancy (National Center for Health Statistics, 2013) and suffer less from diseases due 
to their health habits and hereditary characteristics. Hence, the increase in their population will decrease the rate of hospital expenditures. The male population has a lower rate of healthcare use (Cameron et al., 2009; CDC, 2001) in comparison to the female population. Hence, dominance of the male population in a state will drive the hospital costs down due to less use of health services.

The indirect effects of both the Hispanic population and the male population in state $\mathrm{i}$ have a positive and significant impact $(1 \%)$ on its neighboring states, which might have been caused by the migration effect. One of the reasons that the population in state $\mathrm{i}$ is increasing might be the relocation from its neighboring regions or states in search of better living conditions, work opportunities, and improved health conditions, thereby escalating the adjacent states' hospital spending as their female and non-Hispanic population increases in comparison to the male and Hispanic population.

The rise in the aged population and the population below age 17 of state $i$ has a negative, significant cumulative indirect impact on its neighboring states' hospital expense rates. The rise in the elderly population and the young population of state i might be due to the migration from its nearby states to access better health facilities or amenities if their own state is lacking in providing them (Glaser and Grundy, 1998). Glaser and Grundy (1998) also stated that "poor health is positively associated with the greater likelihood of changes in both living arrangements and address among people over the age of 65." Thus a rise in the elderly population in state i leads to a lower hospital expenditure rate of state j. Furthermore, even though the populations of both age groups are increasing, they are the ones who access hospital care the least. This is because the aged population requires long-term care and is generally treated in home health care, adult day care and respite care, nursing homes, government programs, etc., and the younger population is a much 
healthier population who does not fall sick that often. Therefore, these population groups will have a negative impact on the rate of hospital expenses.

The percentage of the African-American population has a positive and significant direct, indirect, and total influence on the state-level hospital expenditure rate. This is because they mostly comprise of the low or middle income group and majorly suffers from chronic diseases and worse health conditions due to their socio-economic backgrounds and daily lifestyles. They also happen to consist of the larger bracket of the uninsured population. As a result, even if they need more hospital care, they are incapable of paying for high inpatient and outpatient service fees, increasing the costs of the hospitals from the unpaid share of the service charges. The indirect effect being positive and significant illustrates that the rise in percentage of African-American residents in a state also causes an upsurge in bordering states' rates of hospital spending.

While the interaction term of the total number of hospital beds and hospitals per 1,000 residents displays significant positive direct, indirect, and total effects on the rate of hospital expenditures, change in the proportion of active physician per 100,000 residents did not have any significant direct impact, but it had a significant indirect and total effect. These supply-side variables will improve the quality of the hospitals and health care provided, but will also increase the total hospital expenses for the state. The neighboring states, competing among them and with state $\mathrm{i}$ in order to attract patients and federal funds will also follow a similar pattern of improving their health infrastructures, thereby pushing their expenditures up. This is because Fournier and Mitchell (1992) have reported that the "degree of competition" among hospitals have "costincreasing effects."

The unemployment rate and poverty rate of a state both have positive direct, indirect (for the unemployment rate only), and total effects that are statistically significant for hospital expense 
rates. Populations belonging to these groups suffer from sickness and diseases more than other demographics as they do not get proper nutrition and often lack proper cleanliness and hygiene. They are more likely to be admitted to emergency rooms and intensive care units of the hospitals in their own state and also of the nearby bordering states as and when needed (OECD, 2006). Thus, these factors affect the hospital expenditure rates positively. With increases in the rate of unemployed population, migration to the neighboring states tends to increase, in search of a better standard of living or jobs. This leads to an increase in the proportion of unemployed people in the adjacent states too, also leading to a rise in the hospital expenditure rate of the bordering states.

The percentage of Medicaid expenditures as a form of managed care helps in reducing and keeping the total hospital expenses of the state (negative and significant relation) low because these are the funds that are a combined effort of both the state and federal government funds. The more the government supports in sustaining hospitals, the easier it will be for the hospitals to cope up with the rising prices. The increase in the uninsured rate has significant negative indirect impact on hospital expenses. With rise in the number of uninsured people, the use of health care falls as they cannot afford to pay for the high hospital care charges out of their pockets.

Per capita GDP of state $\mathrm{i}$ have a positive significant impact on state $\mathrm{j}$ because as the state gross domestic product of state $\mathrm{i}$ increase; it invests and improves all sections of the economy. This also includes health care reforms. Neighboring states provides evidence of a spatial interaction pattern in terms of fiscal competition. Hence, they will also increase their investment in improving their quality of health care, causing a rise in their hospital costs. As Morey et al. (1992) explained that increasing quality of care of a hospital (reducing death rate) will result in a higher cost burden on the hospital. 
Thus, it is obvious from this study that past literature was successful in capturing the effect of spatial spillover of the independent variables on the rate of hospital expenditures across the states in United States for the period of 2000 to 2009. This study is an advanced analysis, which exhibits the presence of positive spatial dependence of hospital spending of a state on its adjacent regions. Furthermore, this study has highlighted that rate of binge drinking, total number of hospital beds, and hospitals per 1,000 residents, the unemployment rate, the percentage of AfricanAmerican population, proportion of active physicians and state gross domestic product have positive impacts on its neighboring states' rate of hospital expenses. Moreover, the increasing rate of male population, Hispanic population and the rate of un-insurance of a state have negative impacts on its own rate of hospital costs but positive impacts on its bordering states' rate of hospital spending.

\section{CONCLUSION AND POLICY IMPLICATIONS}

\section{Summary}

This study achieves the goal of examining the state-level variations in hospital expenditures. It highlights the presence of positive spatial dependence of rate of hospital spending across the states. No previous studies have considered or examined the influence of factors on state-level hospital expenditures using a spatial Durbin fixed effect model over an extended time period (2000 to 2009). It is important to understand why these variations are occurring so as to know if this is leading to the absence of equity in health care and status across the population and proper utilization of scarce resources. Finding the reasons behind this variation will not only help all of the states to control cost growth but also help in providing the population with better health care services, quality, infrastructures, treatments, and health policies. 
This is the most recent time period data available for analysis, and it reports the demographic profile, economic factors, supply side variables, and substance abuse factor that are the leading causes of the growing state-level hospital costs. This research does not consider comparative analysis, cross-sectional analysis, or panel analysis as these model analyses are not only incomplete in providing a comprehensive explanation of the deviation in hospital expenses across the states but also provide biased or inefficient coefficients. None of the analysis methods stated above incorporates location, peculiarity of space or geographical variation while analyzing the state-level variations of the rate of hospital expenses.

The positive spatial correlation of hospital expenditures across the states can be explained by the fiscal competition (contextual and correlated effect) and the exogenous effect. Hospitals in a referral region (HRR) cross state boundaries. Therefore patients can be referred to any of the hospitals among any of these states in one HRR based on their medical condition. Further hospitals of neighboring region compete among each other to attract patients, thereby improving the quality of care (technology, specialized physicians, hospital beds, etc.), causing the costs to increase (Baltagi and Yen, 2014; Fournier and Mitchell, 1992; Morey et al., 1992). Along with this positive spatial dependence, an increase in a state's rate of population with binge drinking and increase in socio-economic, demographic, and health infrastructure factors such as the total number of hospitals and beds per 1,000 residents, unemployment rate, poverty rate, per capita state GDP and percentage of African-American population increases the rate of hospital expenditure (except GDP) of a state and it also increases the hospital expenditures of the neighboring states (except poverty rate). Alternatively, percentage of male, Hispanic, and percentage of Medicaid expenditures display inverse relation with hospital expenditure of a state. Further, while rise in percentage of male, Hispanic and proportion of active physicians of state $\mathrm{i}$ 
increase the rate of hospital expenses of state $\mathrm{j}$; rise in rate of uninsured, aged and population below age 17 of state $\mathrm{i}$ decrease the rate of hospital expenses of state $\mathrm{j}$.

Increase in the rate of population in state $i$ with binge drinking will increase the rate of population suffering from acute diseases, such as heart attack, liver cirrhosis, cancer, etc., and also suffer from head and body injuries from accidents, rash driving, mental depression, fatalities, etc., who might be referred to a hospital in an adjoining state $\mathrm{j}$ as U.S. hospitals are categorized as HRR, which cross state boundaries, incorporating hospitals from multiple states, where the patients can be referred for acute condition treatment. Further, injured patients from road accidents (interstate, highway) caused by alcohol abuse are also taken to nearby hospitals irrespective of the state in which they reside.

\section{Cost of binge drinking to the government}

Despite having a modest effect on the hospital costs directly, excessive alcohol consumption has an additional huge indirect cost effect in the form of loss of work productivity and suffering from chronic and long term illness. It has been reported $16.9 \%$ of the total population $(312,000,000$ in 2010 (WHO, 2014) who are binge drinkers consume $76 \%$ of the total alcohol consumed (CDC, 2012). The total consumption of pure alcohol in 2010 was 9.2 liters per capita (aged 15 years and above, a population of 249,600,000(WHO, 2014). This means binge drinkers had about 1.7 billion liters of alcohol in 2010. In other words, a binge drinker has 73.85 drinks per week or 556 drinks per year (Cook, 2007). "Binge drinking cost federal, state, and local governments (health) about 62 cents per drink, while federal and state income from taxes on alcohol totaled only about 12 cents per drink (CDC, Vital Signs, 2012)." Therefore, the total health cost to the government was an estimated $\$ 18,176,396,160$ or $\$ 18$ billion and the taxes collected are 
$\$ 3,518,012,160$ or $\$ 3$ billion from binge drinkers. Therefore, this will further increase the total burden on the economy to a larger extent.

\section{Policy Implications}

Findings from this study have profound implications for policies in terms of substance abuse prevention and treatment and economic and social determinants of health to contain hospital expenditures. Although states generate income from alcohol taxation as stated above alcohol use in the form of binge drinking is responsible for $3.6 \%$ of emergency visits and $38.9 \%$ of all hospitalizations which means a large amount of hospital expenditures came from binge drinking (NIH, 2013). Therefore it is important to spread awareness among people about the fatality of alcohol consumption (as it leads to over 54 injuries and diseases along with accidents, violence, unplanned pregnancy, fetal alcohol spectrum disorders and sudden infant death syndrome, sexually transmitted diseases etc.) because the states are indirectly losing huge amount of money by the rise in hospital expenditures and loss in work force and productivity (CDC, Vital Signs, 2012).

Some of the reasons behind this frequent drinking are - cheap alcohol which is becoming much cheaper with time (Office of Justice Programs Office of Juvenile Justice and Delinquency Prevention (OJJDP), 2002), $\$ 4$ billion of alcohol marketing every year, alcohol being the readily available consumer product etc. (OJJDP, 2002). Restricting alcohol outlets, strengthening and enforcing minimum purchase age laws, strategies to curb social availability of alcohol, controlling alcohol advertising and promotion, increase in alcohol tax to pay for prevention programs are some of the policies that has been effective (OJJDP, 2002). Individual state funded policies to prevent and generate awareness of alcohol abuse include examples of ACT Missouri, DHS Office of Alcohol and Drug Abuse Prevention (OADAP) in Arkansas. 
However, there are no joint prevention programs among the states to intervene the growing concern of alcohol abuse on health outcomes. Adjacent states can undertake joint policies to create prevention strategies to promote awareness among the state residents as alcohol consumption is not only negatively impacting the state itself but also the neighboring states. The U.S. government can also "collaborate with states and communities to support effective community strategies to prevent binge drinking" and also "control the marketing and sale of alcohol (CDC, Vital Signs, 2012)."

It is important to go beyond healthcare interventions/healthcare sectors and pay attention to the social determinants and economic profile of health such as unemployment rate, poverty rate, race, gender and ethnicity of the residents. Addressing social determinants of health helps in achieving health equity (CDC website) by "eradicating systematic disparities in health between and within social groups that have different levels of underlying social advantages or disadvantages (Braveman, 2003; page 2139).”

The study findings confirm what numerous other studies have found. Lack of health insurance has a significant effect on state-level variations in hospital expenditures. It has been reported that "people without insurance coverage have worse access to care than people who are insured. Almost a third of uninsured adults in 2013 (30\%) went without needed medical care due to cost. Studies repeatedly demonstrate that the uninsured are less likely than those with insurance to receive preventive care and services for major health conditions and chronic diseases (KFF, 2014)." ACA (Affordable Care Act, 2010) have addressed to this issue by enhancing access to the uninsured and the individuals below $138 \%$ of the federal poverty level to reduce the burden of higher healthcare expenditures from uninsured individuals suffering from chronic diseases. This has decreased the uninsured rate by $1 \%$ (National Center for Health Statistics. 2014). 
As ACA expansion was effective from January 2014, currently there are no available data on whether expanding insurance will reduce the hospital expenditures at the state-level. Future studies need to examine whether states that have expanded health insurance either through Medicaid or setting up health insurance exchanges have reduced hospital expenditures. 


\section{REFERENCES}

American Hospital Association. 2005. The Cost of Caring. The Sources of Growth in Spending for Hospital Care. Washington D.C.

Alcohol Drinking Patterns and Medical Care Use in an HMO Setting, Alcohol and Care in HMO Setting. The Journal of Behavioral Health Services and Research, 27(1).

Anderson, G.F. and G. Bai. 2015. Some Hospitals Marking Up Prices More Than 1,000 Percent. http://www.jhsph.edu/news/news-releases/2015/some-hospitals-marking-up-prices-morethan-1000-percent.html. Accessed on 15th June, 2015.

Anselin, L. 1988. Spatial Econometrics: Methods and Models. Kluwer Academic Publishers, Dordrecht.

Anselin, L., J. L. Gallo, and H. Jayet. 2008. Spatial Panel Econometrics. In The Econometrics of panel data, fundamentals and recent developments in theory and practice, Kluwer Academic Publishers, Dordrecht.

Braveman, P. and S. Gruskin. 2003. Defining equity in health. Journal of Epidemiology and Community Health; 57(4): 254-258.

Baicker, K., A. Chandra and J. S. Skinner. 2012. Saving Money or Just Saving Lives? Improving the Productivity of US Health Care Spending. Annual Review of Economics; 4: 33-56.

Baltagi, B.H. and Y.F. Yen. 2014. Hospital Treatment Rates and Spill-over Effects: Does Ownership Matter? Center for Policy Research. Spring. 165:1-39.

Bertakis, K.D., R. Azari , L.J. Helms , E.J. Callahan, J.A. Robbins. 2000. Gender differences in the utilization of health care services. Journal of Family Practice; 49(2):147-52.

Bonu, S., M. Rani, D. H. Peters, P. Jha and S. Nguyen. 2005. Does use of tobacco or alcohol contribute to impoverishment from hospitalization costs in India? Health Policy and Planning, 20(1): 41-49.

Bopp, A.E., and R.J. Cebula. 2008. State Variations in Hospital Expenditures: An Ecological Approach. International Advances in Economic Research, 15:226-232.

Bose, S. 2015. Determinants of Per Capita State-Level Health Expenditures in the United States: A Spatial Panel Approach. The Journal of Regional Analysis and Policy.45.Forthcoming. 
Bouchery, E.E., H.J. Harwood, J.J. Sacks, C.J. Simon and R.D.Brewer. 2011. .Economic costs of excessive alcohol consumption in the United States 2006.American Journal of Preventive Medicine, 41:516-24.

Bugni, A. 2012. Comments on Manski (1993) Lunch group on Social Interactions, Duke University.

Cameron, K.A., J. Song, L. M. Manheim and D. D. Dunlop. 2010. Gender Disparities in Health and Healthcare Use among Older Adults. Journal of Women's Health. Larchmt19 (9): $1643-1650$.

Center on Addiction and Substance Abuse. 1994. The Cost of Substance Abuse to America's Health Care System: Medicaid Hospital Costs, Columbia University, (1).

Centers for Disease Control and Prevention. Alcohol-Related Disease Impact (ARDI). Atlanta, Georgia.

Center for Medicare and Medicaid Services 2013. http //www cms gov/Research-Statistics-Dataand-Systems/Statistics-Trends-andReports/NationalHealthExpendData/downloads/highlights pdf.

Centers for Disease Control, Vital Signs. 2012. National Center for Chronic Disease Prevention and Health Promotion Division of Adult and Community Health.

Centers for Disease Control. 2001.Women are 100\% more likely than men to seek preventative health care Utilization of Ambulatory Medical Care by Women: United States, 1997-98.

Centers for Disease Control and Prevention (CDC). 2001. National Center for Health Statistics : Vital and Health Statistics, Series 13, 149.

Centers for Medicare and Medicaid Services. 2011. Health Expenditures by State of Residence. http://www.cms.gov/NationalHealthExpendData/downloads/resident-state-estimates.zip. Accessed on August 15th, 2014.

Centers for Medicare and Medicaid Services: http://www.cms.gov/Research-Statistics- Data-andSystems/Statistics-Trends-and-Reports/NationalHealthExpendData/Downloads/restables.pdf. Accessed on July 2nd 2014.

Chenet, L., M. Mckee, D. Leon.1998. Alcohol and cardiovascular mortality in Moscow: New evidence of a causal association. Journal of Epidemiology and Community Health, 52:772774. 
Cryer, P. C., L. M. Jenkins, A. C. Cook, J.S. Ditchburn, C. K. Harris, A. R. Davis and T. J. Peters. 1999. The Use of Acute and Preventative Medical Services by a General Population: Relationship to Alcohol Consumption. Addiction, 94(10): 1523-32.

Cook, P.J. 2007. Paying the Tab: The Costs and Benefits of Alcohol Control.Census Bureau for the National Epidemiologic Survey on Alcohol and Related Conditions. Princeton press.

Dorothy, P. R, C. Conell, C. Weisner, E. M. Hunkeler, B. Fireman and T. Hu. 2000. Elhorst, J.P. 2014. Matlab Software for Spatial Panels .International Regional Science Review, 37(3):389-405.

Ellen, B., C. Simon. 2013. Economic Costs of Excessive Alcohol Consumption in the United States, 2006, the Centers for Disease Control and Prevention and the National Foundation for the Centers for Disease Control and Prevention, the Lewin Group Hendrick Harwood, NASADAD.

Fisher, E.S., D.E.Wennberg, T.A.Stukel and D.J. Gottlieb. 2004. Variations in the longitudinal efficiency of academic medical centers. Health Affairs, 23:19-32.

Fournier, G.M. and J. M. Mitchell. 1992. Hospital Costs and Competition for Services: A Multiproduct Analysis. The Review of Economics and Statistics, 74(4):627-634.

Gilmer, T.P.and R.G. Kronick. 2011. "Differences in the volume of services and in prices drive big variations in Medicaid spending among US states and regions. Health Affairs; 30(7); 13161324.

Gary, A. Z., W.B. Jeremy, F.B. Thomas and C.H.B. John. 2004. Alcohol Drinking Patterns and Health Care Utilization in a Managed Care Organization. Health Services Research, 39(3).

Glaser, K. and E.Grundy.1998.Migration and household change in the population aged 65 and over, 1971-1991 .International Journal of Population Geography; 4(4); 323-339.

Holder, H. D. and J. O. Blose, 1986. Alcoholism Treatment and Total Health Care Utilization and Costs. A Four-Year Longitudinal Analysis of Federal Employees, JAMA. 256(11):14561460. doi:10.1001/jama.1986.03380110062027.

Hausman, J. A. 1978. Specification tests in econometrics. Econometrica, 46:1251-71.

Health Care Spending in the United States and Selected OECD Countries. Apr 12, 2011. Kaiser State Health Facts. Accessed on 14th March, 2015.

Health, United States, 2013. With Special Feature on Prescription drugs. U.S. department of 
Health and Human Services, Center for Disease Control and Prevention. National Center for Health Statistics, May 2014.

HCUP Facts and Figures Statistics on Hospital-based Care in the United States.2009. http //hcupus ahrq gov/reports/factsandfigures/2009/highlights jsp.

HCUP. 2008. Hospitalization Alcohol Disorder Hospital Care for Mental Health and Substance Abuse Conditions HCUP Facts and Figures Statistics on Hospital-based Care in the United States.

HCUPnet Healthcare Costs and Utilization Project - Interactive Tool for Statistics on Hospitals Agency for Healthcare Research and Quality http //hcupnet ahrq gov/ . Accessed on April $26^{\text {th }}, 2015$.

Holder, H. and O. B. James. 1992. The Reduction of Health Care Costs Associated With Alcoholism Treatment: A 14-Year Longitudinal Study. Journal of Studies on Alcohol, 53(4).

Hunkeler, E.M., Hung, Y. Yi, D. P. Rice, C. Weiser and H. T. Wei. 2001. Alcohol consumption patterns and health care costs in an HMO. Drug and Alcohol Dependence. 64(2); 181-190.

James, R. K. and A. M. Foltz. 1984. Regional variation in hospital utilization. Medical care. Nov. 22(11).

James, R. K. and A. M. Foltz. 1985. A statistical analysis for east west difference in hospital use. Inquiry; 45-58.

Joan, C.F. and P.N. Jordi. 2007. Public health expenditure and spatial interactions in a decentralized national health system. Journal of Health Economics, 16:291-306.

Kaiser Family Foundation. Key Facts about the Uninsured Population. 2014. http://kff.org/uninsured/fact-sheet/key-facts-about-the-uninsured-population/.

Kanny, D., Y. Liu, R. D. Brewer. 2011. Binge Drinking --- United States, 2009, National Center for Chronic Disease Prevention and Health Promotion. Supplements, 60(01): 101-104.

Kavilanz, P. B, 2009, CNNMoney.com .These 5 health care culprits cost $\$ 1$ trillion.

Knickman, J.R. and A.M. Foltz .1984.Regional differences in hospital utilization How much can be traced to population differences. Medical Care. 971-86.

Knickman, J.R. and A.M. Foltz .1985.A statistical analysis of reasons for East-West differences in hospital use Inquiry.22 (1):45-58. 
LeSage, J. and P. Pace. 2009. Introduction to Spatial Econometrics. CRC Press, Boca Raton, Louisiana.

Lundberg, J. 2011. On the definition of $\mathrm{W}$ in empirical models of yardstick competition, Department of Economics, Umea University, Sweden.

Manski, C.F. 1993. Identification of endogenous social effects: the reflection problem. Review of Economic Studies, 60(1):531-542.

Marian, G., 1982. Trends and regional variation in hospital use under Medicare health care financing review, march, 3(3).

Martin, A., G. Cuckler, L. Whittle, S. Heffler, A. Sisko, D. Lassman and J. Benson. 2011. Health spending by state of residence, 1991-2009, Health Affairs, 1(4):1-31.

Martin, A., G. Cuckler, L.Whittle, S. Heffler, A. Sisko, D. Lassman and J. Benson. 2011. Health spending by state of residence, 1991-2009. Health Affairs, 1(4):1-31.

Martin, A., L.Whittle, K. Levit, G. Won and L. Hinman. 2002. Health Care Spending During 1991-1998: A Fifty-State Review. Health Affairs, 21(4): 112-126.

Mickael, B. and J. Lauridsen. 2009. Exploring spatial patterns in general practice expenditure. The European Journal of Health Economics, 10:243-254.

Mobley, L., H.E. Frech, III, and L. Anselin. 2004. Spatial Interaction, Hospital Pricing and Hospital Antitrust. Working paper presented at the International Industrial Organization Conference in Chicago, April 23-24.

Moran, P.A.P. 1950. Notes on Continuous Stochastic Phenomena. Biometrika, 37 (1):17-23.

Morey, R.C., D. J. Fine, S. W. Loree, D. L., R. Roberts and S. Tsubakitani. 1992. The Trade-Off between Hospital Cost and Quality of Care: An Exploratory Empirical Analysis; Medical Care, 30(8); 677-698.

National Center for Health Statistics. Health United States. 2013. With Special Feature on Prescription Drugs Hyattsville.MD.2014.CDC.http //www cdc gov/nchs/data/hus/hus13 pdf\#094.

National Center for Health Statistics. 2013. Deaths: Final Data for 2010. National Vital Statistics; 61.

Office of Justice Programs Office of Juvenile Justice and Delinquency Prevention.1999 Drinking in America: Myths, Realities, and Prevention Policy, Updated For 2002 National Survey On Drug Use And Health U.S. Department Of Justice. 
OECD. 2006. Projecting OECD Health and Long term Care Expenditures, What are the Main Drivers? OECD Economics Department Working Paper. OECD Publishing, 477(82).http://dx.doi.org/10.1787/736341548748.

Qureshi AI, Adil MM, Zacharatos H, Suri MF. 2013. Factors associated with length of hospitalization in patients admitted with transient ischemic attack in United States. Stroke.1601-5.

Rehm, J., Colin, M., Svetlana, P., Montarat, T., Yot, T., Jayadeep, P., Volume 373, No. 9682, 2223-2233, 27 June 2009, Global burden of disease and injury and economic cost attributable to alcohol use and alcohol-use disorders.

Rice, D.P. 1999. Economic costs of substance abuse, 1995. Proceedings of the Association of American Physicians, 111(2): 119-125.

SAS/STAT 9.3 User's Guide. http://support.sas.com/. Accessed on June 2014.

Stahre, M., J. Roeber, D. Kanny, R.D. Brewer, X. Zhang. 2014. Contribution of Excessive alcohol consumption to deaths and years of potential life lost in the United States. Preventive Chronic Disorders, 11:130-293.

State Health Facts, Henry J. Kaiser Family Foundation.2000-2009. Accessed on May 25th, 2014,http://kff.org/statedata/.

Substance Abuse and Mental Health Services Administration, Center for Behavioral Health Statistics and Quality (Office of Applied Studies), National Survey on Drug Use and Health, State Estimates of Substance Use and Mental Disorder. Accessed on June 12th, 2014. http://www.samhsa.gov/data/NSDUH.aspx.

SAMHSA 2013 National Survey on Drug Use and Health NSDUH Table 2 46B-Alcohol Use Binge Alcohol Use and Heavy Alcohol Use in the Past Month among Persons Aged 18 or Older by Demographic Characteristics Percentages 2012 and 2013 Available at http //www samhsa gov/data/sites/default/files/NSDUH-

DetTabsPDFWHTML2013/Web/HTML/NSDUH-DetTabsSect2peTabs43to84-2013 htm\#tab2 46b.

Summary Health Statistics for the U.S. Population: National Health Interview Survey, 2013, CDC, vital and health statistics.

The Dartmouth Atlas of Health Care. The Center for the Evaluative Clinical Sciences Dartmouth Medical School. Appendix on the Geography of Health Care in the U.S. 
The Facts about Rising Health Care Costs Underlying medical costs drive growth, Aetna.com. Accessed on 14th March 14, 2015.

U.S. Census Bureau.2000-2009. Population Estimates. Accessed on June 20th 2014,http://www.census.gov/popest/data/historical/2000s/vintage_2009/index.html.

United Census Bureau, U.S. Department of Commerce. 2000-2009. Accessed on May 22nd, 2014.http://www.census.gov/.

World Health Organization (WHO), 2014. http://www.who.int/substance_abuse/publications/global_alcohol_report/profiles/usa.pdf

Wul, V.Y., Y. C. Shen, M.S. Yun and G. Melnick. 2014. Decomposition of the drivers Of the U.S. hospital spending growth, 2001-2009.BMC Health Services Research 2014, 14:230.

Ziaeian B, P.P. Sharma,T.C.Yu , K.W. Johnson and G.C. Fonarow. 2015. Factors associated with variations in hospital expenditures for acute heart failure in the United States. American Heart Journal. 169(2).282-289.

Zhang, Z., M. Hayward, and C. Lu. 2012. Is There a Hispanic Epidemiological Paradox in Later Life? A Closer Look at Chronic Morbidity. Research on Aging 34 (5); 548-71.

Zhao, X., J.W. Burnett and J.J. Fletcher. 2014. Spatial Analysis of China province-level CO2 emission intensity. Renewable and Sustainable Energy Reviews, 22:1-10. 


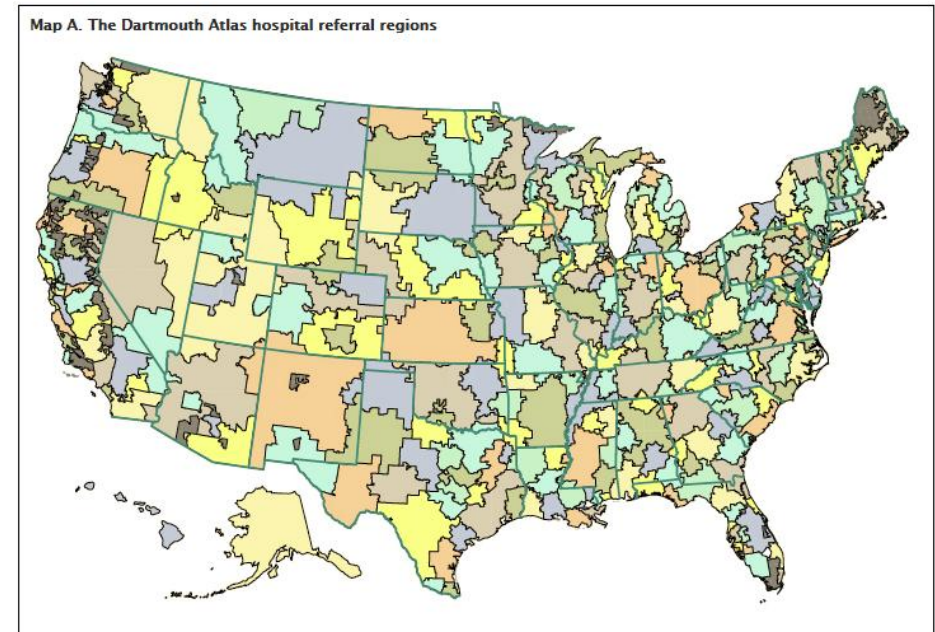

Figure 1: HRR Source: The Dartmouth Institute for Health Policy and Clinical Practice 


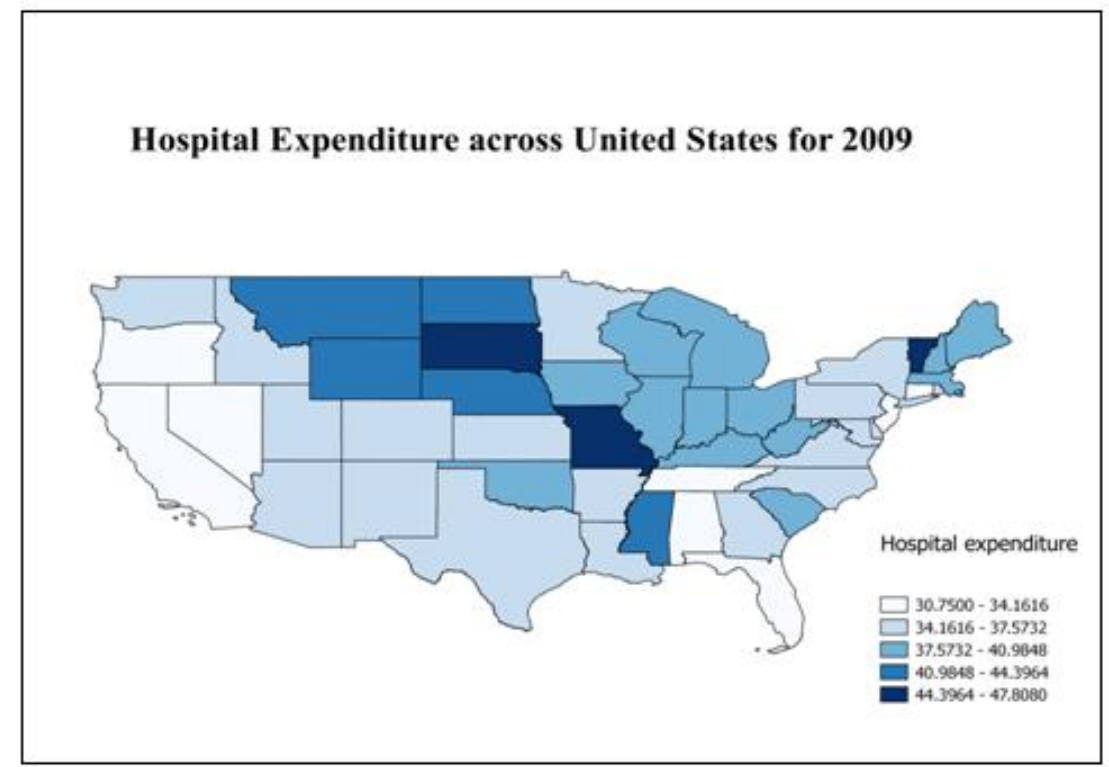

Figure 2: Map depicting variations in hospital expenditure in the U.S. as a percent of total health expenditures, 2009 


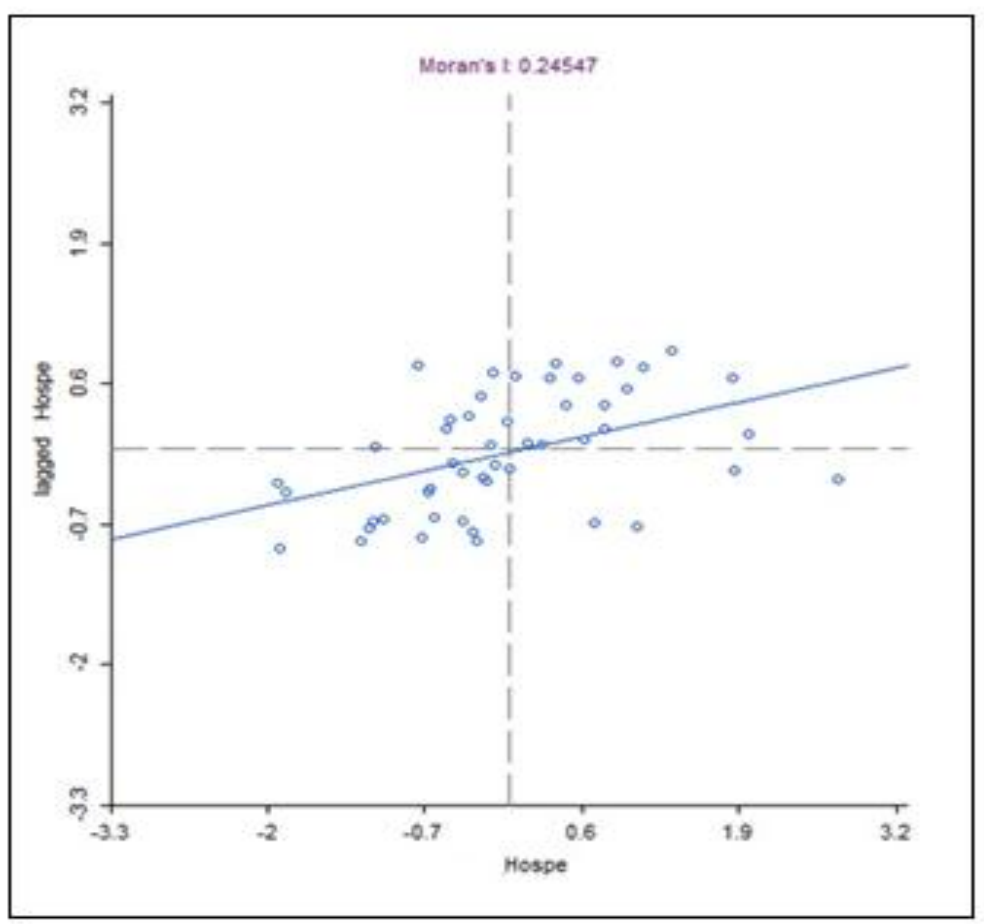

Figure 3: Moran's I scatter plot reporting presence of positive spatial autocorrelation of rate of Hospital Expenditures 


\section{Table 9: Definition of Variables}

\begin{tabular}{|l|l|c|}
\hline Dependent Variables (Y) & \multicolumn{1}{|c|}{ Definition } & Expected sign of coefficients \\
\hline HOSP EXP & $\begin{array}{l}\text { Percentage of Hospital Expenditure to the total health } \\
\text { expenditure (state level) }\end{array}$ & \\
\hline Independent Variables (X) & & \\
\hline UNINS & The proportion of the population without insurance & + on own state, - on neighbors \\
\hline ACTIVE & Number of active physician per 100,000 population & + \\
\hline HOS & Number of hospitals per 1000 population & + \\
\hline HMO & Percentage enrolled in Health Maintenance Organization & - \\
\hline PER CAPITA GDP & Per capita gross domestic product of the state & + \\
\hline POV & Poverty rate & - \\
\hline MEDICAID & Percentage of Medicaid Expenditure & - \\
\hline AGE65 & Proportion of the population above age 65 & + \\
\hline AGE17 & Proportion of the population below age 17 & + \\
\hline BED & Number of hospital beds per 1000 population & Ambiguous \\
\hline AFRICAN-AMERICAN & Percentage of African-American population & + \\
\hline MALE & Percentage of male population & Ambiguous \\
\hline UNEMP & Unemployment rate & + \\
\hline HISPANIC & Percentage of Hispanic population & \\
\hline BINGE & $\begin{array}{l}\text { Percentage of population with binge alcohol use (5 drinks } \\
\text { for men and 4 drinks for women within two-hour time } \\
\text { period in the past 30 days) }\end{array}$ & \\
& & \\
\hline
\end{tabular}


Table 10: Summary Statistics for State Level Hospital Expenses 2000-2009 for 48 States and Federal Districts

\begin{tabular}{|l|l|l|l|l|l|}
\hline Variable & \multicolumn{1}{|c|}{ Unit } & \multicolumn{1}{|c|}{ Mean } & $\begin{array}{l}\text { Standard } \\
\text { deviation }\end{array}$ & Minimum & Maximum \\
\hline Percentage of Hospital Expenditure & $\%$ & 36.510 & 3.453 & 29.111 & 49.528 \\
\hline Uninsured rate & $\%$ & 13.553 & 3.901 & 4.400 & 26.100 \\
\hline Proportion of population below age 17 & $\%$ & 24.591 & 2.099 & 18.930 & 43.757 \\
\hline Proportion of population above age 65 & $\%$ & 12.776 & 1.538 & 8.500 & 17.600 \\
\hline Active physician per 100,000 population & Unit & 265.344 & 95.886 & 154.000 & 852.000 \\
\hline Percentage of population enrolled in HMO & $\%$ & 19.878 & 12.142 & 0.100 & 64.100 \\
\hline Poverty rate & $\%$ & 12.824 & 3.193 & 5.300 & 21.920 \\
\hline Percentage of Medicaid Expenditure & $\%$ & 15.060 & 3.994 & 7.272 & 29.977 \\
\hline Total number of community hospitals & Unit & 99.794 & 79.840 & 5.000 & 428.000 \\
\hline Unemployment rate & $\%$ & 5.189 & 1.665 & 2.300 & 13.300 \\
\hline Percentage of African-American population & $\%$ & 11.639 & 11.595 & 0.311 & 61.106 \\
\hline Percentage of Male population & $\%$ & 49.207 & 0.722 & 47.044 & 51.013 \\
\hline Percentage of Hispanic population & $\%$ & 9.089 & 9.470 & 0.679 & 45.566 \\
\hline Percentage of population with Binge alcohol consumption & $\%$ & 23.319 & 3.502 & 13.730 & 33.820 \\
\hline Hospital bed per 1,000 people & Unit & 3.042 & 1.008 & 1.700 & 6.200 \\
\hline
\end{tabular}


Table 11: Lagrange Multiplier Test Results for Non-Spatial Models

\begin{tabular}{|c|c|c|c|c|}
\hline & Pooled OLS & $\begin{array}{l}\text { Spatial Fixed } \\
\text { effects }\end{array}$ & $\begin{array}{l}\text { Time period } \\
\text { Fixed effects }\end{array}$ & $\begin{array}{l}\text { Spatial and Time } \\
\text { period Fixed effects }\end{array}$ \\
\hline LM test spatial lag & $16.846 * * *$ & $59.453 * * *$ & $7.575^{* * *}$ & $29.394 * * *$ \\
\hline Robust LM test spatial lag & $3.342 * *$ & $16.977 * * *$ & $6.172 * *$ & 0.136 \\
\hline LM test spatial error & $38.295 * * *$ & $44.559 * * *$ & $23.250 * * *$ & $33.926 * * *$ \\
\hline Robust LM test spatial error & $24.792 * * *$ & 2.084 & $21.847 * * *$ & $4.668 * *$ \\
\hline
\end{tabular}


Table 12: Likelihood Ratio Test Results

Likelihood Raito test for joint significance of spatial fixed effects (degrees of freedom)

$966.248 * * *(49)$

Likelihood Raito test for joint significance of time period fixed effects(degrees of freedom)

$36.384 * * *(10)$

The symbols ***, ** and * represent one, five and ten percent significance level. 
Table 13: Estimation Results of Spatial Panel Data Models (SAR and SEM)

\begin{tabular}{|l|l|l|l|l|}
\hline & \multicolumn{2}{|c|}{ SAR } & \multicolumn{2}{c|}{ SEM } \\
\hline Variable & Coefficient & T statistics & Coefficient & T statistics \\
\hline Percentage of Hispanic population & $-0.475^{* * *}$ & -4.504 & $-0.623^{* * *}$ & -5.471 \\
\hline Percentage of Male population & $-2.345^{* *}$ & -2.584 & $-2.553^{* * *}$ & -3.043 \\
\hline Percentage of African-American population & $0.498^{* * *}$ & 3.250 & $0.391^{* * *}$ & 2.755 \\
\hline Uninsured rate & -0.030 & -0.856 & -0.013 & -0.382 \\
\hline Per capita GDP & 0.023 & 1.070 & 0.009 & 0.462 \\
\hline Percentage of Medicaid Expenditure & $-0.075^{* *}$ & -2.352 & $-0.077 * * *$ & -2.608 \\
\hline Active physician per 100,000 population & 0.005 & 1.136 & 0.002 & 0.609 \\
\hline Percentage of population enrolled in HMO & -0.002 & -0.233 & 0.000 & -0.023 \\
\hline (Hospital bed *Total number of hospitals) per 1000 people & $9.593^{* * *}$ & 3.833 & $9.990^{* * *}$ & 4.363 \\
\hline Poverty rate & $0.149^{* *}$ & 2.223 & $0.131^{* *}$ & 2.092 \\
\hline Proportion of population above age 65 & 0.049 & 0.189 & 0.080 & 0.331 \\
\hline Proportion of population below age 17 & -0.066 & -1.401 & -0.040 & -0.941 \\
\hline Unemployment rate & $0.116^{*}$ & 1.661 & $0.144 * *$ & 2.064 \\
\hline Percentage of population with Binge alcohol consumption & $0.049^{* * *}$ & 1.837 & $0.074 * * *$ & 2.790 \\
\hline$\lambda($ Lambda) & $0.370^{* * *}$ & 6.586 & & \\
\hline$\eta$ (eta) & & & $0.396^{* * *}$ & 6.964 \\
\hline R square & 0.9441 & & 0.9387 & \\
\hline Log Likelihood & -601.061 & & -597.364 & \\
\hline Number of observations & 490 & & 490 & \\
\hline The symbols $* * *, * * a n d *$ represent one, five and ten percent significance level. & & \\
\hline
\end{tabular}


Table 14: Wald Tests and Likelihood Ratio Tests Results

\begin{tabular}{|l|l|l|l|l|}
\hline & $\begin{array}{l}\text { Wald } \\
\text { Test(SAR vs. } \\
\text { SDM) }\end{array}$ & $\begin{array}{l}\text { LR } \\
\text { test(SAR } \\
\text { vs. SDM) }\end{array}$ & $\begin{array}{l}\text { Wald } \\
\text { Test(SEM } \\
\text { vs. SDM) }\end{array}$ & $\begin{array}{l}\text { LR } \\
\text { test(SAR vs. } \\
\text { SDM) }\end{array}$ \\
\hline Value & $107.411 * * *$ & $91.531 * * *$ & $99.036 * * *$ & $84.138 * * *$ \\
\hline Degrees of freedom & 14 & 14 & 14 & 14 \\
\hline \multicolumn{2}{|l|}{ The symbols $* * *, * *$ and $*$ represent one, five and ten percent significance level. } \\
\hline
\end{tabular}


Table 15: Spatial Durbin Fixed Effect Model Results

\begin{tabular}{|c|c|c|}
\hline Variable & Coefficient & T-statistics \\
\hline Percentage of Hispanic population & $-0.657 * * *$ & -4.671 \\
\hline Percentage of Male population & $-2.882 * * * *$ & -3.300 \\
\hline Percentage of African-American population & $0.489 * * *$ & 3.252 \\
\hline Uninsured rate & -0.003 & -0.075 \\
\hline Per capita GDP & 0.012 & 0.602 \\
\hline Percentage of Medicaid Expenditure & $-0.062 * *$ & -1.997 \\
\hline Active physician per 100,000 population & 0.000 & 0.020 \\
\hline Percentage of population with Health Maintenance Organization & -0.002 & -0.224 \\
\hline Hospital bed per 1,000 people *Total number of hospitals & $11.185^{* * * *}$ & 4.753 \\
\hline Poverty rate & $0.108 *$ & 1.685 \\
\hline Proportion of population above age 65 & -0.242 & -0.919 \\
\hline Proportion of population below age 17 & -0.055 & -1.237 \\
\hline Unemployment rate & $0.192 * * *$ & 2.592 \\
\hline Percentage of population with Binge alcohol consumption & $0.076 * *$ & 2.901 \\
\hline W*Percentage of Hispanic population & $0.984 * * *$ & 3.904 \\
\hline W*Percentage of Male population & $4.933 * *$ & 2.179 \\
\hline $\mathrm{W}^{*}$ Percentage of African-American population & $0.902 * *$ & 2.243 \\
\hline $\mathrm{W}^{*}$ Uninsured rate & $-0.153^{* *}$ & -1.853 \\
\hline W*Per capita GDP & $0.084 * *$ & 1.789 \\
\hline $\mathrm{W} *$ Percentage of Medicaid Expenditure & -0.018 & -0.221 \\
\hline $\mathrm{W}^{*}$ Active physician per 100,000 population & $0.015^{* *}$ & 1.920 \\
\hline W*Percentage of population with Health Maintenance Organization & -0.031 & -1.345 \\
\hline W*Hospital bed per 1,000 people *Total number of hospitals & 1.299 & 0.195 \\
\hline W*Poverty rate & 0.168 & 1.149 \\
\hline W*Proportion of population above age 65 & $-2.194 * * *$ & -3.570 \\
\hline W*Proportion of population below age 17 & $-0.188^{*}$ & -1.811 \\
\hline W*Unemployment rate & $0.223^{*}$ & 1.655 \\
\hline W*Percentage of population with Binge alcohol consumption & -0.001 & -0.021 \\
\hline$\lambda$ (lambda) & $0.120 * *$ & 1.740 \\
\hline R square & 0.9526 & \\
\hline Log Likelihood & -555.295 & \\
\hline Number of obs. & 490 & \\
\hline
\end{tabular}


Table 16: Direct, Indirect and Total Effect Results of the Spatial Durbin Fixed Effect Model

\begin{tabular}{|c|c|c|c|c|c|c|}
\hline Variable & Direct Coefficient & T statistics & Indirect Coefficient & T statistics & Total Coefficient & T statistics \\
\hline Percentage of Hispanic population & $-0.638 * * *$ & -4.663 & $1.009 * * *$ & 3.822 & 0.371 & 1.666 \\
\hline Percentage of Male population & $-2.763 * * *$ & -3.151 & $5.151 * *$ & 2.023 & 2.388 & 0.853 \\
\hline Percentage of African-American population & $0.516 * * *$ & 3.252 & $1.089 * *$ & 2.446 & $1.605 * * *$ & 3.239 \\
\hline Uninsured rate & -0.006 & -0.171 & $-0.177 *$ & -1.900 & $-0.182 *$ & -1.796 \\
\hline Per capita GDP & 0.015 & 0.707 & $0.093 * *$ & 1.828 & $0.107 * *$ & 1.991 \\
\hline Percentage of Medicaid Expenditure & $-0.064 * *$ & -2.074 & -0.031 & -0.343 & -0.095 & -0.962 \\
\hline Active physician per 100,000 population & 0.000 & 0.121 & $0.017 * *$ & 1.931 & $0.017 *$ & 1.823 \\
\hline Hospital bed per 1,000 people $*$ Total number of hospitals & $11.144 * * *$ & 4.663 & $2.909 *$ & 3.850 & $14.054 *$ & 1.713 \\
\hline Poverty rate & $0.110 *$ & 1.793 & 0.204 & 1.234 & $0.314 *$ & 1.769 \\
\hline Proportion of population above age 65 & -0.288 & -1.078 & $-2.517 * * *$ & -3.587 & $-2.806 * * *$ & -3.643 \\
\hline Proportion of population below age 17 & -0.056 & -1.294 & $-0.206 * *$ & -1.732 & $-0.263 * *$ & -1.995 \\
\hline Unemployment rate & $0.197 * * *$ & 2.671 & $0.274 *$ & 1.847 & $0.470 * *$ & 3.194 \\
\hline Percentage of population with Binge alcohol consumption & $0.076 * * *$ & 2.901 & $0.079 * * *$ & 3.005 & $0.155 * * *$ & 2.481 \\
\hline R square & 0.9526 & & & & & \\
\hline Total number of observations & 490 & & & & & \\
\hline
\end{tabular}


CHAPTER 4 


\section{CHAPTER 4: STATE-LEVEL HEALTHCARE SPENDING AND HEALTH OUTCOMES: AN APPLICATION OF SPATIAL DURBIN PANEL APPROACH TO MORTALITY}

\section{INTRODUCTION}

There exists a complex relationship between healthcare spending and health outcomes. At the national level, it has been documented that higher healthcare expenditures were not associated with a corresponding improvement in health outcomes or better quality of care (Nolte and McKee, 2012; Squires, 2012). Fischer et al. (2003) displayed that, neither quality nor access to healthcare improved with higher spending. Baicker and Chandra (2004) reported that "higher Medicare spending have lower-quality care." Fischer et al. (2004) highlighted that increased intensity of hospital services do not have any association with quality of care.

When examining survival, it has been accounted that higher healthcare spending was not associated with increased survival (Fischer et al., 2004) following hip-fracture or heart attack or cancer (Fischer et al., 2003).'Life expectancy of the United States was one year above the OECD average in 1970, but it is now more than one year below the average. It ranks $26^{\text {th }}$ in life expectancy among 34 OECD countries (OECD, 2013).” The mortality rate for the US has declined by $1 \%$ in a decade, but expenditures at both the state and national level have been steadily increasing at an annual average of 6.2\% (CMS, 2012). The mortality rate has remained relatively stable with 8.5 per 1,000 residents in the year 2000 and to 8.39 per 1,000 residents in 2013 (CDC, 2011).

At the state-level, higher healthcare expenditures may or may not be associated with better health outcomes. Using 2004 state-level data, it has been reported by Cooper (2009) that states with more total health spending per capita had better-quality care. Campbell et al. (2012) deduced that aggregated state level health expenditures (local health department) were associated 
with significant "decline in state-level infectious disease (health outcomes) and morbidity." Mays et al. (2011) reported that local public health spending decreased the mortality rate significantly (mortality rate decreased between $1.1 \%$ and $6.9 \%$ for each $10 \%$ increase in spending). As highlighted by Dunn et al. (2005), public expenditures by state and local government in the U.S. are highly associated with reduction in the mortality rate. It is also important to evaluate the relationship between healthcare expenditures and health outcomes because as stressed by Skinner et al. (2009), improved efficiency in healthcare and not just increasing supply side factors (by spending more as proposed by Cooper, 2009) is fundamental to improve quality of healthcare.

\section{Determinants of the mortality rate}

Furthermore, the health outcomes of residents in a state are influenced by the residents' demographic profiles, healthcare needs, socio-economic factors, environmental factors, and healthcare needs. The association between mortality and unequal distribution of the social and economic resources has been highlighted by several studies. In state-level analysis, Kawachi et al. (1997) and Daly et al. (1998) reported that economic variables such as income inequality drive the mortality rate upwards. Sorlie et al. (1995), examining the variations in the mortality rate in the US, found that income, education, occupation, race, and marital status comprise a significant amount of fluctuation in the mortality rate. Mansfield et al. (1999) reported that "community structure factors" such as the percentage of rural population, African-American population, lower level of education and the availability of physicians are the fundamental components that explained the high mortality rate. They also reported that rural counties of the Southeast and Southwest had higher premature mortality in comparison to other regions. Shi et al. (2001) evaluated the relationship between income inequality and the primary care physician 
to find that they have higher impact on mortality and it varies across races. McLaughlin et al. (2001) explained that the mortality rate in 1990 was lower for the nonmetropolitan U.S. counties than the metropolitan counties even after having lower average incomes, greater percentage of population living in poverty, lower levels of health insurance, less preventive health care, and poorer health status. McLaughlin and Stokes (2002) have also reported that the U.S. counties and metropolitan areas with low-income inequality and higher percentage of the African-American population have a higher mortality rate than the counties with high-income inequality and higher population of African-Americans. Hence, location or geographical distribution of inhabitants has a significant effect on the mortality rate.

\section{Purpose of spatial analysis of the mortality rate}

While the above-mentioned studies highlighted the relationship between socio-economic, demographic, and geographic factors and mortality, these studies did not control for spatial relationships that may exist. None of above mentioned studies has considered the examination of neighborhood effects in their analysis (LeClere et al., 1998). Cossman et al. (2007) explained the importance of spatial analysis when examining mortality. According to Cossman and his colleagues, Upper Greater Plains (low economic activity and higher out-migration) have lower mortality when compared to the South (South Eastern, Appalachia, and Mississippi Delta) with the same levels of "population loss and economic contraction. Based on these observations, Cossman and colleagues inferred that mortality may be influenced by spatial variation along with other characteristics of a region.

\section{Previous spatial dependence study on the mortality rate}

The importance of accounting for spatial dependence in explaining variations in mortality rate has been demonstrated by McLaughlin et al. (2007), Yang et al. (2011), Chen et al. (2012), 
Sparks and Sparks $(2009,2012)$ and Yang et al. (2015). McLaughlin et al. (2007) provided evidence of spatial patterns of mortality rates across the counties of the US using the data from 1996 to 2000. They presented that income inequality, socio-economic status, health care services (such as hospital beds and active physician), and environmental risk factors verify the changes in the mortality rates among the counties.

Yang et al. (2011), in their analysis of 1998 to 2002 U.S. county-level mortality data, described that the concepts of rural paradox and social capital negatively influence the mortality of a county. In addition, they demonstrated that spatial dependence of the mortality rate (using the spatial error model and spatial lag model) is strongly evident among the counties. Chen et al. (2012), using weighted Poisson regression model demonstrated that cardiovascular mortality rates and its predictors (social disadvantage, stability, sensitive group and rurality) varied spatially in Taiwan. Sparks and Sparks (2009) found that there is spatial spillover of mortality rates across the counties of the U.S. for the time period of 1998 to 2002. They found that sociodemographic and economic characteristics such as gender, race, location (urban/rural), Hispanic origin, unemployment rate, income, and Gini coefficient (income inequality) are the major influencing factors. While Sparks and Sparks (2009) used spatial Error model to capture the spatial interaction of mortality across the county, Sparks et al. (2012) used Bayesian regression model analysis to report association of race and poverty segregation with the infant mortality rate.

Yang et al. (2015) reported using the spatial Durbin model for 5-year average mortality data of the U.S. counties (2003 to 2007) that "mortality rate of a certain county is associated with the features of its neighbors (page 18)." They also stated that while Hispanic population, concentrated disadvantage, and social capital are inversely proportional to mortality, health 
insurance, non-Hispanic, and income inequality positively impacted it. They further suggested that the spatial Durbin model is preferred to the "traditional analytic approach such as ordinary least squares (OLS), spatial error, and spatial lag regression" because a spatial Durbin model is able to capture the exogenous effect of the variables, the local and global spillover effects of the determinants and offers an unrestricted magnitude of the spatial effect (Anselin, 2008; LeSage and Pace, 2009; Yang et al., 2015), thereby eliminating the possibility of the presence of inefficient estimates. This model considers both spatially lagged dependent variables and spatially lagged independent variables while estimating, thus provides unbiased coefficients.

The justification behind spatial interaction or spillover for local-, regional-, or state-level analysis has been described by Manski (1993). The first was the endogenous effect, meaning that behavior of one individual state is affected by its neighboring states' behaviors. The second was the exogenous effect, meaning that a state's behavior is affected by the characteristics of the exogenous group (states) (Bugni, 2012). The third was the contextual or correlated effect, suggesting that policies of one state will affect the budgets of its neighboring state governments in a similar manner (Lundberg, 2011). Holod and Reed (2004) also validated how "uncompensated spillovers" of knowledge, human capital or economic growth helped in economic development and economic integration at the regional or national level. For example, the effect of improvement of quality of economic assets of one state such as educational or health infrastructures will not only increase the state's quality of care by improving the living standard of the people, but the neighboring states will also report similar impact as they will also have access to this improved health care system.

Although the aforementioned researches have considered spatial model analysis for their studies, some have used an average mortality rate data (5-year average (Yang et al., 2015) while 
others have used pooled data (Sparks and Sparks, 2009)), thereby smoothing out the fluctuations of the variables over time and providing biased estimates. It is important to include time as a factor (temporal dimension) in an analysis because it removes unobserved heterogeneity, inconsistency, and improves the quantity and quality of the data (Yafee, 2003). Further, all the studies till now have evaluated spatial dependence only at the county-level. To date, state level spatial analysis of the mortality rate has not been examined. It is important to evaluate the spatial dependence of mortality rates across states because mortality rates vary extensively across states (Cossman et al., 2007; Mansfield et al., 1999).

\section{State level variations in mortality rate}

During the years between 2007 and 2009, West Virginia had the highest annual mortality rates (11.5 persons per 1,000 residents and 11.6 persons per 1,000 residents), which were $43.7 \%$ and $46.8 \%$ higher than the average U.S. mortality rate, respectively. During the same period, Alaska had the lowest annual mortality rate of 5.1 and 5.2, per 1,000 residents respectively (36\% and 34\% below the U.S. average rate) (NCHS Data Brief, 2011). In 2011, West Virginia continued to have the highest death rate $(11.8$ per 1,000), followed by Pennsylvania, Arkansas, and Alabama (all at 10.1 per 1,000). Alternatively, Alaska continued to have the lowest death rate $(5.3$ per 1,000$)$, followed by Utah $(5.4$ per 1,000$)$, California $(6.4$ per 1,000$)$, Colorado $(6.4$ per 1,000), and Texas (6.6 per 1,000). To summarize, mortality rates for 30 states were higher than the overall U.S. rate (National Vital Statistics System, Mortality Public Use Data Files, 2011).

\section{Purpose of State level analysis}

Analyzing these variations in the mortality rate at the state level is important because healthcare policy formation takes place at the state level (state government conducts health 
policy decision, implementation and evaluation). It has been noted that even though there are structural differences in the health care system among the states, policy measures taken by a state have a similar influence on its neighboring states. There is a cluster formation of states with respect to health expenditures (Bose, 2015) or the mortality rate (Figure 4). As a result, statelevel spatial analysis is a more advanced way to address the problem of variations in mortality rate. This is because understanding the factors associated with state-level variations will not only help the government to frame policies needed to reduce the mortality rate, but will also help in providing the residents with actions and strategies that aim towards a superior and uniform level of medical care.

\section{Unique Contribution}

Hence, to overcome the limitations of the previous literature, a spatial panel analysis for the U.S. state-level mortality rate has been used to analyze the effect of the determinants on the deviation of the mortality rate with spatial and temporal dimension. This paper is an improved study and robustness check of the analysis of Yang et al. (2015). In comparison to Yang et al. (2015), this analysis uses state-level data (48 states and the District of Columbia) of the U.S. for a longer time period (2000 to 2009) and a spatial Durbin panel regression model that controls for the effect of time variation and spatial interaction. The present research has eliminated some of the potential explanatory variables as used in Yang's study, such as percentage of the female household, the population receiving public assistance, social capital index score, rural-urban resident continuum code (as data are not available for all years for these variables), and residential stability (as it was statistically insignificant). Instead this paper includes new explanatory variables such as: percentage of inpatient spending (hospital expenses), total healthcare expenditures, percentage of male population, percentage of elderly population, total 
number of hospitals, percentage of married population and percentage of population with substance abuse.

Thus, this paper: 1) Explain the variation of the mortality rate across 48 states and the District of Columbia in the U.S. over a time period of 10 years (2000 to 2009) with respect to the demographic profile (the percentage of African-American, male, Hispanic population, the percentage of elderly population, percentage of married population), economic factors (income, poverty rate, violent crime rate per 100,000 residents, the property crime rate per rate 100,000 residents, percentage of population with bachelor's degree and higher, voting rate, employment rate, uninsured rate), health expenditure variables (rate of hospital expenditure or total healthcare expenditures), supply factors (active physicians per 100,000 residents, and the total number of hospitals and beds per 1,000 residents) and substance abuse factors (rate of alcohol, tobacco and drug use); 2) Find the presence of any spatial pattern among the states and if so, how it causes changes in the state's mortality rate; and last but not least, 3) Evaluate the direct and indirect impacts of these variables on mortality rate across the states.

\section{MODEL}

In order to comprehend the effect of the explanatory variables on the mortality rate value across the states, the regression framework can be expressed as:

$$
Y_{i t}=\beta_{0}+\beta_{1} X_{i t}+\mu_{i}+\lambda_{t}+\varepsilon_{i t}
$$

Where $\mathrm{Y}=$ dependent variable, $\mathrm{X}=$ independent variables, $\mathrm{t}$ is the time period, $\mathrm{i}$ is the state variable, $\mu_{\mathrm{i}}$ represents the individual state effects, $\lambda_{\mathrm{t}}$ denotes time period effects (2000 to 2009) and $\varepsilon_{\mathrm{it}}$ signifies the error term for the time period $\mathrm{t}$ and state $\mathrm{i}$. The entire set of dependent and independent variables is defined in percentage or logarithmic form to remove any nonlinear relationship among the variables and also convert any highly skewed variable to the normal 
form. The set of variables used for analysis have been illustrated in Table 17. Three models have been considered for empirical analysis to highlight the impact of healthcare expenditures on health outcomes (mortality rate)—1) without hospital or healthcare expenditure variables 2) with only percentage of hospital expenditure 3) with only total health expenditures.

Employing non-spatial panel methods to explain the variation in the mortality rate across the states will provide biased estimates, as these analyses "violate the traditional assumption of independence between observations (LeSage and Pace, 2009).” LeSage and Pace (2009) has explained that spatial econometric model analysis captures time variation, spatial heterogeneity (assuming "observational units in close proximity should exhibit effect levels that are similar to those from neighboring units (LeSage and Pace, 2009)"), peculiarities caused by space or location, externalities of both positive and negative form "arising from neighborhood characteristics (LeSage and Pace, 2009),” and uncertainties.

\section{Moran's I index}

First, it is necessary to see if there is existence of spatial autocorrelation at the state-level mortality rate. This is measured by Moran's I index (1950) developed by Patrick Alfred Pierce Moran, which is stated as the following:

$$
\mathrm{I}=\frac{N \sum_{i} \sum_{j} w_{i j}\left(Y_{i}-Y\right)\left(Y_{j}-Y\right)}{\sum_{i} \sum_{j} w_{i j} \sum_{i}\left(Y_{i}-Y\right) 2}
$$

Where $Y$ is the mean value of $Y_{i}$ (which is the mortality rate for state $i$ ) and $Y_{j}$ (which is the mortality rate for state $\mathrm{j}$ ). $\mathrm{w}_{\mathrm{ij}}$ captures the value of the ith and jth state's contiguity weight matrix and $\mathrm{N}$ is the total number of observations. $\mathrm{w}_{\mathrm{ij}}$ is a row standardized contiguity matrix whose value is one if $\mathrm{i}$ and $\mathrm{j}$ has a shared border and zero if not. Moran's I index ranges from 1(complete dispersion) to 0 (or random spatial pattern) to +1 (correlation). The null hypothesis 
for this test is considered as $\mathrm{H}_{0}=$ No spatial clustering of values (ESRI). If the $\mathrm{z}$ score of the index value is significant, the null hypothesis is rejected highlighting either the presence of cluster (if the value of the index is greater than 0) or dispersion (if the value of the index is less than 0) among the dependent variable of own state and the neighboring states dependent variable. In addition, Moran's I scatter plot provides a graphical representation of the cluster or dispersion characteristics among the states for the mortality rate.

\section{Spatial models for analysis (SAR, SEM and SDM)}

After establishing the fact that the state-level mortality rate exhibits spatial clustering or dispersion, this study compares three spatial panel data regression methods (LeSage and Pace, 2009; Anselin, 2008; Elhorst, 2014) to find the best model applicable for analysis. The three models are the following: 1) the Spatial Durbin panel model, also known as the SDM panel model, 2) Spatial Auto regressive panel model, also known as the SAR panel model, and 3) Spatial Error panel model, also known as the SEM panel model. With spatial lagged dependent and independent variable constituted in SDM analysis, SAR and SEM incorporate spatially lagged dependent variable and spatial interaction of the error term consecutively in the regression method.

The formula for the three models mentioned above are specified as-

$$
\begin{aligned}
& \mathrm{Y}_{\mathrm{it}}=\phi+\lambda \sum_{\mathrm{j}=1}^{\mathrm{N}} W_{i j} \mathrm{Y}_{\mathrm{jt}}+\mathrm{X}_{\mathrm{it}} \beta+\sum_{\mathrm{j}=1}^{\mathrm{N}} \mathrm{W}_{\mathrm{ij}} \mathrm{X}_{\mathrm{jt}} \theta+\mu_{\mathrm{i}}+\delta_{\mathrm{t}}+\varepsilon_{\mathrm{it}} \\
& \mathrm{Y}_{\mathrm{it}}=\lambda \sum_{\mathrm{j}=1}^{\mathrm{N}} \mathrm{W}_{\mathrm{ij}} \mathrm{Y}_{\mathrm{jt}}+\mathrm{X}_{\mathrm{it}} \beta+\phi+\mu_{\mathrm{i}}+\delta_{\mathrm{t}}+\varepsilon_{\mathrm{it}} \\
& \mathrm{Y}_{\mathrm{it}}=\phi+\mathrm{X}_{\mathrm{it}} \beta+\mu_{\mathrm{i}}+\delta_{\mathrm{t}}+\eta \sum_{\mathrm{j}=1}^{\mathrm{N}} \mathrm{W}_{\mathrm{ij}} \mathrm{u}_{\mathrm{it}}+\varepsilon_{\mathrm{it}}
\end{aligned}
$$

$\phi$ is the constant term, $\mathrm{t}$ is the time period, $\mathrm{k}$ is the nearest number of neighbors, and $\mathrm{N}$ is the total number of observations. $\mathrm{Y}_{\mathrm{it}}$ is the mortality rate value for state $\mathrm{i}$ at time period $\mathrm{t}$, and $\mathrm{Y}_{\mathrm{jt}}$ is the mortality rate for the neighboring state $\mathrm{j} . \mathrm{X}_{\mathrm{it}}$ is the matrix of independent variables, and $\mathrm{W}_{\mathrm{ij}}$ 
is the element of $\mathrm{NxN}$ non-negative spatial weight matrix (Zhao et al., 2014). $\lambda$ is the coefficient

of the interaction effect of the dependent variable $\left(\sum_{\mathrm{j}=1}^{\mathrm{N}} W_{i j} Y_{\mathrm{jt}}\right)$ (Elhorst, 2014). $\beta$ is the vector of direct coefficients of the explanatory variables $\mathrm{X}_{\mathrm{it}} \cdot \theta$ is the estimate of an interaction effect of the independent variables $\left(\sum_{\mathrm{j}=1}^{\mathrm{N}} \mathrm{W}_{\mathrm{ij}} \mathrm{X}_{\mathrm{jt}}\right) . \eta$ is the coefficient of interaction of the error term $\left(\sum_{\mathrm{j}=1}^{\mathrm{N}} \mathrm{W}_{\mathrm{ij}} \mathrm{u}_{\mathrm{it}}\right), \mu_{\mathrm{i}}$ is the state effect, $\delta_{\mathrm{t}}$ is the time period effect, and $\varepsilon_{\mathrm{it}}$ is the error term (Elhorst, 2014).

\section{STATISTICAL ANALYSIS}

After identifying the presence of spatial autocorrelation (positive or negative) for the mortality rate by rejecting the null hypothesis of absence of spatial association across the statelevel mortality rate (from the Moran's I index), the four-stage specification tests is performed. This helps in finding the best fit spatial panel model for analysis. Firstly, both the classic and robust Lagrange Multiplier (LM) tests are used to distinguish between non-spatial panel models and spatial panel models (SAR or SEM). If the "non-spatial model based on the LM tests is rejected in favor of the spatial lag model or the spatial error model" (Elhorst, 2014), it signifies that spatial model is the correct approach for data analysis.

Secondly, the Likelihood Ratio (LR) test is used "to investigate the null hypothesis that the spatial fixed effects are jointly insignificant" and "the null hypothesis that the time-period fixed effects are jointly insignificant" (Elhorst, 2014). If both of these null hypotheses are rejected, it provides a model with joint significance of both spatial and time-period fixed effects, also called the two-way fixed effects model (Baltagi, 2005; Elhorst, 2014).

Thirdly, the Wald test and the LR test are applied to compare between SAR, SEM, and SDM methods. It is specified by the two null hypotheses: a) $\mathrm{H}_{0}: \theta=0$ ("spatial Durbin model can be simplified to the spatial lag model" (Elhorst, 2014) and b) $\mathrm{H}_{0}: \theta+\lambda \beta=0$ ("spatial 
Durbin model can be simplified to the spatial error model" (Elhorst, 2014, page 6). If both a and $\mathrm{b}$ are rejected, SDM is the favored model, but if a is not rejected then SAR is the preferred model, and if $\mathrm{b}$ is not rejected then SEM is the preferred model.

Finally, the Hausman specification test is performed to find if spatial random effect model (null hypothesis) or spatial fixed-effect model (alternative hypothesis) is the bestdescribed model. If the null hypothesis falls in the critical region, then spatial fixed-effect model is the chosen one for analysis. The spatial Durbin panel model results in the form of direct effect (change in the independent variables of a state impacts its own state mortality rate) and indirect effect (variation in the independent variables of a state impacts the neighboring state's mortality rate).

\section{TYPES AND SOURCES OF DATA}

The data used in this paper are drawn from four different sources. The first data source is compressed mortality files from the Centers for Disease Control and Prevention (CDC) Wonder website of the National Center for Health Statistics. State-level data for 10 years (2000 to 2009) on mortality rate have been obtained from this data source. The second data source is the United States Census Bureau. The Bureau provides data on variables, namely state shape files, Federal Information Processing Standard (fips) code for the states, median income, the percentage of the population above age 65 , the number of active physicians per 100,000 civilians, poverty rate, unemployment rate, the percentage of uninsured people, percentage distribution of people by gender, race, and Hispanic origin, percentage of people who voted in the elections, property crime rate per 100,000 residents, violent crime rate per 100,000 residents, percentage of population using illicit drugs, smoking and consuming alcohol and Gini coefficient. "Gini coefficient measures the extent to which the distribution of income or 
consumption expenditure among individuals or households within an economy deviates from a perfectly equal distribution (World Bank website)." The value of Gini index varies from 0 to 100. The nominal median income for each year is converted into real dollars (year 2009 is considered as the base year) by using the consumer price index (CPI) for each state.

The third data source is the Behavioral Risk Factor Surveillance System (BRFSS) (Prevalence and Trends Data). Data on the percentage of the population with bachelor's degree and higher and percentage of married population were assimilated from this source. The fourth and the final data source is the State Health Facts published annually by the Henry J. Kaiser Family Foundation. The number of hospital beds in community hospitals per 1,000 residents, and the total number of community hospitals in a state are the two variables for which data have been acquired for this analysis. These two explanatory variables were determined to be highly correlated. Hence an interaction term of these two determinants has been used for the regression purpose. The fifth data source Centers for Medicare and Medicaid Services (CMS), 2011. Data has been obtained on total personal healthcare spending and hospital care expenditure for each state for the study period (Health Expenditures by State of Residence).

State-level shape data files, acquired from the U.S. Census Bureau (Tiger) report, give the latitudinal and longitudinal value of each state, providing information of a geographic area of each state. This is used to create the spatial weight matrix needed to perform the analysis. Data for the years 2000 to 2009 for 48 states and the District of Columbia have been considered for the study, dropping out Alaska and Hawaii. These two states are not considered because they do not have neighbors, which will cause measurement error for the current model analysis and biased parameter estimates. Data for the years 2000 to 2009 are considered the period of analysis 
because this is the time period for which data are available for all the independent and dependent variables considered under this analysis. MATLAB 12 is the software used to obtain the results.

\section{Independent variables}

This study concentrates on capturing the variation in the state-level mortality rate in the presence of spatial and temporal effects of the independent variables.

1) Total healthcare spending is expected to be associated with better-quality care and declines in state-level infectious disease (health outcomes), morbidity and mortality rate (Cooper, 2009; Campbell et al. 2012; Mays et al., 2011; Dunn et al., 2005).

2) Hospital expenditures are also predicted to improve quality of care and provide better health outcomes at the state level (Dunn, 2005; Cooper, 2009).

3) A rise in the median income level of a state is anticipated to improve the living standard of the people leading to an overall decline in the mortality rate (Hitris et al., 1992; Jodi et al., 2002; Novignon et al., 2011).

4) Furthermore, an increase in the proportion of uninsured population will lead to an increase in the death rate. This population will not access health services due to unaffordable high health cost and thereby will be more susceptible to disease and death (Wilper et al., 2009; McLaughlin, 2001).

5) In contrast to this, the employment rate will have a negative effect on the mortality rate. People with jobs live a better life with improved health conditions, thereby not suffering from accidents, suicide, injuries, prolonged diseases, mental depression, frustration, etc., leading to a decrease in the death rate.

6) In reference to the National Center for Health Statistics (NCHS) Data Brief, 2011, out of all the deaths that occurred in $2009,72.3 \%$ of them consisted of the elderly population. 
Therefore, the elderly is observed as the most vulnerable population, suffering highly from diseases and chronic ailments. Therefore, an increase in the aged population in a state will impact the mortality rate in a positive way (NCHS, 2011).

7) It is anticipated that with an increase in the poverty rate, the mortality rate will increase, since poor people suffer from incurable sicknesses and severe health conditions such as chronic diseases, malnutrition, infections, etc., and they cannot afford the high healthcare expenditure due to their financial condition (Mokdad, 2004).

8) The African-American population is inclined to have a higher mortality rate due to suffering from chronic diseases, their lifestyle, cultural differences, socio-economic disadvantages and the social and psychological consequences of discrimination (Chang et al., 2014; LeClere, 1997; Manton, 1987; McLaughlin, 2002; Menchick, 1993; William, 1995).

9) Studies reported that the Hispanic population is inclined to have a lower mortality rate (NCHS, 2011; Sparks and Sparks, 2009; Chang et al., 2014), better health condition and suffer less from chronic health diseases compared to non-Hispanics even though Hispanics as a group have a lower economic status (Yang et al., 2015).

10) The male population has a lower life expectancy (76.2) in comparison to female (81.2), thereby presenting an inverse relation with the mortality rate (National Center for Health Statistics; Chang et al., 2014).

11) Increase in supply-side variables such as the number of active physicians or hospital beds (McLaughlin, 2007; McLaughlin, 2001; Starfield et al., 2005) will reduce the mortality rate of the state as people will have greater access to better healthcare facilities for their sickness and ailments. 
12) Liu and Johnson (2009) found that married people from 1986 to 2000 had a lower or stable mortality rate. Sorlie et al. (1995) and Gove (1973) also saw a similar negative relationship of the mortality rate with the percentage of married population in comparison to unmarried, widowed, divorced, or single population.

13) Education level reduces the mortality rate (Mokdad, 2004). It has also been reported by Deaton (2003), "Better educated people live longer than the less educated people." Populations with higher education have more information about the health care system, and they can benefit more from the health services and also afford a better livelihood (Deaton, 2003).

14) Based on previous research, the percentage of people who voted in an election and high crime rates might exhibit a weak relation with the mortality rate (Yang et al., 2015).

15) Income inequality should have a major positive influence on mortality rate (Cossman, 2007; James and Porter, 2012; Kawachi et al., 1997; Sparks and Sparks, 2009, 2012; Yang et al., 2011; Yang et al., 2012; Yang et al., 2015). All these studies found that the mortality rate is positively correlated with income inequality.

16) The rise in proportion of population consuming alcohol, using drugs and smoking cigarettes will have a positive effect on the mortality rate. With increase in substance uses, there will be higher risk of diseases such as lung cancer, accidents, unintentional and intentional injuries, alcohol poisoning, high blood pressure, stroke, other cardiovascular diseases (Mokdad, 2004, CDC, 2011) leading to a higher death rate. The independent variables are used in logarithmic or percentage form for the analysis. The map in Figure 4 demonstrates the variation of mortality rate across the states in the year 2009. It illustrates that West Virginia has the highest mortality rate in 2009. The Appalachian 
region, some parts of the Midwest and the Southeast are inclined toward having higher mortality rates, while the Southwest and the Northeast of the U.S. have lower mortality values.

\section{Descriptive Statistics}

The descriptive statistics for the dependent and independent variables used for analysis is summarized in the Table 18. The dependent variable is the mortality rate with the highest value for West Virginia (11.8) and the lowest for Utah (5.2). The African-American population varies from Maine $(0.37 \%)$ being the smallest to the District of Columbia $(60.26 \%)$ being the largest. Hispanic population can be seen to be residing mostly in New Mexico (45.56\%), with the lowest percentage in West Virginia $(0.67 \%)$. The uninsured rate also covers a large range, from $4.4 \%$ to 26.1\%, with Florida, Georgia, Nevada, and Texas falling in the higher bracket. Connecticut has the lowest percentage of hospital care expenses, while Washington, D.C., has the highest. Per capita healthcare expenditures are the largest for California, while it is the least for Wyoming. The poverty rate ranges from $6 \%$ to $21.9 \%$, with employment rate ranging from $32.8 \%$ (Nevada) to $83.28 \%$ (Washington D.C.). The total number of community hospitals fluctuates from six (Delaware) to 428 (Texas). While, New Jersey has the highest income level among all states with West Virginia having the lowest income level, Utah has the lowest income inequality with Washington D.C. being the highest.

\section{RESULTS AND DISCUSSION}

The variables for healthcare spending and percentage of hospital expenditures were dropped from the analysis due to absence of any association (Table 25) of these variables individually with the residuals of the SDM regression results (Table 23) of the current analysis (without including them). As indicated from Table 25, these variables did not influence the 
unexplained variations in mortality rate. Zero association means they have no implication on the variation of the mortality rate. Thus, they have been dropped from the actual spatial Durbin fixed effect model analysis.

The scatter diagram (Figure 5) of Moran's I index highlighting positive clustering (0.326) for the mortality rate among the states justified the existence of spatial autocorrelation. This is followed by the four-stage specification tests of Elhorst (2014). Thus, firstly, as seen from Table 19, both the classic and robust LM test values have rejected the non-spatial models and favored the spatial models. The null hypothesis of presence of no spatial lag term is rejected for classic LM tests for all four non-spatial models (pooled ordinary least square model (OLS), the spatial fixed effect model, the time period fixed effect model, and the spatial and time period fixed effect model). The null hypothesis of presence of no spatial lag term is rejected for robust LM tests for only spatial fixed effects model. The classic LM test for the hypothesis of presence of no spatial error term is rejected for all four a-spatial models. In addition, the robust LM test for the hypothesis of the presence of no spatial error term is rejected for three of the four non-spatial models (except time period fixed effect model). Therefore, with spatial analysis chosen over the non-spatial one, the SEM panel model is considered to be a better fit as the null hypothesis of presence of no spatial error term has been rejected for all four models for classic LM test and three models for robust LM tests.

Secondly, from Table 20, it is visible that the LR tests have rejected both the null hypothesis of joint insignificance of spatial fixed effects $(975.754$, degrees of freedom $=49, \mathrm{p}$ $=0.000<0.001)$ and the null hypothesis of the joint insignificance of the time period fixed effects $(132.528$, degrees of freedom $=49, \mathrm{p}=0.000<0.001)$, confirming the presence of a two-way fixed-effect model. Table 22 provides the estimated coefficients of the variables in question 
using the SAR and SEM models. Thirdly, both the Wald test (SAR vs SDM: $\chi^{2}=47.098$ d.f. $=19$ $\mathrm{p}$ value $=0.000<0.001$, SEM vs SDM: $\chi^{2}=36.027$ d.f. $=19 \mathrm{p}$ value $\left.=0.000<0.001\right)$ and the LR test values (SAR vs SDM: $\chi^{2}=44.459$ d.f. $=19$ p value $=0.000<0.001$, SEM vs SDM: $\chi^{2}=40.871$ d.f. $=19 \mathrm{p}$ value $=0.000<0.001)$ in Table 21 fall in the critical region for both the hypotheses of "spatial Durbin model can be simplified to the spatial lag model" and "spatial Durbin model can be simplified to the spatial error model," thereby inferring that the spatial Durbin panel model is the most appropriate one. With the final step of Hausman's (1978) specification test deciding between spatial Durbin random effects and spatial Durbin fixed effects model, the results (71.890, degrees of freedom: 33, p value: 0.000 ) in Table 21 invalidate the null hypothesis of using random effects model and favor the fixed effects model specification. Thus, it has been demonstrated that the spatial Durbin fixed effect model result is the best-fit model for the study.

The coefficient of the interaction term of the dependent variable or the coefficient of the spatial lag term (lambda $=0.29$ ) is significant at $1 \%$ (Table 23). This result reveals that the rise in the mortality rate of own state (for example, i) by $1 \%$ has a positive and significant influence on its neighboring states' (for example, $\mathrm{j}$ ) mortality rate by $0.29 \%$. The direct effect coefficients from the SDM panel model results in Table 23 reported that active physician per 100,000 residents, the percentage of Hispanic population, the percentage of married population, and percentage of people with a college degree or higher displays negative and significant influence on the mortality rate of the states.

The direct effects of Table 23 differ from those in Table 24 as the direct effects in Table 24 also include feedback effects. An increase in health supply variables, such as the number of doctors, represents an improvement in the quality of care and specialized treatments provided in 
health facilities and also access to better health services, thereby reducing the death rate as a direct effect.

As stated earlier, Hispanics are healthier and live longer in comparison to non-Hispanic individuals despite belonging to a lower economic background and have higher rate of uninsurance. "According to the CDC, life expectancy among Hispanics, the largest minority in the US, is two years longer than whites (Dominguez et al., 2015)." They have "lower smoking rates, better diet and better general health (Dominguez et al., 2015)." Another theory of explanation behind this might be the "foreign-born advantage" that the migrated population has, also known as the "salmon-bias" effect (Palloni and Arias, 2004). In contrast to this theory, Abraído-Lanza et al. (1999) described this as the Hispanic mortality paradox, which cannot be explained by the "salmon or healthy migration hypothesis."

Therefore, states with a higher percentage of Hispanic inhabitants have declining death rate. Liu and Johnson, 2009; Johnson et al., 2000 and Gove, 1973 presented reasons behind the negative relation of the mortality rate with marital status in their studies, which looks into the reasons behind this inverse association. They explained that increased social support, social integration, self-regulation, network, reduction in stress, anxiety, and pressure provided the married people with a higher life expectancy and a better and healthier lifestyle in comparison with the rest of the population.

College education leads to a clearly observable decline in the mortality rate. Higher education level provides people with greater income and better work environment, more access to information on health care, higher utilization of health resource facilities, more preventive care, and advanced socio-economic status (Hummer and Hernandez, 2013; Muney, 2004). All of these factors contribute to a reduction in the mortality rate. 
The percentage African-American population has a positive relationship with the mortality rate. As a group, African-Americans have a lower life expectancy when compared to other racial groups because of the low percentage of "health care access, type or quality of medical care, behavioral risk factors" (Sorlie et al., 1992), the higher rate of chronic diseases, the high rate of un-insurance with a low rate of public insurance coverage, greater social disadvantages, low income level, and unhealthy living environment. It is also evident that with age, people fall sick, more often and have more health issues due to their deteriorating physical conditions as they are frail and weak and more susceptible to diseases, leading to a rise in the mortality rate. Finally, increase in the percentage of population above age 65 also increases mortality rate of the state.

The cumulative indirect effects explain the changes in all the neighboring states' mortality rate due to changes in independent variables of own state. The higher ratio of Hispanic population in state i drives the mortality rate upward for the neighboring states. The increase in education level in a given state has a positive spillover on neighboring states, driving their mortality rate downwards. As state i has increased economic affluence (by reduction in income disparity) and knowledge gain (higher education), the adjacent states will also have benefits from their spillover effects, which will lead to a slower death rate in these states too.

Finally the total effect in Table 24, which is the sum of direct and indirect effects, is positively significant for the interaction term of hospitals and beds and is negatively significant for education level. 


\section{CONCLUSION AND POLICY IMPLICATIONS}

\section{Summary}

This paper using the Spatial Durbin panel model (spatial and time both included), examined the socio-economic, health infrastructure and political impact on the mortality rate of the states of the U.S. for a period of 10 years (2000 to 2009). This study not only captures the variation in the mortality rate of own state but also the variation in the neighboring states' mortality rate. The net significant positive spatial dependence of the mortality rate on its neighboring states suggests that policy decisions, implementation, social profile, economic resources, health care services and access, crime rates, educational level and marital status of a state not only impacts the mortality rate of an individual state but they also impact the neighboring states in a similar manner.

This research represents an improvement from that of Yang et al. (2015). This study captures both the spatial and time period effect of the variables for state-level analysis. With evidence of variation of the mortality rate at the regional and national levels and knowing that health policies and general fund distribution decisions across the economic sectors are taken at the state level, it is important to analyze the causes of variation in the mortality rate at the state level. As defined by Manski (1993), the spatial dependence across the states mortality rate is explained by the exogenous effect and the correlated effect among the states. Holod and Reed's (2004) theory of "spillovers of knowledge, human capital, and economic growth" that helps in economic development and economic integration also justifies this positive association or spatial interaction of the variable of interest of this study.

This paper reports that demographic features such as African-American and the elderly population significantly increase the mortality rate of a state, while Hispanic population reduces 
it. The indirect effect of the rise in Hispanic population in a state increases the mortality rate of the neighboring states' (outmigration, relative aspect). An increase in health supply factors such as the number of active physicians provides better health care services and access to specialized treatments, thereby reducing the mortality rate of own state. Further, rise in the interaction term of hospitals and beds of individual state leads to rise in the mortality rate of the neighbors. Changes in social characteristics such as rise in education level slow down the death rate of not only one's own state, but also of its neighbors by the positive spillover effect of knowledge. Additionally, rise in the proportion of married population of a state has an inverse effect on the mortality rate, thereby displaying that social-interaction, social-engagement, self-regulation, networking decrease in stress, tension, depression, etc. help in reducing the mortality rate of a state.

\section{Policy implications}

This study has successfully captured the demographic profiles, economic factors and healthcare supply factors that explained the US state-level variations mortality rates. These study findings have significant policy implications for the local legislatures and state representatives.

The study findings have highlighted the narrow vision of existing policies that focus only on health sector. It has shown in Table 25 that increasing healthcare/hospital expenditures have no influence or association with mortality rate (ineffective on healthcare outcomes). This analysis is of much importance as this result confirms that the prevailing insignificant relation existing at the national level between healthcare expenditures and healthcare outcomes (Nolte and McKee, 2012; Squires, 2012, Fischer et al., 2003) prevails at the state level too. Hence it establishes the fact that neither at national level nor at the state level, higher healthcare spending helps in achieving better quality of care. 
Thus it implies that reforming health sector just by increasing healthcare spending may not be the answer to improve healthcare outcomes such as survival. Health policies should also consider economic and social determinants to improve health outcomes. Changes in social norms by denormalization/stigmatization (eliminate or change health behaviors which were considered acceptable or desirable to reduce or eradicate resistance towards health policies) and increasing networks should be the goal to enact health policy successfully.

Social capital is one of the prime factors to invest on to enhance population health. Health polices including efforts to strengthen and encourage civic involvement and society engagement among residents will facilitate population health (Healthy people, 2020). Social stability, support, social integration, self-regulation, network, reduction in stress, anxiety, and pressure provides married people with a higher life expectancy and a better and healthier lifestyle in comparison with the rest of the population as it helps in enhancing trust and creating better social capital thereby improving health outcomes (Yang, 2011; Liu and Johnson, 2009; Johnson et al., 2000 and Gove, 1973).

Findings from this study with regard to education echo findings from prior studies in the literature For example, there is ample evidence on the causal relationship between education and mortality (Hummer and Hernandez, 2013; Muney, 2004, Sorlie et al., 1995). Education provides access to higher income levels and different types of jobs, both of which affect health (Muney, 2004). Grossman (2005) also stated that "years of formal schooling completed is the most important correlate of good health". Therefore, investing in education level can have a significant influence on population health outcomes (Healthy people 2020). As advancing health structure and improving health outcomes of one state will improve the health outcomes of the adjoining states (Spatial spillover), therefore joint programs of neighboring states to support 
healthy lifestyle and prevention programs would succeed achieving higher quality of living of all individuals and thereby reduce the mortality rate.

It is also important to look into the theory explaining the lower mortality rate of Hispanics compared to non-Hispanics despite of being in the lower income level or having higher poverty level. One theory of explanation behind this might be the "foreign-born advantage" that the migrated population has, also known as the "salmon-bias" effect (Palloni and Arias, 2004). In contrast to this theory, Abraído-Lanza et al. (1999) described this as the Hispanic paradox, which cannot be explained by the "salmon or healthy migration hypothesis." Understanding the Hispanic paradox (health advantage and behaviors) and integrating it into health reform policy would help in lowering the mortality rate for all population groups. Social networks, stronger family bond, active community involvement, family structure, love and faith might be some of the reasons behind this paradox. 


\section{REFERENCES}

Abraido-Lanza, A.F., B. P. Dohrenwend, D. S. Ng-Mak, and J. B. Turner. 1999. The Latino mortality paradox: a test of the "salmon bias" and healthy migrant hypotheses. American Journal of Public Health.89 (10); 1543-1548.

Ali, H. M., S.M. James, F.S. Donna and G. Julie. 2004. Actual Causes of Death in the United States, 2000, American Medical Association, 291:10.

Anselin, L. 1988. Spatial Econometrics: Methods and Models. Kluwer Academic Publishers, Dordrecht.

Anselin, L., J. Le Gallo, and H. Jayet 2008. Spatial Panel Econometrics. In The econometrics of panel data, fundamentals and recent developments in theory and practice, third edition, eds. L.Matyas and P. Sevestre, Kluwer Academic Publishers, Dordrecht.

Arialdi, M. M. 2009. Death in the United States, 2009, Division of Vital Statistics. U.S. Department Of Health And Human Services Centers for Disease Control and Prevention National Center for Health Statistics, 64.

Backlund, E., P. Sorlie, C. Loveless and N. J Johnson. 2004. Marital Status and Mortality the National Longitudinal Mortality Study, Annals of Epidemiology, 10(4), 224-238.

Baicker K and A. Chandra. 2004. Medicare spending, the physician workforce, and beneficiaries' quality of care. Health Affairs;W4:184-97.

Baltagi, B.H. 2005. Econometric analysis of panel data, 3rd edition. Chichester, UK: Wiley.

Bugni, A. 2012. Comments on Manski (1993) Lunch group on Social Interactions, Duke University.

Case, A. and C. Paxson. 2004. Sex Differences in Morbidity and Mortality. Center for Health and Wellbeing Princeton University.

Centers for Disease Control and Prevention, National Center for Health Statistics. 2014.

Compressed Mortality File, 1999-2011 On CDC Wonder Online Database.

Http://Wonder.Cdc.Gov/Cmf-Icd10.Html. Accessed on September 1, 2014, 1:50:30 AM.

Centers for Medicare and Medicaid Services. 2011. Health Expenditures by State of Residence. http://www.cms.gov/NationalHealthExpendData/downloads/resident-state-estimates.zip. Accessed on August 15th, 2014. 
Centers for Medicare and Medicaid Services: http://www.cms.gov/Research-Statistics- Dataand-Systems/Statistics-Trends-and-Reports/NationalHealthExpendData/Downloads/restables.pdf. Accessed on July 2nd 2014.

Chang, M.H., Molla, B.I. Truman, H. Athar, R. Moonesinghe, P.W. Yoon. 2014. Differences in healthy life expectancy for the US population by sex, race/ethnicity and geographic region: 2008. Journal of Public Health (Oxford).

Chen, V.Y.J., W.S. Deng, T.C. Yang and S.A. Mathews. 2012. Geographically weighted quantile regression (GWQR): An application to U.S. mortality data. Geographical Analysis; 44(2):134-150.

Cossman, J.S., R.E. Cossman, W.L. James, C.R. Campbell, T.C. Blanchard, A.G. Cosby. 2007. Persistent clusters of mortality in the United States. American Journal of Public Health 97(12): 2148-2150.

Daly, M.C., G.J. Duncan, G.A. Kaplan, J.W. Lynch. 1998. Macro-to-micro links in the relation between income inequality and mortality. The Milbank Quarterly; 76(3): 315-339.

Daly, M. and G. Duncan. 1998. Income Inequality and Mortality Risk in the United States: Is There a Link? Federal Reserve Bank of San Francisco, Economic letters. 29.

Daw, R.H. 1961. The Comparison of Male and Female Mortality Rates Author(s): Source: Journal of the Royal Statistical Society; 124; 1:20-43.

Deaton, A. 2003. Health, Income, and Inequality NBER Reporter: Research Summary.

Diez-Roux, A.V., T. Franklin , M. Alazraqui and H. Spinelli. 2007. Intraurban Variations in Adult Mortality in a Large Latin American City. Journal of Urban Health; 84: 319-333.

Dominguez, K., A. Penman-Aguilar, M.-H. Chang, R. Moonesinghe, T. Castellanos, A. R. Lainz and R. Schieber. 2015. Vital Signs: Leading Causes of Death, Prevalence of Diseases and Risk Factors, and Use of Health Services Among Hispanics in the United States. 20092013. Morbidity and Mortality Weekly Report. 64(17);469-478. http://www.cdc.gov/mmwr.

Dmytro, H. and R. R. Reed. 2004. Regional spillovers, economic growth, and the effects of economic integration; 85(1); 35-42.

Dunn J.R., B. Burgess and N.A. Ross. 2005. Income Distribution, Public Services Expenditures, and All-Cause Mortality in U.S. States. Journal of Epidemiology and Community Health; 59(9):768-774. 
Elhorst, J.P. 2014. Matlab Software for Spatial Panels .International Regional Science Review; 37(3):389-405.

Erwin P.C., G. P. Mays and W. J. Riley. 2012. Resources That May Matter: The Impact of Local Health Department Expenditures on Health Status. Public Health Rep; 127(1): 89-95.

ESRI Developer Network. How Spatial Autocorrelation: Moran's I (Spatial Statistics) works.http://edndoc.esri.com/arcobjects/9.2/net/shared/geoprocessing/spatial_statistics_to ols/how_spatial_autocorrelation_colon_moran_s_i_spatial_statistics_works.htm.

Fisher, E.S., D.E. Wennberg, T.A. Stukel, D.J. Gottlieb, F.L. Lucas, E.L. Pinder. 2003.The implications of regional variations in Medicare spending. Part 1: the content, quality, and accessibility of care. Annals of Internal Medicine.18; 138(4):273-87.

Fisher, E.S., D.E. Wennberg, T.A. Stukel, D.J. Gottlieb, F.L. Lucas, E.L. Pinder. 2003. The implications of regional variations in Medicare spending. Part 2: health outcomes and satisfaction with care. Annals of Internal Medicine; 138:288-98.

Fisher, E.S., D.E. Wennberg, T.A.Stukel and D.J. Gottlieb. 2004. Variations in the longitudinal efficiency of academic medical centers. Health; Suppl Variation: 19-32.

Gove, W. R. 1973. Sex, Marital Status, and Mortality American Journal of Sociology.79 (1); 4567.

Grossman, M. 2005. Education and Non-market Outcomes. NBER Working Paper 11582, Cambridge, MA.

Healthy People 2020. http://www.healthypeople.gov/. Accessed on April 26th, 2015.

Hummer, R., M. Elaine and Z. Hernande. 2013. The Effect of Educational Attainment on Adult Mortality in the United States. Population Bulletin. Population Reference Bureau; 68 (1).

Johnson, N.J., E. Backlund, P.D. Sorlie and C.A. Loveless. 2000. Marital status and mortality: the national longitudinal mortality study. Annual Epidemiology. 10(4):224-38.

James, W.L. and J.R. Porter. 2012. Inequality, health infrastructure, and spatial context: Understanding pathways to variations in the causal determinants of race-specific mortality rates. Sociological Spectrum.32 (4): 322-345.

Kawachi, K., B P Kennedy, K Lochner, and D. Prothrow-Stith. 1997. Social capital, income inequality, and mortality Am J Public Health; 87(9): 1491-1498. 
LeClere, F.B., R.G. Rogers and K. Peters. 1998. Neighborhood social context and racial differences in women's heart disease mortality. Journal of Health Social Behavior; 39:91-107.

LeClere, F.B., R.G. Rogers and K.D. Peters. 1997. Ethnicity and Mortality in the United States: Individual and Community Correlates. Social Forces; 76:169-198.

LeSage, J. and Pace, P. 2009. Introduction to Spatial Econometrics. CRC Press, Boca Raton. Liu, H. and D. Johnson. 2009. Till Death Do Us Part: Marital Status and U.S. Mortality Trends, 1986-2000.Journal of Marriage and Family; 71(50); 1158-1173.

Lundberg, J. 2011. On the definition of W in empirical models of yardstick competition, Department of Economics, Umea University, Sweden.

Mansfield, C.J., J.L.Wilson, E.J. Kobrinski and J. Mitchell. 1999. Premature mortality in the United States: the roles of geographic area, socioeconomic status, household type, and availability of medical care. American Journal of Public Health 89(6): 893-898.

Manski, C.F. 1993. Identification of Endogenous Social Effects: The Reflection Problem. Review of Economic Studies, 60(1):531-542.

Manton, K.G., C. Patrick and K. Johnson. 1987. Health Differentials between Blacks and Whites: Recent Trends in Mortality and Morbidity. Milbank Q; 65:129-199.

Mays, G.P. and S.A. Smith. Evidence links increases in public health spending to declines in preventable deaths. Health Affairs; 30:1585-93.

Mclaughlin, D.K. and Stokes, C.S. 2002. Income Inequality And Mortality In US Counties: Does Minority Racial Concentration Matter? American Journal of Public Health; 92(1):99104.

Mclaughlin, D.K., Stokes, C.S. and Nonoyama A. 2001. Residence and Income Inequality: Effects on Mortality among US Counties. Rural Sociology; 66: 579- 598.

Mclaughlin, D.K., C.S. Stokes, P.J. Smith and A. Nonoyama. 2007. Differential Mortality across the United States: The Influence of Place-Based Inequality. In The Sociology of Spatial Inequality. State University of New York Press: Albany, NY: 141-162.

Menchick, P.L. 1993. Economic Status As A Determinant Of Mortality Among Black And White Older Men: Does Poverty Kill? Population Studies. 47:427-436.

Moran, P.A.P .1950. Notes on Continuous Stochastic Phenomena, Biometrika, 37 (1): 17-23. 
Mokdad, A.H., J.S. Marks, D.F. Stroup, J.L.Gerberding. 2000. Actual causes of death in the United States. The Journal of the American Medical Association; 291(10):1238-45. Muney, A.L. 2004. The Relationship between Education and Adult Mortality in the United States. http://www.econ.ucla.edu/alleras/research/papers/mortalityrevision2.pdf.

National Center for Health Statistics, National Vital Statistics Reports. www.cdc.gov/nchs. National Health Expenditure Projections 2012-2022http://www.cms.gov/Research-StatisticsData-and-Systems/Statistics-Trends-andReports/NationalHealthExpendData/downloads/proj2012.pdf.

Nolte, E. and C.M. McKee. 2012. In Amenable Mortality—Deaths Avoidable Through Health Care-Progress In The US Lags That Of Three European Countries. Health Affairs. doi: 10.1377/hlthaff.2011.0851.

Organisation for Economic Co-operation and Development. 2013. Health at a Glance 2013: OECD Indicators, OECD Publishing.

Palloni, A. and E. Arias. 2004. Paradox lost: Explaining the Hispanic adult mortality advantage. Demography. 41(3): 385-415.

Sorlie, P., E. Rogot, R. Anderson, N.J. Johnson and E. Backlund.1992. Black-White Mortality Differences by Family Income. Epidemiology. The Lancet. 340(8815); 346-350.

Skinner, J., A. Chandra, D. Goodman, and E. S. Fisher. 2009. The Elusive Connection between Health Care Spending and Quality. Health Affairs; 28(1): 119-123.

Shi, L., Starfield B. 2001. The effect of primary care physician supply and income inequality on mortality among blacks and whites in US metropolitan areas. Am J Public Health; 91(8):1246-50.

Sorlie, P., Backlund, E. Keller and B. Jacob. 1995.US mortality by economic, demographic, and social characteristics: The National Longitudinal Mortality Study. American Journal of Public Health 85(7): 949-56.

Sparks, J. and C.S. Sparks. 2009. An Application of Spatially Autoregressive Models To the Study of US County Mortality Rates Patrice Department of Demography and Organization Studies, University of Texas at San Antonio, Population, Space and Place Population. doi: 10.1002/psp.56. 
Squires DA. Explaining High Health Care Spending in the United States: An International Comparison of Supply, Utilization, Prices, and Quality. The Commonwealth Fund. May 2012.

Starfield, B., L. Shi, A. Grover, and J. Macinko. 2005. "The Effects of Specialist Supply on Populations' Health: Assessing the Evidence." Cancer 103:20.93-23.18. United Census Bureau, U.S. Department of Commerce, 2000-2009. Washington, DC. Accessed on November 2nd, 2013. http://www.census.gov/.

Williams, D.R. and C. Collins. 1995.US Socioeconomic and Racial Differences in Health: Patterns and Explanations. Annul Rev Social; 21:349-386.

Woolf, S.H. and L. Aron. 2013. U.S. Health in International Perspective: Shorter Lives, Poorer Health, Editors, National Research Council and Institute of Medicine, National Academic press, Washington, D.C.

Yang, T.C., L. Jensen and M. Haran. 2011. Social Capital and Human Mortality: Explaining the Rural Paradox with County-Level Mortality Data. Rural Sociology 76(3): 347-374.

Yang, T.C., A.J. Noah and C. Shoff. 2015. Exploring Geographic Variation in Us Mortality Rates Using a Spatial Durbin Approach. Population, Space and Place; 21:18 -37.

Yang, T.C., Y. J. Chen, V. Shoff and S.A. Matthews. 2012. Using quantile regression to examine the effects of inequality across the mortality distribution in the US counties. Social Science and Medicine 74(12): 1900-1910.

Zhao, X., J.W. Burnett and J.J. Fletcher. 2014. Spatial Analysis of China province-level CO2 emission intensity. Renewable and Sustainable Energy Reviews, 22:1-10. 
Figure 4: Variation of mortality rate across the states of the U.S. in the year 2009

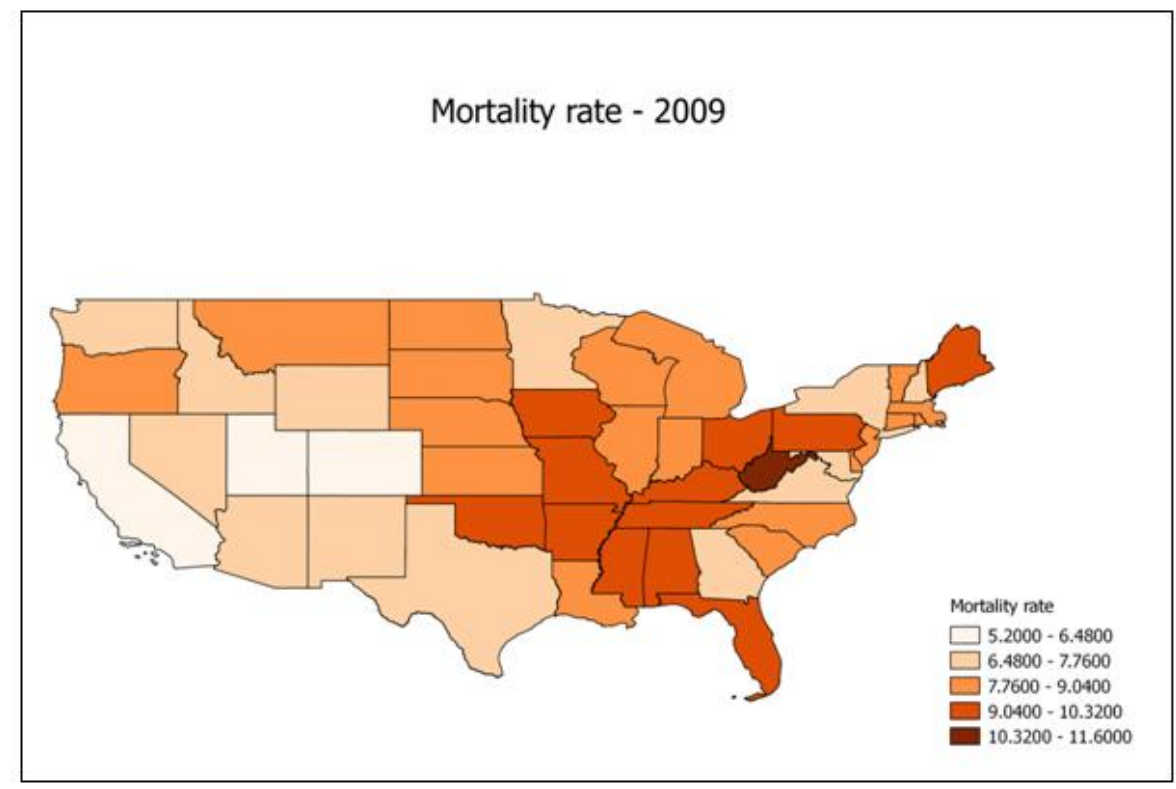


Figure 5: Moran's I index scatter plot reporting positive autocorrelation of mortality rate

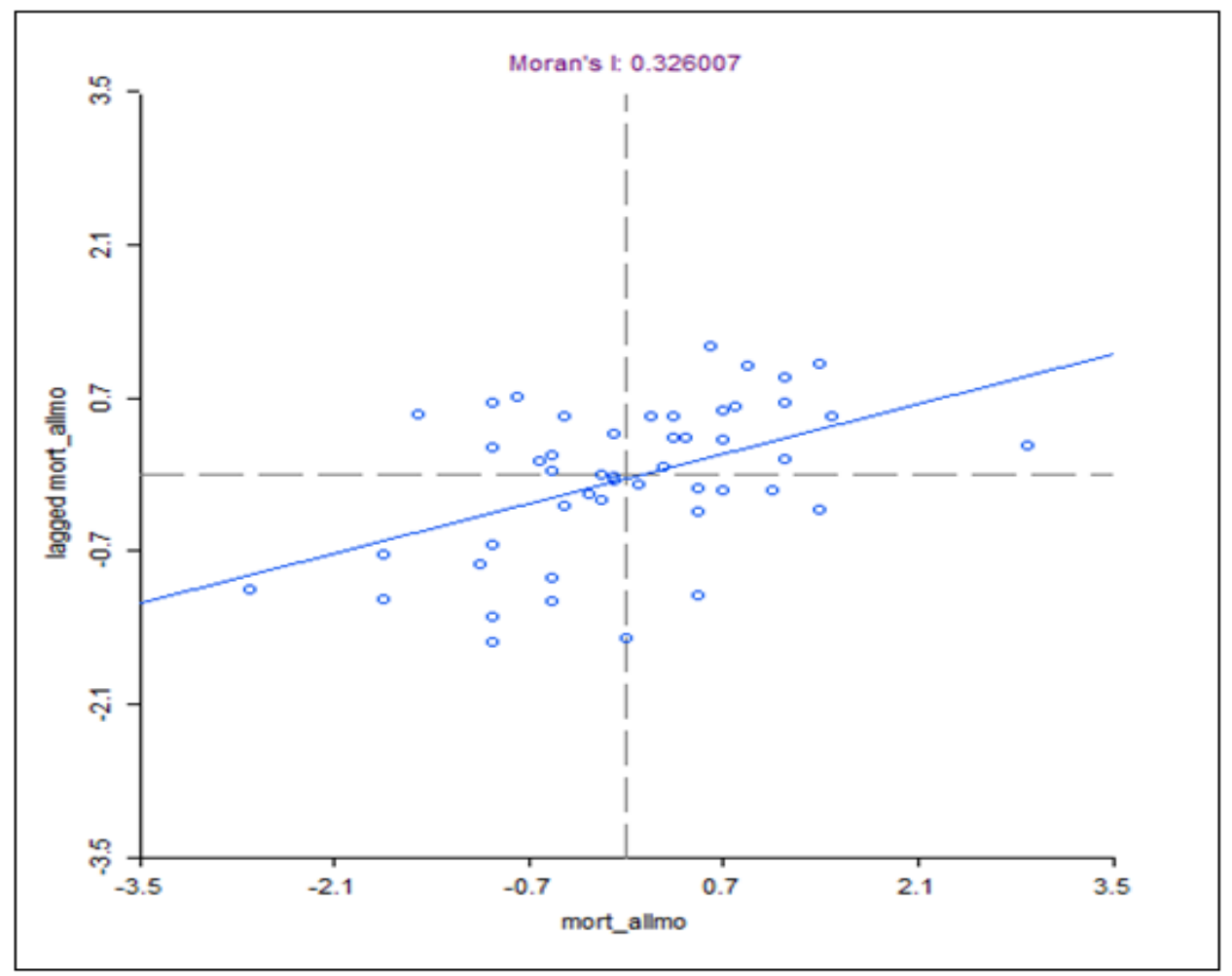


Table 17: Definition of Variables

\begin{tabular}{|l|l|c|}
\hline Dependent Variables & \multicolumn{1}{|c|}{ Definition } & $\begin{array}{c}\text { Expected sign } \\
\text { of coefficients }\end{array}$ \\
\hline MORTALITY & Mortality rate of a state & \\
\hline Independent Variables & & \\
\hline HOSP & Percentage of hospital expenditure to the total health care expenditure & Ambiguous \\
\hline Log HCE & Health care expenditure of a state & Ambiguous \\
\hline UNINS & Proportion of the population without insurance & + \\
\hline ACTIVE & Number of active physician per 100,000 population & - \\
\hline Log INCOME & Median income of a state & - \\
\hline POVERTY & Poverty rate & + \\
\hline AGE65 & Proportion of the population above age 65 & + \\
\hline RACE & Percentage of African-American population & + \\
\hline GENDER & Percentage of male population & + \\
\hline EMPLOYMENT & Employment rate & + \\
\hline MARRIED & Percentage of Married population in a state & - \\
\hline HISPANIC & Proportion of population with Hispanic Origin & - \\
\hline TOTHOS & Total number of community hospitals in the State & - \\
\hline HOSPBED & Hospital beds per 1000 population & + \\
\hline GINI & Gini Coefficient & - \\
\hline COLLEGE ABOVE & Percentage of population with bachelor's degree and above & + \\
\hline PROP CRIME & Rate of property crime per 100,000 population & + \\
\hline VIOLENT CRIME & Rate of violent crime per 100,000 population & - \\
\hline VOTED & Percentage of people voted in the election & + \\
\hline TOBACCO & Percentage of population that uses tobacco & + \\
\hline ALCOHOL & Percentage of population consumes alcohol & + \\
\hline DRUG & Percentage of population uses drugs & \\
\hline ** Log INCOME and Log HCE are in real terms as they have been deflated by the consumer price index (CPI) for \\
each state for 2009/ CPI value of the respective state and year)
\end{tabular}


Table 18: Summary Statistics of the Dependent and Independent Variables: 2000-2009

\begin{tabular}{|l|c|l|c|c|c|}
\hline Variables & Unit & Mean & Standard Deviation & Minimum & Maximum \\
\hline Mortality rate & $\%$ & 8.59 & 1.154 & 5.2 & 11.8 \\
\hline Percentage of Hospital Expenditures & $\%$ & 36.910 & 3.453 & 29.111 & 49.528 \\
\hline Log of per capita Health Expenditures & Unit & 8.615 & 0.2136 & 8.016 & 9.244 \\
\hline Uninsured rate & $\%$ & 13.553 & 3.901 & 4.4 & 26.1 \\
\hline Active physician per 100,000 population & Unit & 265.344 & 95.886 & 154 & 852 \\
\hline Poverty rate & $\%$ & 12.109 & 3.193 & 4.5 & 23.1 \\
\hline Percentage of Male population & $\%$ & 49.207 & 0.722 & 47.044 & 51.013 \\
\hline Percentage of African-American population & $\%$ & 11.639 & 11.595 & 0.311 & 61.106 \\
\hline Percentage of Hispanic population & $\%$ & 9.089 & 9.470 & 0.679 & 45.566 \\
\hline Gini coefficient & Unit & 0.446 & 0.023 & 0.391 & 0.545 \\
\hline Violent Crime rate per 100,000 population & $\%$ & 427.854 & 230.109 & 78.3 & 1608.4 \\
\hline Property Crime rate per 100,000 population & $\%$ & 3361.585 & 846.987 & 1606.05 & 6293.64 \\
\hline Percentage of Married Population & $\%$ & 60.427 & 5.0692 & 29.1 & 69.4 \\
\hline Percentage of population with Bachelor's degree or above & $\%$ & 31.306 & 6.339 & 15.9 & 62.2 \\
\hline Total Hospitals & Unit & 99.794 & 79.841 & 5 & 428 \\
\hline Hospital beds per 1000 population & $\%$ & 3.042 & 1.0083 & 1.7 & 6.2 \\
\hline Log Income & Unit & 11.039 & 0.1952 & 10.513 & 11.559 \\
\hline Percentage of population aged 65 and above & $\%$ & 12.77 & 1.538 & 8.5 & 17.6 \\
\hline Employment rate & $\%$ & 57.585 & 12.448 & 32.803 & 82.28 \\
\hline Percentage of people voted in election & $\%$ & 58.921 & 7.767 & 36.7 & 76.7 \\
\hline Drug & $\%$ & 3.508 & 0.656 & 1.800 & 5.900 \\
\hline Tobacco & $\%$ & 25.352 & 2.984 & 15.300 & 34.800 \\
\hline Alcohol & $\%$ & 50.402 & 7.668 & 27.820 & 63.950 \\
\hline
\end{tabular}


Table 19: Lagrange Multiplier Test Results for Non-Spatial Models (without \% of Hospital Expenditures or Total Healthcare Expenditures

\begin{tabular}{|l|l|l|l|l|}
\hline & Pooled OLS & $\begin{array}{l}\text { Spatial Fixed } \\
\text { effects }\end{array}$ & $\begin{array}{l}\text { Time period } \\
\text { Fixed } \\
\text { effects }\end{array}$ & $\begin{array}{l}\text { Spatial and Time } \\
\text { period Fixed } \\
\text { effects }\end{array}$ \\
\hline LM test spatial lag & $3.076 *$ & $144.936^{* * *}$ & $3.187 *$ & $46.6873 * * *$ \\
\hline Robust LM test spatial lag & 0.355 & $14.733^{* * *}$ & 0.002 & 1.9236 \\
\hline LM test spatial error & $6.441^{* *}$ & $145.243^{* * *}$ & $3.654 *$ & $51.318^{* * *}$ \\
\hline Robust LM test spatial error & $3.720^{* *}$ & $15.041^{* * *}$ & 0.4702 & $6.5543 * *$ \\
\hline
\end{tabular}

The symbols $* * *, * *$ and $*$ represent one, five and ten percent significance level. 
Table 20: Likelihood Ratio Test Results

\begin{tabular}{|l|l|}
\hline Likelihood Raito test for joint significance of spatial fixed effects (degrees of freedom) & $975.7539 * * *(49)$ \\
\hline
\end{tabular}

\begin{tabular}{|l|l}
\hline Likelihood Raito test for joint significance of time period fixed effects(degrees of freedom) & $132.528 * * *(10)$
\end{tabular}

The symbols $* * *, * *$ and $*$ represent one, five and ten percent significance level. 
Table 21: Wald Tests, Likelihood Ratio Tests and Hausman Specification Test Results

\begin{tabular}{|l|l|l|l|l|l|}
\hline & $\begin{array}{l}\text { Wald Test(SAR vs. } \\
\text { SDM) }\end{array}$ & $\begin{array}{l}\text { LR test(SAR vs. } \\
\text { SDM })\end{array}$ & $\begin{array}{l}\text { Wald Test(SEM } \\
\text { vs. SDM) }\end{array}$ & $\begin{array}{l}\text { LR test(SAR } \\
\text { vs. SDM) }\end{array}$ & $\begin{array}{l}\text { Hausman } \\
\text { Specification Test }\end{array}$ \\
\hline Value & $47.0978 * * *$ & $44.4591 * * *$ & $40.8708 * * *$ & $36.027 * *$ & $71.8904 * * *$ \\
\hline d.f. & 19 & 19 & 19 & 19 & 39 \\
\hline
\end{tabular}

The symbols ***, ** and * represent one, five and ten percent significance level. 
Table 22: Estimation Results of Spatial Panel Data Models (SAR and SEM)

\begin{tabular}{|l|l|l|l|l|}
\hline & \multicolumn{3}{l}{ SAR } & \multicolumn{2}{l|}{ SEM } \\
\hline Variable & Coefficient & T statistics & Coefficient & T statistics \\
\hline Active physician per 100,000 population & -0.0008 & -1.4867 & $-0.0009^{*}$ & -1.7913 \\
\hline Hospital bed * Hospitals per 1000 population & -0.2817 & -0.8356 & -0.2709 & -0.8694 \\
\hline Log Income & 0.0043 & 0.0450 & 0.0080 & 0.0899 \\
\hline Poverty rate & -0.0079 & -0.8961 & -0.0115 & -1.3832 \\
\hline Percentage of African-American population & $0.1276^{* * *}$ & 7.4856 & $0.1224^{* * *}$ & 8.0778 \\
\hline Percentage of Hispanic population & $-0.0642^{* * *}$ & -4.2922 & $-0.0717^{* * *}$ & -4.5267 \\
\hline Percentage of Male population & 0.1754 & 1.4558 & 0.1774 & 1.5868 \\
\hline Percentage of population aged 65 and above & $0.3427^{* * *}$ & 9.8719 & $0.3501^{* * *}$ & 10.7869 \\
\hline Uninsured rate & -0.0003 & -0.0687 & 0.0015 & 0.3446 \\
\hline Gini coefficient & 0.0021 & 0.1947 & -0.0004 & -0.0399 \\
\hline Percentage of Married Population & $-0.0077^{*}$ & -1.7295 & $-0.008^{*}$ & -1.7437 \\
\hline Violent Crime rate per 100,000 population & 0.0000 & -1.0207 & 0.0000 & -0.8128 \\
\hline Property Crime rate per 100,000 population & 0.0003 & 1.6319 & 0.0003 & 1.4009 \\
\hline Percentage of population with Bachelor's degree or above & $-0.0090^{* *}$ & -1.9581 & $-0.0076^{*}$ & -1.8085 \\
\hline Employment rate & 0.0050 & 1.2831 & 0.0039 & 1.0583 \\
\hline Percentage of people voted in election & -0.0016 & -0.8637 & -0.0009 & -0.5100 \\
\hline Tobacco & 0.0006 & 0.1419 & 0.0002 & 0.0578 \\
\hline Drug & 0.0010 & 0.1125 & 0.0041 & 0.5341 \\
\hline Alcohol & 0.0078 & 0.7294 & 0.0042 & 0.4390 \\
\hline$\lambda$ & $0.3659 * * *$ & 7.2283 & & \\
\hline H & & & $0.4350^{* * *}$ & 7.9889 \\
\hline R square & 0.991 & & 0.990 & \\
\hline Sigma square & 0.013 & & 0.435 & \\
\hline Log likelihood & 394.616 & & 398.832 & \\
\hline N observations & 490 & & 490 & \\
\hline
\end{tabular}

The symbols $* * *, * *$ and $*$ represent one, five and ten percent significance level. 
Table 23: Spatial Durbin Fixed Effect Model Results

\begin{tabular}{|l|l|l|}
\hline Variable & Coefficient & T statistics \\
\hline Active physician per 100,000 population & $-0.0010^{*}$ & -1.8217 \\
\hline Hospital bed * Hospitals per 1000 population & 0.1099 & 0.3374 \\
\hline Log Income & -0.0423 & -0.4653 \\
\hline Poverty rate & -0.0128 & -1.4953 \\
\hline Percentage of African-American population & $0.1241^{* * *}$ & 7.1915 \\
\hline Percentage of Hispanic population & $-0.0761^{* * *}$ & -4.1637 \\
\hline Percentage of Male population & 0.1800 & 1.5513 \\
\hline Percentage of population aged 65 and above & $0.3290^{* * *}$ & 9.1383 \\
\hline Uninsured rate & 0.0032 & 0.7299 \\
\hline Gini coefficient & 0.0046 & 0.4523 \\
\hline Percentage of Married Population & $-0.0073^{*}$ & -1.7256 \\
\hline Violent Crime per 100,000 population & 0.0000 & -0.3275 \\
\hline Property Crime per 100,000 population & 0.0003 & 1.2721 \\
\hline Percentage of population with Bachelor's degree or above & $-0.0105^{* *}$ & -2.4520 \\
\hline Employment rate & $0.0066^{*}$ & 1.7308 \\
\hline Percentage of people voted in election & -0.0011 & -0.6054 \\
\hline Tobacco & 0.0005 & 0.1193 \\
\hline Drug & 0.0014 & 0.1753 \\
\hline Alcohol & 0.0071 & 0.7227 \\
\hline W*Active physician per 100,000 population & 0.0009 & 0.7638 \\
\hline W*Hospital bed * Hospitals per 1000 population & $1.9433^{* *}$ & 2.2032 \\
\hline W*Log Income & -0.2964 & -1.5372 \\
\hline W*Poverty rate & 0.0218 & 1.1592 \\
\hline W*African-American & -0.0501 & -1.1683 \\
\hline W*Hispanic & $0.1091^{* *}$ & 2.9045 \\
\hline W*Male & -0.1234 & -0.4189 \\
\hline W*Percentage of population aged 65 and above & $-0.2159^{* *}$ & -2.5146 \\
\hline W*Uninsured rate & -0.0119 & -1.1035 \\
\hline W*Gini coefficient & 0.0325 & 1.3521 \\
\hline W*Percentage of Married Population & -0.0058 & -0.5013 \\
\hline W*Violent Crime per 100,000 population & 0.0000 & 0.0477 \\
\hline W*Property Crime per 100,000 population & 0.0004 & 0.8326 \\
\hline W*Percentage of population with Bachelor's degree or above & -0.0162 & -1.4901 \\
\hline W*Employment rate & 0.0078 & 0.9155 \\
\hline W*Percentage of people voted in election & -0.0049 & -1.1070 \\
\hline W*Tobacco & 0.0032 & 0.3744 \\
\hline W*Drug & 0.0293 & 1.4518 \\
\hline W*Alcohol & 0.0403 & 1.4225 \\
\hline$\lambda$ & $0.2850^{* * *}$ & 4.6732 \\
\hline & & \\
\hline
\end{tabular}




\begin{tabular}{|l|l|l|}
\hline $\mathrm{R}^{2}$ & 0.9921 & \\
\hline$\sigma^{2}$ & 0.5166 & \\
\hline Log likelihood & 416.845 & \\
\hline Number of observation & 490 & \\
\hline
\end{tabular}

The symbols $* * *, * *$ and $*$ represent one, five and ten percent significance level. T-test values are specified in the column after the coefficient values of each model. 
Table 24: Direct, Indirect and Total Effect Results of the Spatial Durbin Fixed Effect Model

\begin{tabular}{|l|l|l|l|l|l|l|}
\hline Variable & $\begin{array}{l}\text { Direct } \\
\text { Coefficient }\end{array}$ & $\begin{array}{l}\text { Indirect } \\
\text { statistics }\end{array}$ & Coefficient & $\begin{array}{l}\text { T } \\
\text { statistics }\end{array}$ & $\begin{array}{l}\text { Total } \\
\text { Coefficient }\end{array}$ & $\begin{array}{l}\text { T } \\
\text { statistics }\end{array}$ \\
\hline Active physician per 100,000 population & $-0.0009^{*}$ & -1.7245 & 0.0009 & 0.5789 & 0.0000 & 0.0108 \\
\hline Hospital bed * Hospitals per 1000 population & 0.2051 & 0.6307 & $2.6390^{* *}$ & 2.1617 & $2.8441^{* *}$ & 2.1158 \\
\hline Log Income & -0.0587 & -0.6508 & -0.4349 & -1.6279 & -0.4935 & -1.6385 \\
\hline Poverty rate & -0.0117 & -1.3352 & 0.0234 & 0.9141 & 0.0116 & 0.4058 \\
\hline Percentage of African-American population & $0.1240^{* * *}$ & 6.7583 & -0.0177 & -0.3165 & 0.1063 & 1.5903 \\
\hline Percentage of Hispanic population & $-0.0713^{* * *}$ & -4.0180 & $0.1214^{* *}$ & 2.5357 & 0.0501 & 1.0860 \\
\hline Percentage of Male population & 0.1749 & 1.4953 & -0.0947 & -0.2389 & 0.0802 & 0.1807 \\
\hline Percentage of population aged 65 and above & $0.3210^{* * *}$ & 9.1045 & -0.1695 & -1.4225 & 0.1515 & 1.1273 \\
\hline Uninsured rate & 0.0027 & 0.5809 & -0.0151 & -1.0265 & -0.0124 & -0.7476 \\
\hline Gini coefficient & 0.0066 & 0.6472 & 0.0447 & 1.3091 & 0.0513 & 1.3307 \\
\hline Percentage of Married Population & $-0.0076 *$ & -1.7273 & -0.0103 & -0.6392 & -0.0179 & -0.9629 \\
\hline Violent Crime per 100,000 population & 0.0000 & -0.3074 & 0.0000 & 0.0407 & 0.0000 & -0.0752 \\
\hline Property Crime per 100,000 population & 0.0003 & 1.3820 & 0.0006 & 0.9490 & 0.0009 & 1.2257 \\
\hline Rate of population with Bachelor's degree or above & $-0.0116^{* * *}-2.7070$ & $-0.0255^{*}$ & -1.7601 & $-0.0371 * *$ & -2.1468 \\
\hline Employment rate & 0.0072 & 1.8115 & 0.0135 & 1.1621 & 0.0207 & 1.5463 \\
\hline Percentage of people voted in election & -0.0013 & -0.7233 & -0.0074 & -1.2242 & -0.0087 & -1.2937 \\
\hline Tobacco & 0.0003 & 0.0772 & 0.0043 & 0.3482 & 0.0046 & 0.2811 \\
\hline Drug & 0.0002 & 0.0298 & -0.0392 & -1.4497 & 0.0390 & 1.2807 \\
\hline Alcohol & 0.0094 & 0.9049 & 0.0568 & 1.5611 & 0.0662 & 1.5667 \\
\hline
\end{tabular}

The symbols ***,**and * represent one, five and ten percent significance level. T-test values are specified in the column after the coefficient values of each model. 
Table 25: Regression analysis of residuals of SDM Panel Model analysis (without Percentage of Hospital Expenditures or Total Healthcare expenditures) on percentage of Hospital expenditures and Total Healthcare expenditures separately

\begin{tabular}{|l|l|l|l|}
\hline \multicolumn{5}{|l|}{} \\
\hline Model 1: & Coefficient & SE & T value \\
\hline Residuals_SDM & -0.006 & 0.004 & -1.29 \\
\hline Hospercent & 0.213 & 0.165 & 1.29 \\
\hline Constant & 0.004 & & \\
\hline $\mathrm{R}^{2}$ & 1.68 & & \\
\hline F value & \multicolumn{5}{l|}{} \\
\hline Model 2: & & & \\
\hline Residuals_SDM & -0.009 & 0.053 & -0.17 \\
\hline Log HCE & 0.098 & 0.571 & 0.17 \\
\hline Constant & 0.001 & & \\
\hline $\mathrm{R}^{2}$ & 0.03 & & \\
\hline F value & & & \\
\hline
\end{tabular}

The symbols $* * * * *$ and $*$ represent one, five and ten percent significance level. T-test values are specified in the column after the coefficient values of each model. 
CHAPTER 5 


\section{CHAPTER 5: SUMMARY AND CONCLUSIONS}

\section{STUDY SUMMARY}

State level healthcare financing and policies have major impacts on improving health outcomes and healthcare quality in the U.S. This study examined state-level variations in healthcare financing, hospital expenditures, and the association between healthcare expenditures and outcomes using spatial regression analyses. The overall goal of this study was to empirically demonstrate what factors impact state-level healthcare spending and outcomes not only at the individual state, but also neighboring states using panel data for years 2000 through 2009 extracted from publicly available data files.

As mentioned above, the rising cost of healthcare has been long-standing issue both at the federal and state-level. Containing costs have become a priority for all levels of government. Therefore, to understand the appropriate policy responses of state governments in containing healthcare expenditures, it is critical to examine the sources of funding for healthcare at the state level.

In this context, the first essay demonstrated significant state-level variations in the funding of healthcare. State-level variations in public financing (Medicare and Medicaid) of healthcare were associated with demographic composition (proportion of the female population, percentage of individuals over age 65, and percentage of Hispanic population), economic factors (unemployment rate, per capita gross domestic product (GDP) of the state, per capita state tax revenue, and FMAP rate), political climate (percentage of individuals enrolled in Medicare or Medicaid and rate of enrollment in HMO), healthcare supply factors (active physicians per 100,000 population, number of hospitals and beds) and healthcare needs (obesity rate). Additionally, variations in state-level private insurance financing was proportional to economic 
factors (rate of federal funding and per capita state GDP), a supply side factor (active physicians per 100,000 population), political climate (percentage of individuals enrolled in Medicare or Medicaid), and healthcare needs (obesity rate). Lastly, state-level variations in out of pocket expenditures was associated with economic factors (per capita state tax revenue and per capita state GDP), demographic factors (percentage of African-American, percentage of female population, percentage of elderly population (aged 65 and above), percentage of Hispanic individuals, and proportion of the population below age 17), a supply side factor (active physicians per 100,000 population), political characteristics (percentage of individuals enrolled in Medicare or Medicaid) and healthcare needs (obesity rate).

In 2013, nearly one-third (32.3\%) or $\$ 936.9$ billion of the healthcare spending was for inpatient care (CMS, 2013). Because of considerable state-level variations in the rate of hospital expenditures, the second essay examined the spatial association of demographic profile, socioeconomic characteristics, healthcare status, supply-side factors and the rates of binge drinking on state-level variations in rate of hospital expenditures. This essay revealed the presence of positive spatial dependence of hospital spending of a state on its adjacent states. This study also highlighted that rate of binge drinking, total number of hospital beds and hospitals per 1,000 residents, the unemployment rate, the percentage of African-American population, proportion of active physicians and state gross domestic product had positive impacts on its neighboring states' rate of hospital expenses. Moreover, the increasing rate of male population and Hispanic population of a state had negative impacts on its own rate of hospital costs but positive impacts on its bordering states' rate of hospital spending.

The third essay examined the complex relationship between healthcare spending and health outcomes at the state-level, with an emphasis on the spatial pattern of health outcomes. 
Health outcomes were represented by the state-level mortality rates. This essay found evidence of a significant positive spatial dependence of the mortality rate on its neighboring states. Statelevel demographic characteristics (percentage African Americans and percentage of individuals above 65 years of age) significantly increased the mortality rate of a state, while population composition (percentage of Hispanic population), supply side factor (number of active physicians), social structure (percentage of married population) and social determinants (percentage with bachelors or higher education level) reduced the mortality rates. Higher rates of Hispanic population and better hospital infrastructure of an individual state increased the mortality rates of the neighboring states and higher the education level of the state decreased the mortality rate of the neighboring states.

\section{IMPLICATIONS}

Cost of healthcare is a perennial policy concern. Policy responses to contain healthcare have been fragmented and have focused on some aspects. Findings from first essay highlighted the role of factors beyond healthcare sector. Healthcare policy reforms to date have exclusively focused on healthcare sector. Policy efforts are needed to strengthen non-health sector as well. Social determinants of health are also needed to become one of the most essential parts of healthcare conversation.

To promote a social determinant approach towards healthcare policy, policy efforts need to be coordinated among different sectors of the economy, different population groups and organizations. Patient Protection and Affordable Care Act (ACA) included some reforms to reduce overall healthcare spending and financing while maintaining reasonable healthcare quality. In this study, it was also seen that states with higher obesity rates had higher share of healthcare funding across all sources. Therefore increasing funding for obesity-prevention 
programs will be important to achieve results in improving health and reducing healthcare costs and financing for the future. Another way of addressing this issue is changing the choice structure of people (people are forced to make healthy choices) to make the prevention programs and health policies more effective to control costs. Hence, the study findings suggest that investment in prevention of diseases, managed care and promoting health and wellness in the population may reduce healthcare spending by all.

Findings from the second essay have profound implications for policies in terms of substance abuse prevention and treatment. Spreading awareness among people about the fatality of alcohol consumption, restricting alcohol outlets, strengthening and enforcing minimum purchase age laws, strategies to curb social availability of alcohol, controlling alcohol advertising and promotion, increase in alcohol tax to pay for prevention programs have been effective policies (OJJDP, 2002).

The study also demonstrated spatial dependence among neighboring states. As no joint prevention programs exist among the states to intervene the growing concern of alcohol abuse on health outcomes, collaboration of states and communities to support effective community, policies, promote awareness and create strategies to prevent binge drinking will also help in reducing hospital costs.

Findings from the third essay highlighted the role of social determinants on healthcare outcomes. The social determinant included upstream factor such as education level. These findings suggest that it is important to eradicate systematic disparities in social determinants of health (Braveman, 2003) to achieve improved health outcomes at lower healthcare spending. For example, high levels of education can lead to high income, which can lead to good health 
(Muney, 2004; Grossman, 2005).Therefore, investing in education level can have a significant influence on population health outcomes (Healthy people 2020).

Findings from all the aims highlighted the narrow vision of existing policies that focused only on health sector. Reforming health sector only may not be the answer to improve health outcomes such as survival. Health policies should also consider incorporating economic and social determinants to improve health outcomes. Health polices including efforts to strengthen and encourage civic involvement and society engagement among residents will facilitate population health (Healthy people, 2020).Social stability, support, social integration, selfregulation, network, reduction in stress, anxiety and pressure provides higher life expectancy and a better and healthier lifestyle. This helps in enhancing trust and creating better social capital thereby improving health outcomes (Yang, 2011; Liu and Johnson, 2009; Johnson et al., 2000; Gove, 1973). Joint programs of neighboring states to support healthy lifestyle and prevention programs would succeed achieving higher quality of living of all individuals and thereby reduce the mortality rate.

It is also important to learn and adopt healthy behaviors and practices from immigrant populations such as the Hispanic groups. Lower mortality rates were observed in Hispanic population despite its economic disadvantages (i.e. low income and high poverty). This was explained as "Foreign-born advantage" also known as the "salmon-bias" effect (Palloni and Arias, 2004). In contrast to this theory, Abraido-Lanza et al. (1999) described this as the "Hispanic paradox". Social networks, stronger family bond, active community involvement, family structure, love and faith might be some of the reasons behind this paradox. Understanding the Hispanic paradox (health advantage and behaviors) and integrating it into health reform policy may help in lowering the mortality rate for all population groups. 


\section{STUDY LIMITATIONS}

This study had some limitations such as restricted number of years in the dataset. This is because all the variables used for the study were available for only the selected time period. The study also excluded CHIP data from public funding analysis in first aim as data were not available for all the years. Due to unavailability of data and insignificance in previous studies, variables such as the percentage of female households, population receiving public assistance, social capital index score, and rural-urban resident continuum code were not included in the analysis. Despite these limitations, to the best of knowledge, these essays represent the first study to extensively examine and document the relationships between financing of healthcare, expenditures, health outcomes at the state level. The study findings confirmed the spatial relationships between states and demonstrated that state-level healthcare spending and outcomes of the individual state affected not only the individual state but also its neighbors. 


\section{REFERENCES}

Abraido-Lanza, A.F., B. P. Dohrenwend, D. S. Ng-Mak, and J. B. Turner. 1999. The Latino mortality paradox: a test of the "salmon bias" and healthy migrant hypotheses. American Journal of Public Health.89 (10); 1543-1548.

Braveman, P. and S. Gruskin. 2003. Defining equity in health. Journal of Epidemiology and Community Health; 57(4): 254-258.

Centers for Medicare and Medicaid Services. 2013. Health Expenditures by State of Residence. http://www.cms.gov/NationalHealthExpendData/downloads/resident-state-estimates.zip.

Grossman, M. 2005. Education and Non-market Outcomes. NBER Working Paper 11582, Cambridge, Massachusetts.

Gove, W. R. 1973. Sex, Marital Status, and Mortality American Journal of Sociology.79 (1); 4567.

Healthy people 2020. http://www.healthypeople.gov/. Accessed on April 26th, 2015.

Johnson, N.J., E. Backlund, P.D. Sorlie and C.A. Loveless. 2000. Marital status and mortality: the national longitudinal mortality study. Annual Epidemiology. 10(4):224-38.

Liu, H. and D. Johnson. 2009. Till Death Do Us Part: Marital Status and U.S. Mortality Trends, 1986-2000.Journal of Marriage and Family; 71(50); 1158-1173.

Muney, A.L. 2004. The Relationship between Education and Adult Mortality in the United States. http://www.econ.ucla.edu/alleras/research/papers/mortalityrevision2.pdf.

Palloni, A. and E. Arias. 2004. Paradox lost: Explaining the Hispanic adult mortality advantage. Demography. 41(3): 385-415.

Office of Justice Programs Office of Juvenile Justice and Delinquency Prevention.1999 Drinking in America: Myths, Realities, and Prevention Policy, Updated For 2002 National Survey On Drug Use And Health U.S. Department Of Justice.

Yang, T.C., L. Jensen and M. Haran. 2011. Social Capital and Human Mortality: Explaining the Rural Paradox with County-Level Mortality Data. Rural Sociology 76(3): 347-374. 